\title{
Technology Insights and Perspectives for Nuclear Fuel Cycle Concepts
}

Samuel E. Bays

Steven J. Piet

Nick R. Soelberg

Michael J. Lineberry

Brent W. Dixon

September 2010

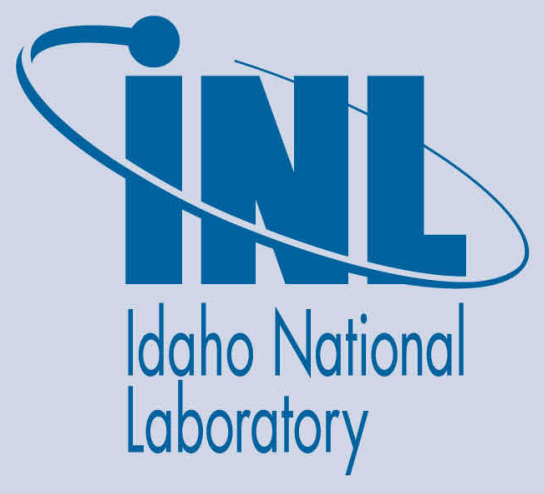

The INL is a U.S. Department of Energy National Laboratory operated by Battelle Energy Alliance 
INL/EXT-10-19977

FCRD-SYSA-2010-000184

\title{
Technology Insights and Perspectives for Nuclear Fuel Cycle Concepts
}

\author{
Samuel E. Bays \\ Steven J. Piet \\ Nick R. Soelberg \\ Michael J. Lineberry \\ Brent W. Dixon
}

September 2010

\author{
Idaho National Laboratory \\ Fuel Cycle Research \& Development \\ Idaho Falls, Idaho 83415
}

http://www.inl.gov

Prepared for the

U.S. Department of Energy

Office of Nuclear Energy

Under DOE Idaho Operations Office

Contract DE-AC07-05ID14517 


\section{DISCLAIMER}

This information was prepared as an account of work sponsored by an agency of the U.S. Government. Neither the U.S. Government nor any agency thereof, nor any of their employees, makes any warranty, expressed or implied, or assumes any legal liability or responsibility for the accuracy, completeness, or usefulness, of any information, apparatus, product, or process disclosed, or represents that its use would not infringe privately owned rights. References herein to any specific commercial product, process, or service by trade name, trade mark, manufacturer, or otherwise, does not necessarily constitute or imply its endorsement, recommendation, or favoring by the U.S. Government or any agency thereof. The views and opinions of authors expressed herein do not necessarily state or reflect those of the U.S. Government or any agency thereof. 


\section{ABSTRACT}

This report characterizes fuel cycle options in four areas - resource utilization, radioactive waste, fuel cycle safety, and proliferation resistance and physical protection. Graphs and tables provide insights regarding which features of a fuel cycle option most impact performance for a given characteristic. For example, some characteristics are insensitive to reactor technology but very sensitive to whether and what is recycled. Sometimes it is variations within a class of options that matter. For still other characteristics, the pattern is that a feature impacts performance only under certain situations and is irrelevant in others.

Resource utilization: The utilization of uranium ranges from $<1 \%$ for all thermal reactor concepts, up to $\sim 10 \%$ for fast reactors with no fuel recycle, and approaching $100 \%$ for sustained recycle with fast reactors. The patterns for utilization of thorium are less clear due to less study of option space.

Radioactive waste: There are many possible ways to reduce radiotoxicity and/or the mass of waste streams having both high-heat and high long-term radiotoxicity. The combination of decay heat and radiotoxicity complicates waste disposal and there is no international precedent for disposal of waste that has both high decay heat and high long-term radiotoxicity. The value of a given improvement method can range from very little to orders of magnitude depending on which other improvement methods are also used in a fuel cycle. For example, low processing loss of transuranic material to waste has little value in a single-recycle strategy but can have orders of magnitude impact in sustained recycle.

Fuel cycle safety: Safety is too important to ignore during concept selection and development. Historical experience suggests that some types of safety issues are easier to resolve in concept development, detailed design, and/or operation than others. "Easier" can mean lower design cost to add safety systems as a design goes from concept to details, fewer iterations and delays with regulators, easier operation, a more transparent safety case engendering higher trust, less chance for expensive changes during construction, less chance of expensive retrofitting during operation, etc. Co-location of facilities, e.g., separation and fuel fabrication, is one of the ways that the potential risk of future fuel cycles may be reduced. Although the radiological risk from transportation has been shown to be low, public concerns are high and any industrial transport involves common daily transportation risks.

Proliferation resistance and physical protection: There are many perspectives in this area, but there is no tool and no single indicator that covers the entire area and all four stages from material acquisition, transportation, transformation of material, and weapon fabrication. Conflicting claims can be often be better understood if it is realized that each claim can be valid within its subset of the entire area. 


\section{SUMMARY}

This report characterizes fuel cycle options in four areas - resource utilization, radioactive waste, fuel cycle safety, and proliferation resistance and physical protection. Graphs and tables provide insights regarding which features of a fuel cycle option most impact performance for a given characteristic. For example, some characteristics are insensitive to reactor technology but very sensitive to whether and what is recycled. Sometimes it is variations within a class of options that matter. For other characteristics, the pattern is that a feature is important only under certain situations and irrelevant in others. The report makes no attempt to weight or combine individual characteristics.

Several concepts in this report are evolving designs. The reader is cautioned that continuing optimization of a maturing design may yield improved fuel cycle performances in a single characteristic or in general. Similarly, the contemporary nomenclature to describe advanced concepts is evolving.

Although we recognize its importance, economics is not addressed in this report. Economics will be analyzed for various fuel cycles in FY 2011.

\section{RESOURCE UTILIZATION}

By definition, complete uranium or thorium utilization occurs only when all of the natural uranium or thorium resource can be introduced into the nuclear reactor long enough or often enough (via recycling) for all of it to fission. Generally, this requires that the natural fertile isotopes are first converted into fissile isotopes, primarily $\mathrm{Pu}-239$ from U-238 or U-233 from Th-232.

The utilization of uranium ranges from $<1 \%$ for all thermal reactor concepts, up to $\sim 10 \%$ for oncethrough fast reactors, and approaching $100 \%$ for sustained recycle with fast reactors. With the exception of neutron-rich breeder fission reactors and external neutron-driven concepts, most reactors do not have sufficient excess neutrons to sustain a chain reaction while still being an effective converter of fertile into fissile material. As shown in Figure S-1, there is a marked step increase in the uranium utilization that can be achieved in fuel cycles based solely on fast reactors as the only reactor type versus those having thermal reactors as part of the energy mix. The patterns for thorium utilization are less clear due to less study of option space. Sustained recycle of thorium in thermal reactors can exceed the $1 \%$ barrier for uranium utilization. 


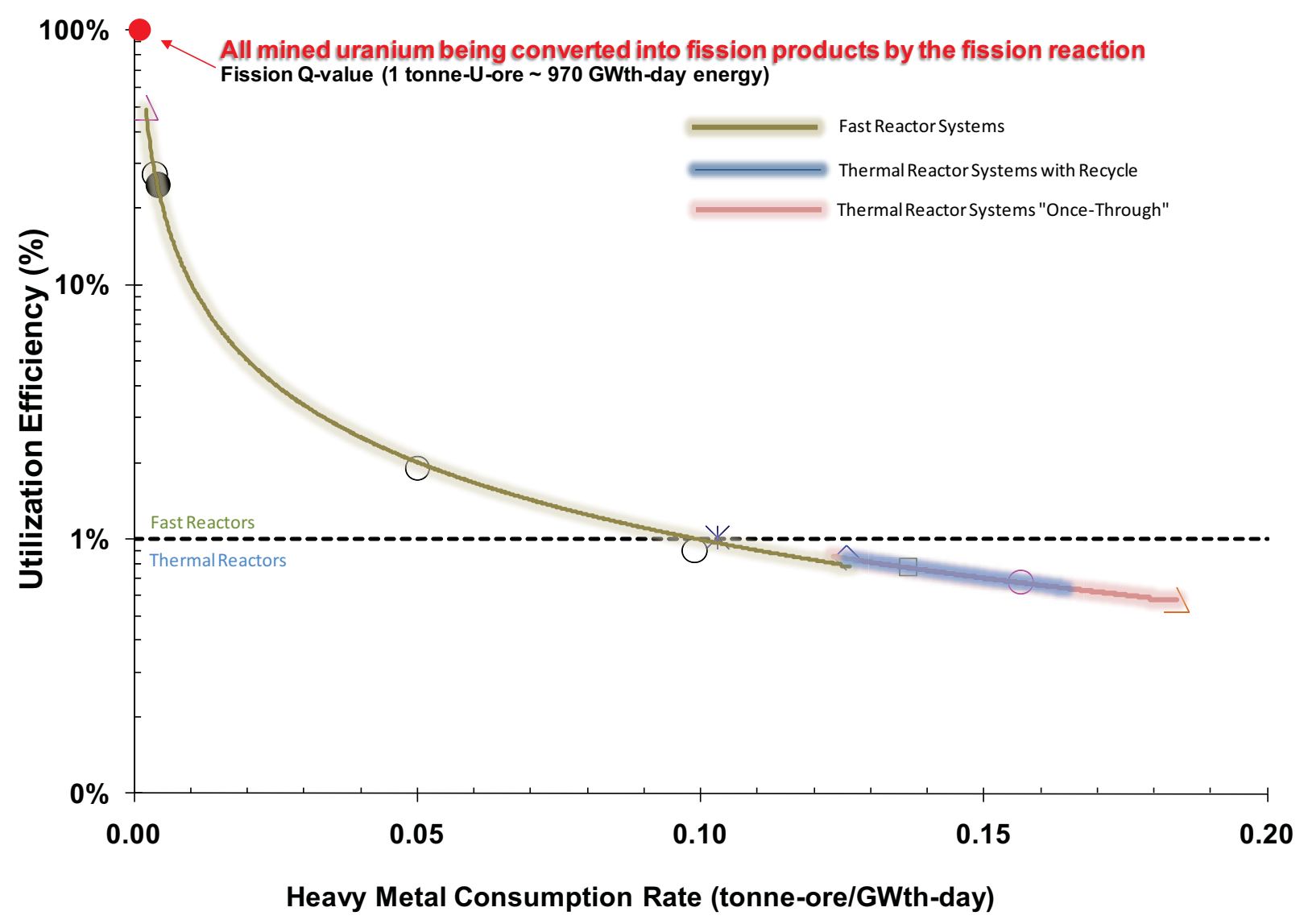

Figure S-1. Uranium utilization for fuel cycles with varying combinations of reactors and recycle strategies.

\section{RADIOACTIVE WAS TE}

Many parameters are relevant to radioactive waste management, including radiotoxicity (the level of hazard of the material to be disposed), heat, and the mass to be disposed. The higher the radiotoxicity for longer time periods, the more difficult the disposal challenge as associated uncertainties tend to increase with time in a disposal site, as of course the estimated value of hazard decreases. High heat complicates handling, transportation, emplacement, and relatively short-term disposal challenges as heat changes a disposal site and waste packages. There are international disposal precedents for disposal of high longevity/low heat, low longevity/high heat, and low longevity/low heat wastes. However, there are no international disposal precedents for high longevity/high heat and therefore one characteristic in this report is the mass of such waste.

Four components of mass that may be disposed after each fuel discharge are non-fuel mass (zirconium cladding, steel cladding, TRISO fuel coating, fuel assembly structure, etc.), transuranics, uranium, and fission products. Direct disposal means all four components are disposed together, which means that this waste falls into the category of high longevity/high heat because of the transuranics. Strategies that disassemble used fuel allow the mass of high longevity/high heat waste to be reduced by either reuse of material (transuranics) or separation of high longevity/low heat (uranium) from low longevity/high heat (some fission products) and other components.

Figure S-2 shows how improvements in either radiotoxicity (of all waste) or mass that is high longevity/high heat can work together. Non-fuel mass often dominates the total mass to be disposed, 
unless it is removed from fuel meat; if so, higher fuel burnup in once through options is the next key improvement. Compared to once through options, single recycle options more effectively concentrates and consumes that radioactive fuel meat constituent. If all transuranics are present in waste, the time to decay to uranium ore toxicity levels is over 100,000 years. If the plutonium is recycled and consumed, the time to decay to uranium more toxicity is over 10,000 years. If all the transuranics are recycled and consumed, this time is $\sim 1000$ years. Once transuranics are fully recycled, further high longevity/high heat mass reductions can be reduced intra-partitioning of the fission products, e.g., separating low longevity/high heat (such as cesium and strontium) from high longevity/low heat (such as technetium and iodine).

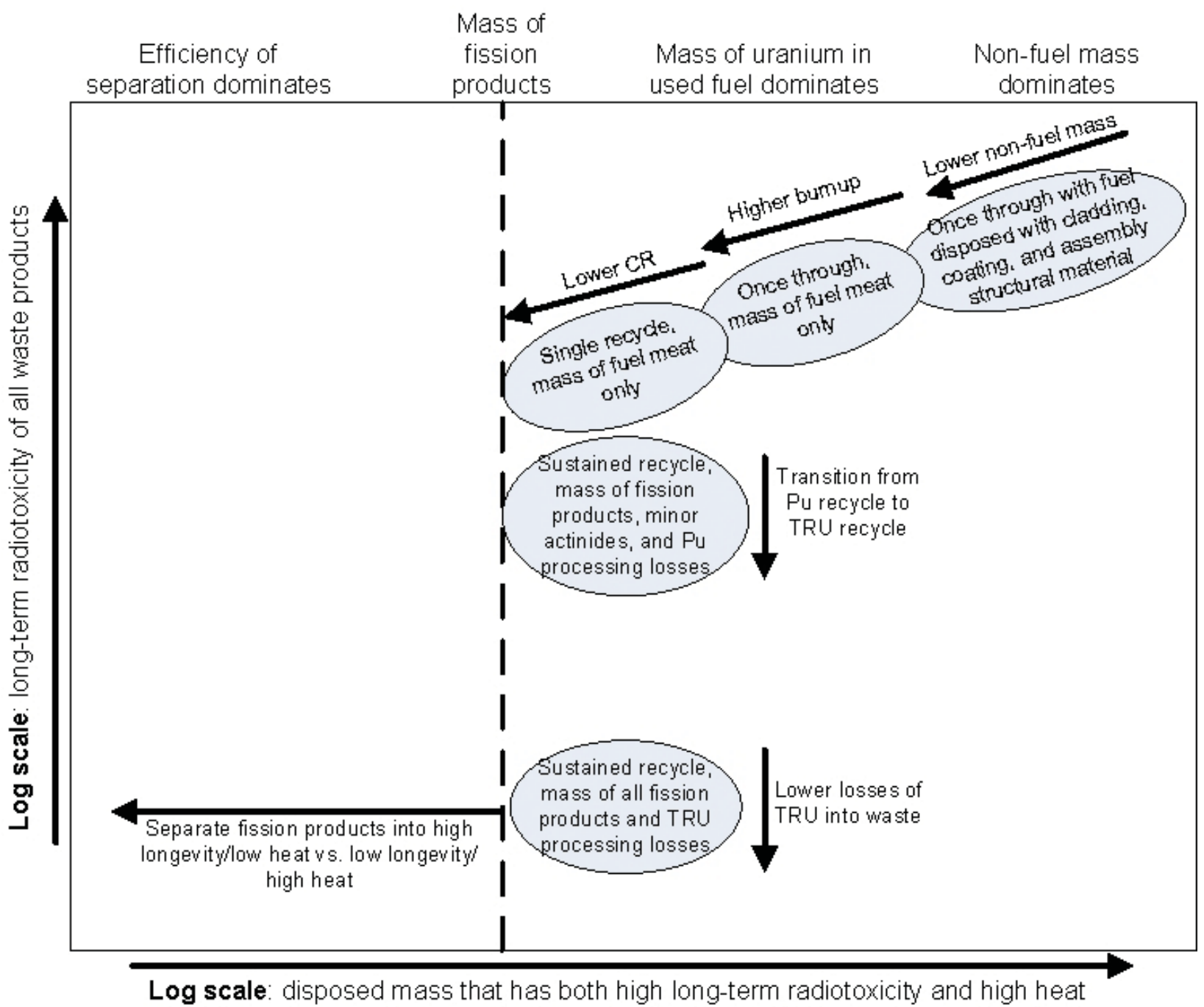

Figure S-2. Log-log diagram of how different improvement ideas may fit together; the mass added to make waste forms or waste packaging is not included.

\section{FUEL CYCLE S AFETY}

Safety performance measures are particularly dependent on design details; it is also dependent on maintenance and operational experience. Indeed, the availability factors for the U.S. reactor fleet have climbed from below $50 \%$ to over $90 \%$ in the past 40 years as maintenance and operation have improved. Off-normal events have correspondingly declined as availability and reliability of systems have increased. Non-reactor fuel cycle facility safety has also improved as evidenced by the fact that most incidents are 
many years in the past, see examples in (Cadwallader 2005). Thus, in the safety area, neither design information (even when it is available) nor decades-old experience are necessarily adequate to predict future performance. When there are neither design details nor operational experience, it is difficult or impossible to quantitatively predict the performance of a future system.

Historical experience suggests that some types of safety issues are easier to resolve in concept development, detailed design, and/or operation than others. "Easier" can mean lower design cost to add safety systems as a design goes from concept to details, fewer iterations and delays with regulators, easier operation, a more transparent safety case engendering higher trust, less chance for expensive changes during construction, less chance of expensive retrofitting during operation, etc.

Co-location of facilities, e.g., separation and fuel fabrication, is one of the ways that the potential risk of future fuel cycles may be reduced. Although the radiological risk from transportation has been shown to be low, public concerns are high and any industrial transport involves common daily transportation risks.

Although high-actinide-content fuels in light water reactors (LWRs) such as mixed oxide fuels (MOX) have been criticized for increasing the accident source term relative to uranium oxide fuel, data indicate that this is not actually a problem. However, this illustrates the need for having off-normal fuel performance data in addition to data for routine operation.

\section{PROLIFERATION RES ISTANCE AND PHYS ICAL PROTECTION}

The relevant proliferation resistance of a fuel cycle system is enhanced with increasing reliance on international fuel cycle services, decreasing adaptability for technology misuse, technologies for which material accountability is more straightforward, and decreasing material attractiveness. Thus, there are technical characteristics of advanced reactor and recycle technologies that, if implemented and operated under the right conditions, will collectively decrease the fuel cycle's inherent affinity for misuse.

Figure S-3 shows a loose mapping of the indicators in this report into the areas of proliferation resistance and physical protection and the four stages of material acquisition, transport, transformation of material, and weapon fabrication. There are many perspectives in this area, but there is no tool and no single indicator that covers the entire area and all four stages from material acquisition, transportation, transformation of material, and weapon fabrication. Conflicting claims can be often be better understood if it is realized that each claim can be valid within its subset of the entire area, essentially an issue of local "optimum" versus global "optimum."

There is one issue - adaptability - that spans both proliferation resistance and physical protection and spans the four stages. Adaptability of technologies and skills is not shown explicitly in Figure S-3. No assessment would be complete without this consideration as it explains why UREX and COEX get little "credit" relative to PUREX for a host nation threat. Yet, "adaptability" is one of the least explicit topics in existing methodologies. (For subnational threats, UREX and COEX do receive some credit.) 


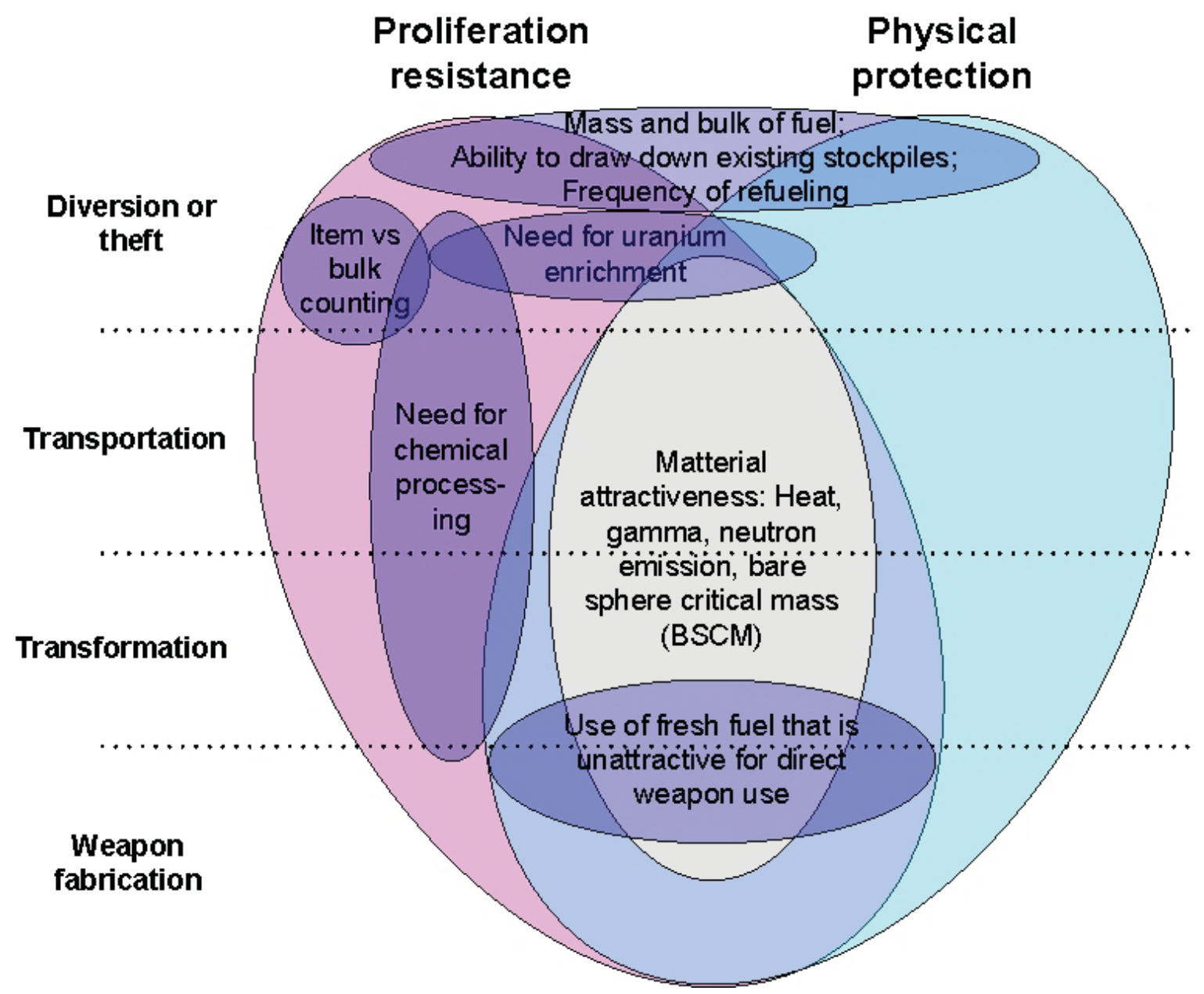

Figure S-3. Indicators in this report relevant proliferation resistance and physical protection; no single indicator covers all four stages and both proliferation resistance and physical protection. 


\section{ACKNOWLDEDGEMENTS}

The authors would like to thank: Taek Kim (ANL), Temitope Taiwo (ANL), Robert Bean (INL), Robert Buell (INL), Brett Carlsen (INL), William Galyean (NL), Richard Metcalf (INL), Roald Wigeland (INL), Hongbin Zhang (INL), Haihua Zhao (INL), Charles Bathke (LANL), George Flanagan (ORNL), Jess Gehin (ORNL), Joe Carter (SNL), Erich Schneider (University of Texas), and Karl Fleming (Technology Insights, San Diego) for their contributions of data and insightful perspectives. 
Technology Insights and Perspectives 


\section{CONTENTS}

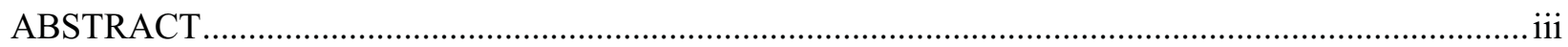

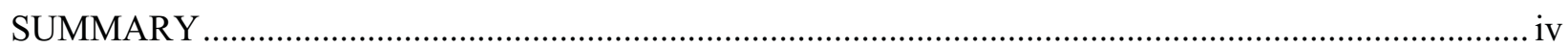

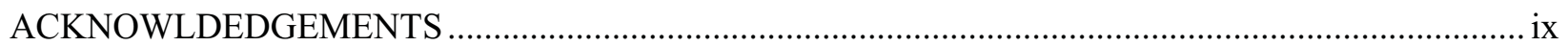

ACRONYMS, TERMINOLOGY, AND USE CASES …................................................................... xvi

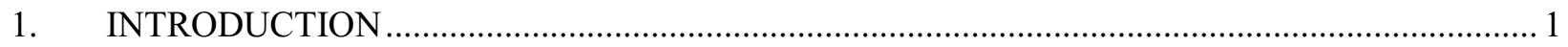

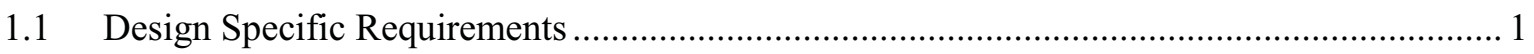

1.2 Consideration of Distinct Versus Generalized Technologies ........................................... 2

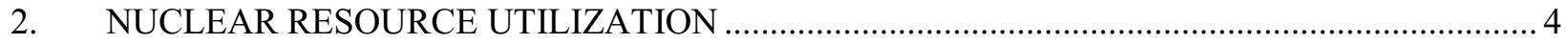

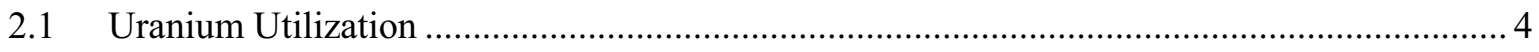

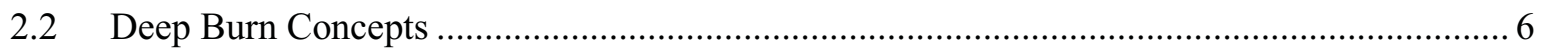

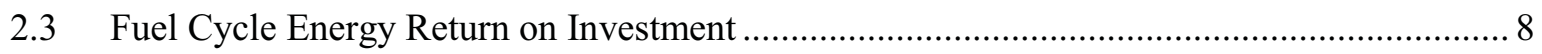

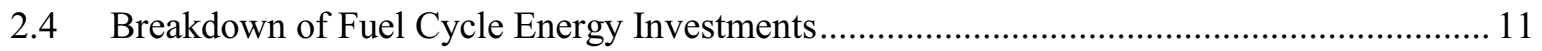

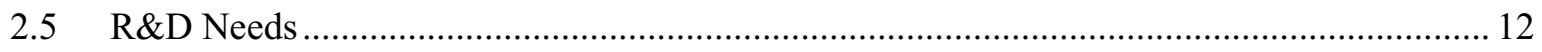

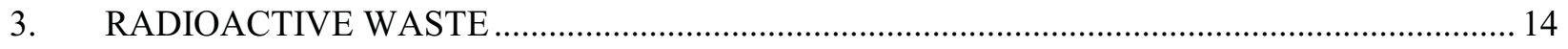

3.1 Existing U.S. Radioactive Waste Classification and Disposal............................................ 14

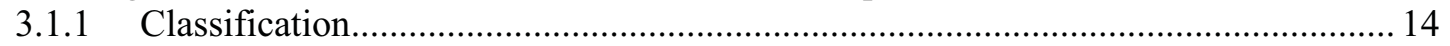

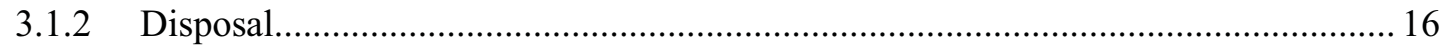

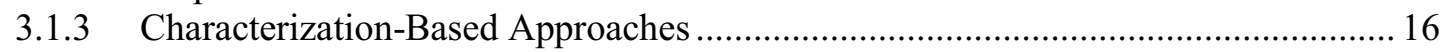

3.2 Radiotoxicity of Fuel Cycle Options............................................................................ 18

3.3 Decay Heat of Fuel Cycle Options................................................................................ 20

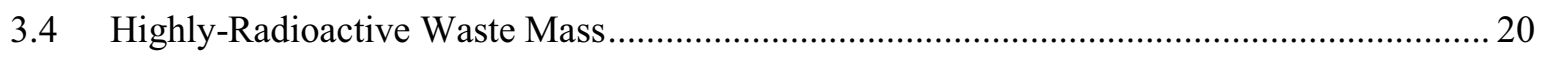

3.5 Considering Radiotoxicity and Mass Together................................................................. 23

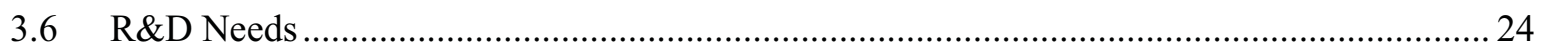

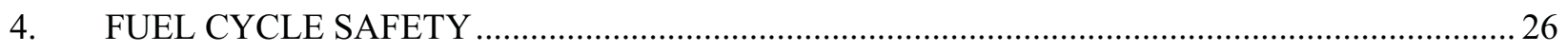

4.1 Hazard Identification and Safety Functions ................................................................. 26

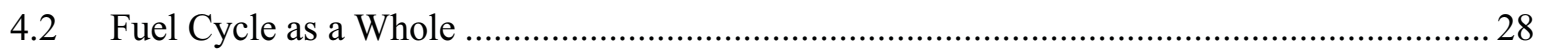

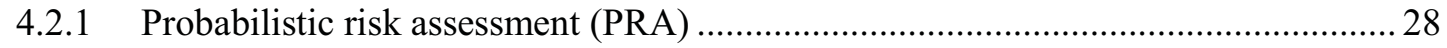

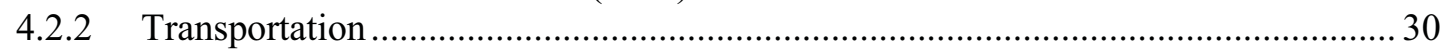

4.3 Fuel Cycle Facilities Other than Reactor .......................................................................... 32

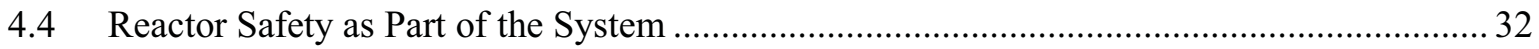

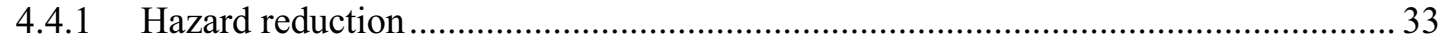

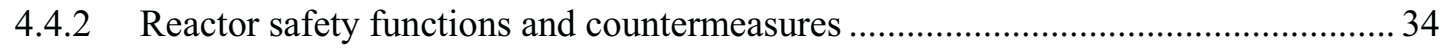

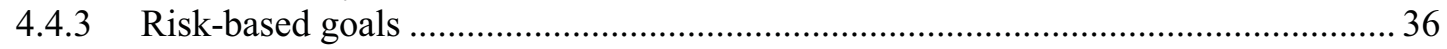

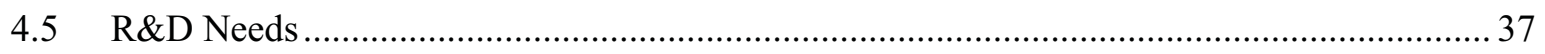

5. PROLIFERATION RESISTANCE AND PHYSICAL PROTECTION ........................................... 39

5.1 Adaptability of Technologies and Skills to Overall Fuel Cycle........................................... 41 


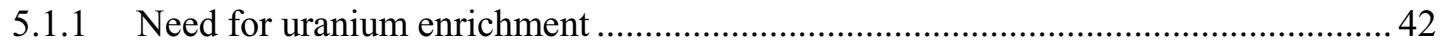

5.1.2 Use of fresh fuel that is unattractive for direct weapon use .................................... 43

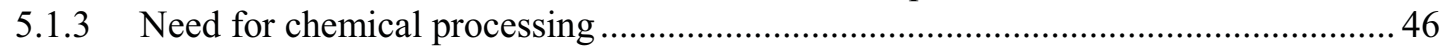

5.1.4 Adaptability of specific technologies to make weapon-usable material ................... 47

5.1.5 Adaptability of technologies and skills of fuel cycles............................................ 50

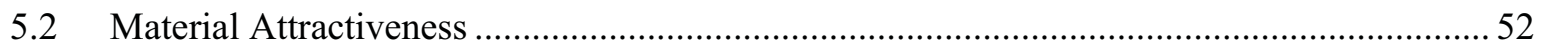

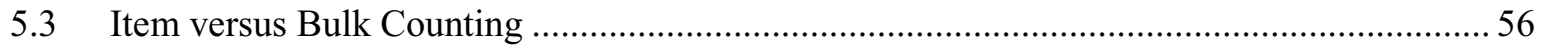

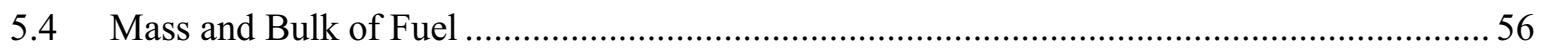

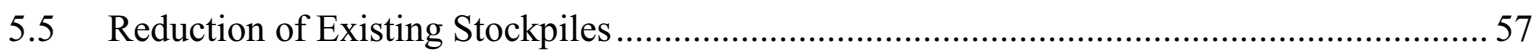

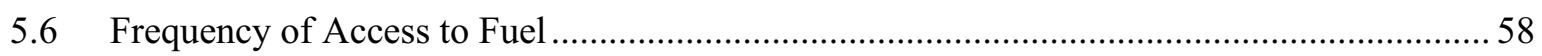

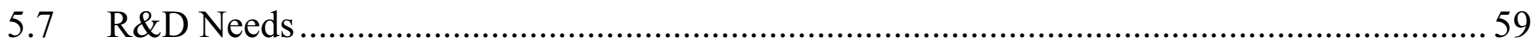

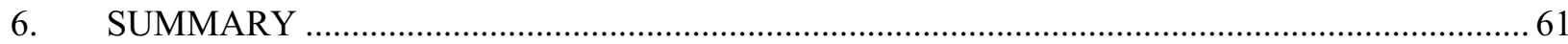

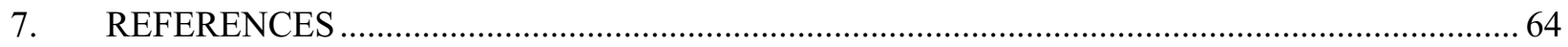

\section{FIGURES}

Figure S-1. Uranium utilization for fuel cycles with varying combinations of reactors and recycle strategies

Figure S-2. Log-log diagram of how different improvement ideas may fit together; the mass added to make waste forms or waste packaging is not included.

Figure S-3. Indicators in this report relevant proliferation resistance and physical protection; no single indicator covers all four stages and both proliferation resistance and physical protection.

Figure 2-1. Control volume analogy used in calculating resource utilization.

Figure 2-2. Uranium resource utilization efficiency as a function of consumed mass-in natural uranium.

Figure 2-3. Resource utilization efficiency for deep-burn concepts. ................................................ 7

Figure 2-4. Energy return on investment comparison showing uranium utilization differences .................9

Figure 2-5. Energy return on investment over a wide range of technology options.

Figure 2-6. Breakdown of energy supplied (electric and combusted fuels) in each fuel productions step per electric energy produced.

Figure 3-1. Radiotoxicity of waste as function of time after reactor discharge; processing losses are $0.1 \% /$ recycle.

Figure 3-2. Long-term decay heat of radioactive waste from various fuel cycle options.........................20

Figure 3-3. Compositions of fuel assemblies for different fuel designs. ...............................................2 21

Figure 3-4. Total fuel assembly mass, normalized to mass of initial heavy metal. .................................22

Figure 3-5. Total fuel assembly mass, normalized to thermal energy production..................................2 23

Figure 3-6. Long-term radiotoxicity (taken at 1,000 years) per mass of disposed actinide and fission product constituents of used nuclear fuel. 
Figure 4-1. Gamma emission from fresh fast reactor metal fuel as function of fast reactor TRU conversion ratio (Bays2009).

Figure 4-2. Neutron emission from fresh fast reactor metal fuel as function of fast reactor TRU conversion ratio (Bays2009).

Figure 4-3. Maximum LWR release fractions, data from (NRC1995), as graphed in (Piet2006)

Figure 4-4. Fundamental safety characteristics used in reactor design with relevance to advanced concepts.

Figure 4-6. The frequency-consequence curve for a risk-informed and performance-based regulatory structure for future plant licensing (NUREG-1860). 37

Figure 5-1. Proliferation Resistance and Physical Protection for four stages toward a weapon. .40

Figure 5-2. Indicators used this chapter, relevant to differing stages toward a weapon; no single indicator covers all four stages and both proliferation resistance and physical protection.

Figure 5-3. Need for uranium enrichment among fuel cycle options; an indicator in essentially all evaluation methodologies.

Figure 5-4. Enrichment required, U-235/U-total, $\mathrm{Pu} / \mathrm{HM}$, or TRU/HM, as appropriate; this is a topic addressed by the IAEA and all methodologies but the criteria for Pu and TRU vary.

Figure 5-5. Need for chemical processing among fuel cycle options; combining indicators in TOPS, INPRO, and PR\&PP methodologies.

Figure 5-6. Adaptability of individual technologies to make attractive material, combining considerations from several methodologies especially TOPS for clarifying "adaptability" and Bathke2009 for defining criteria for Pu/HM and TRU/HM.

Figure 5-7. Adaptability of fuel cycle options to make high attractive material, consideration the "lowest resistance" in the previous four figures..

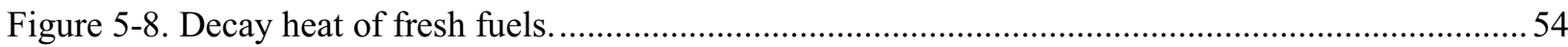

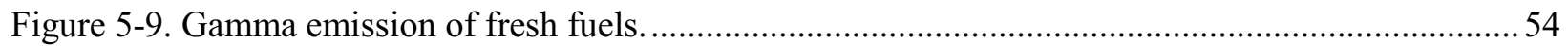

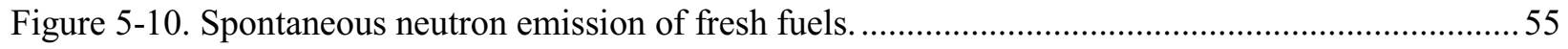

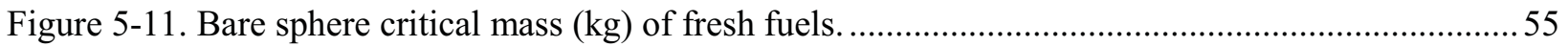

Figure 5-12. Frequency of access to fuel in reactor; inferred by considerations in the TOPS and

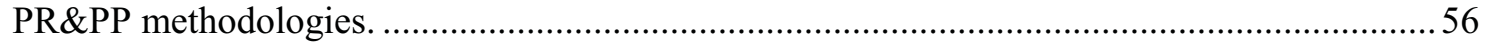

Figure 5-13. Ability of fuel cycle options to reduce existing actinide inventories (Goodman 2009).

Figure 5-14. Frequency of access to fuel in reactor; inferred by considerations in the TOPS and PR\&PP methodologies.

\section{TABLES}

Table 1-1. Level of information needed to evaluate performance in each fuel cycle area.

Table 1-2. Technology use-cases chosen for each level of design detail within each technology

family. 
Table 3-1. Radioactive waste characterization based on decay heat and long-term radiotoxicity 17

Table 4-1. Fuel cycle hazards and protective safety functions.

Table 4-2. Frequency-consequence matrix contrasting the radioactive source term intensity with probability that a member of the public will be exposed. 30

Table 4-3. Illustrative hazard identification of candidate separation technologies.................................. 32

Table 5-1. Isotopic Composition Classification (assembled from TOPS 2002).................................... 44

Table 5-2. TOPS Classification Schemes Related to Adaptability of Technologies for Misuse (TOPS 2000) 48

Table 5-3. Mass of Fuel Assemblies in Various Options (Piet 2010c). .57 
Technology Insights and Perspectives

September 30, 2010 


\section{ACRONYMS, TERMINOLOGY, AND USE CASES}

AIROX

Atomics International Reduction Oxidation Process

A type of "limited separations" reprocessing technology whereby used nuclear fuel is exposed to repeating cycles of oxygen and hydrogen gasses. Cycling through these oxidation and reduction cycles (and later during pellet sintering) gassifies volatile and some semi-volatile fission products to varying separation efficiency depending on the reaction properties of each chemical species.

\section{Aqueous}

A familly of reprocessing technologies that uses nitric acid and organic solvents to partition various used fuel chemical groups into separate waste streams. The general process utilizes differences in valence states between different chemical species to enable mass transport between organic and aqueous phases.

\section{Breed-and-Burn}

A generic descriptor for core designs (and/or fuel management strategy within a reactor core) that enables a self-perpetuating generation of fissile material with subsequent in-situ burning. This generation of fissile material allows the reactor to stay critical longer than traditional reactors without addition of fissile support through fresh enriched or recycled fuel. The issue in these systems is always fast neutron fluence, i.e., materials damage.

BSCM

Bare-Sphere-Critical-Mass

Mass of fissionable material required to go critical in a spherical geometry with no neutron reflection

BWR

Boiling Water Reactor

A type of LWR design where bulk boiling of the reactor coolant is a design feature

CANDLE

Constant Axial shape of Neutron flux, Nuclide Density and power shape During Life of Energy production

A variant of liquid metal cooled fast reactors (both sodium and lead coolants considered) conceptualized to generate a breed-and-burn moving wave that propogates from an igniter zone through a breeding zone of a right circular cylinder

\section{CANDU}

Canadian Deuterium Uranium

The predominant commercial heavy water reactor design developed and supported by Atomic Energy of Canada Limited

CDF

Core Damage Frequency

A measure of the probabillity (per reactor-year) of a reactor core being damaged from event sequences internal to the reactor system itself 
An LWR fuel assembly concept utilizing both UOX and IMF fueled rods developed by Massachusetts Institute of Technology.

CR

Conversion Ratio

A measure of a reactor's abillity to breed or burn new isotopic material. There are two related concepts. The transuranic conversion ratio is defined as the rate of transuranic material production divided by the rate of transuranic material destruction. The fissile conversion ratio (or breeding ratio) is defined as the rate of fissile material production divided by the rate of fissile material destruction. In both cases, "destruction" includes all appropriate pathways for the ratio in question, such as fission.

\section{DB-LWR}

Deep Burn - Light Water Reactor

An LWR fuel assembly concept utilizing both UOX and IMF fueled rods. For this deep-burn variant of inert matrix fuels, TRISO coated fuels are employed in a SiC matrix

DB-MHR

Deep Burn - Modular Helium Reactor

An HTGR concept utilizing fertile-free TRISO coated fuels in either a prismatic blocks or spherical pebble format

\section{Deep Burn}

A generic descriptor for a fuel cycle strategy employing fertile-free fuels and reactor engineering optimization to give high transuranic destruction in a single reactor pass. In this report, it does not mean "high burnup" of a uranium-based fuel.

\section{DUPIC}

Direct Use of spent PWR fuel In CANDU

A suite of limited separations technologies envisioned to to recycle used PWR fuel into fresh CANDU fuel. Options range from directly encapsulating PWR fuel rods in CANDU rods to utilization of oxidation/reduction reaction cycles to volatize gaseous and volatile fission products.

\section{DOE}

Department of Energy

Federal executive department chartered to research energy issues for the United States

\section{Electrochemical}

A familly of reprocessing technologies that utilizes selective electro-transport of chemical groups passed between an anode and cathode within a salt bath. The process generally involves collection of one fuel species on a cathode as a solid that can be mechanically separated once the it is removed from the bath. 
A variant of gas cooled fast-neutron reactor being designed by General Atomics. Current design versions emphasize fuel performance under very high neutron fluence by way of porous mono-carbide fuel and structural materials, vented fuel technology, and limited separations of the used fuel. The design uses plutonium from used nuclear fuel but has a design goal to have zero net production of plutonium in the fuel cycle.

\section{EROI}

Energy Return on Investment

A measure of energy efficiency for a fuel cycle system. It is defined as the ratio of usable energy output (either electricity or hydrogen heating value) divided by the energy input (either electricity or combusted fuels). In this report, the ratio only assumes energy inputs from operating the fuel cycle and excludes the energy imparted in building infrastructure.

\section{Full recycle}

Full Recycle

A fuel cycle where all nuclear fuel is recycled. All fuel that has had any number of lifetimes in a nuclear reactor is considered used (not spent).

\section{Flouride Volatillity}

A familly of reprocessing technologies that utilize the volatilities of the hexaflouride of plutonium and uranium to separate them from fission products (and thorium). In the process uranium and plutonium are "volatized" into a hexaflouride gas leaving behind un-volatized fission products and/or thorium.

\section{FMSR}

Fast Mixed Spectrum Reactor

A variant of fast-neutron reactor (both gas and sodium coolants considered) conceptualized to breed its own plutonium fuel purely from depleted uranium blankets in a Berylium moderated zone. The only external fuel supply to the reactor are fresh blanket fertile-uranium assemblies.

\section{FR}

Fast Reactor

A reactor core with a chain reaction dictated by fast-neutron physics.

\section{GTCC}

\section{Greater Than Class C}

A low level waste categorization type that is generally considered not to be acceptable for near surface burial and requires more stringent and robust disposal methods than other US LLW disposal categories.

\section{High Burnup}

High Level Waste

A generic descriptor for reactor fuels with reactor lifetimes well beyond the conventional experience base, typically by utilizing advanced materials that achieve: high neutron damage tolerance, high thermal conductivity, high melting point, etc. 
A generic descriptor for highly radioctive nuclear wastes.

HM

\section{Heavy Metal}

\section{High Temperature Electrolysis}

A method of splitting water molecules to liberate hydrogen which utilizes mostly input electricity and some supplied heat input into a solid electrolyte.

\section{HTGR}

High Temperature Gas Reactor

A familly of graphite moderated and gas cooled thermal-neutron reactors utilizing TRISO coated particle fuels. This combination of fuel, moderator and coolant choice is optimized towards high reactor temperatures which enables substantial increases in thermodynamic efficiency regarding both electrical and hydrogen production.

HWR

Heavy Water Reactor

A heavy water cooled and moderated thermal-neutron reactor technology that burns natural or slightly enriched uranium uranium oxide fuel.

IAEA

International Atomic Energy Agency

International center for nuclear collaboration and safeguards established within the United Nations.

IMF

Inert Matrix Fuel

A generic descriptor for a familly of LWR fuel forms that do not contain any fertile (232Th, 238U) constituent. It thus breeds no fissile material during irradiation.

INPRO

International Project on Innovative Nuclear Reactors and Fuel Cycles

An International Atomic Energy Agency project to study innovative nuclear energy systems

\section{Limited separations}

A generic descriptor for a familly of recycle technologies that capitalize on mechancial and chemical properties that prevent high fission product decontamination of used fuel from a first principles standpoint.

\section{LMFBR}

Liquid Metal Fast Breeder Reactor

Typically used to describe a sodium cooled fast reactor with a conversion ratio greater than unity.

\section{LLW}

Low Level Waste

A generic but generally incorrect descriptor for non-high level waste, shorter lived, low activity, low 
concentration nuclear waste. In contrast, under current Nuclear Regulatory Commission rules, low-level waste is defined by what it is not, namely, High Level Waste.

\section{Low Temperature Electrolysis}

A method of splitting water molecules to liberate hydrogen which utilizes electricity input into a liquid electrolyte.

\section{LWR}

Light Water Reactor

$\mathrm{H} 2 \mathrm{O}$ cooled and moderated thermal-neutron reactor technology that burns low enriched uranium uranium oxide fuel. There are two fundamental types of LWR, Boiling Water Reactors (BWR) and Pressurized Water Reactors (PWR)

\section{MAGNOX}

Magnesium non-Oxidizing

Graphite moderated and carbon dioxide cooled thermal-neutron reactor technology that burns natural uranium oxide fuel. The finned fuel element consists of a uranium metal fuel and a non-oxidizing magnesium-alluminum alloy

\section{Melt Refining}

A type of "limited fuel separations" reprocessing technology whereby metallic used nuclear fuel is brought to its melting point. The main attribute was volatilization of fission products with low solubility in molten fuel such as the inert gases. In 1960s experiments, certain fission products (and uranium) reacted with the zirconia or yittria wash on the graphite crucible, which led to oxidation of some fission products, which were removed as slag.

\section{MHTGR}

Modular High Temperature Gas Reactor

A HTGR design produced by General Atomics (c. 1980's) intended for commercialization. The design has had a preliminary review by the Nuclear Regulatory Commission.

MOC

Modified Once-through Cycle

A fuel cycle with a limited number of recycles before used fuel is considered spent fuel, and/or a fuel cycle where limited recycle is performed until the quality of the recycled fuel degrades to the point where it can no longer be used in a nuclear reactor.

\section{Molten salt}

Usually a mixture of flouride or chloride salts with lithium and/or beryllium, used either as a reactor coolant or the dissolution bath of some reprocessing technologies

An LWR fuel technology comprised of both transuranic (conventionally plutonium) and uranium oxides. 
If this acronym appears by itself it is in reference to a $235 \mathrm{U} / \mathrm{U}$ enrichment of $\sim 4.2 \mathrm{w} / \mathrm{o}$ and a burnup of 50 $\mathrm{MWD} / \mathrm{kg}$.

\section{MOX-UE}

\section{Mixed Oxide Fuel - Enriched Uranium}

A variant of MOX where the uranium constituent is enriched to have a higher concentration of 235U/U than that found in nature. The uranium enrichment is a means of compensating for a degrading plutonium quality in successive recyclings of MOX

\section{MSR (or MSBR)}

Molten Salt (Breeder) Reactor

A familly of reactors where the fuel and coolant are mixed together in a liquid phase of flouride or chloride salts. This technology can use either a thermal or fast-neutron spectrum depending if a moderator is present. Generally, reactor concepts are envisioned as ${ }^{233} \mathrm{U}$ breeders in a thorium fuel cycle. Reactor concepts are typically introduced with a co-located reprocessing facillity to enable continuous (or regular) removal of fission products and thorium/uranium fuel management.

MSRE

Molten Salt Reactor Experiment

An engineering-scale molten salt reactor that operated at Oak Ridge National Laboratory in the late 1960s.

NGNP

Next Generation Nuclear Power Plant

A hight temperature gas reactor design being designed by a collaboration of the Department of Energy with industry partners.

NRC

Nuclear Regulatory Commission

Federal regulator of the United States commercial nuclear fuel cycle.

OTC

Once-Through Cycle

A fuel cycle with no used fuel reycling. All fuel that has had one lifetime in a nuclear reactor is considered spent.

PRA

Probabilistic Risk Assessment

PRA is a safety methodology that systematically analyzes both frequency and consequence of undesired events. It can provide quantitative metrics indicating relative safety based on reliability data, physics-offailure models, test data, and expert opinon solicitation.

\section{PRISM}

Power Reactor Innovative Small Module

A sodium-cooled fast reactor design developed by General Electric (c. 1980s-1990s) intended for commercialization. The design has had a preliminary review by the Nuclear Regulatory Commission. 
A general set of analysis methodologies intended to gauge the possible risk that a given technology or fuel cycle (implemented commercially) could be diverted to a non-civillian use

\section{PUREX}

Plutonium Uranium Extraction

Thus far, the predominant commercial reprocessing technology used to partition used nuclear fuel, by solvent extraction methods, into a pure plutonium and uranium product stream. Minor actinide and fission product wastes stay together and flow to a combined waste stream.

\section{PWR}

Pressurized Water Reactor

A type of LWR designed for no bulk boiling of the reactor coolant. Data designated as LWR in this report are generally from analyses of PWR designs as most fuel cycle studies have considered the PWR rather than BWR; there are more PWRs in the US and internationally.

\section{Radiotoxicity}

A measure of dose attributable to ingestion or inhallation of radioactive material. In this report, only ingestion radiotoxicity is discussed as it pertains to the source-term of hazard that can be attributed to nuclear waste disposal.

\section{SFR}

Sodium cooled Fast Reactor

A fast-neutron reactor using sodium coolant. For this report, this acronym applies to conventional variants on this concept and separate from breed-and-burn variations.

SI

Sulfur Iodine

A thermo-chemical method for liberting hydrogen from water that utilizes chemical reactions of hydrogen and oxygen with iodine and sulfur.

\section{SNF}

Spent Nuclear Fuel

A fuel that has had at least one life in a nuclear reactor that is not intended for further use in the nuclear fuel cycle, due to loss of real or perceived value.

The approximate quantity of nuclear material in respect of which, taking into account any conversion process involved, the possibility of manufacturing a nuclear explosive device cannot be excluded. By definition, the only authority to define an SQ is the International Atomic Energy Agency. Key SQ values include $25 \mathrm{~kg}$ of $\mathrm{U}-235$ and $8 \mathrm{~kg}$ of plutonium. 
A variant of sodium-cooled fast reactor conceptualized to breed its own plutonium fuel purely from depleted uranium blankets in an un-moderated zone. The only external fuel supply to the reactor are fresh blanket fertile-uranium assemblies.

\section{Thermal Reactor}

A reactor core with a chain reaction dictated by thermal-neutron physics.

\section{THOREX}

Thorium Uranium Extraction

A type of aqueous reprocessing designed to partition thorium-based used nuclear fuel into a pure thorium, uranium and transuranic and fission product waste streams.

TOPS

Technological Opportunities to Increase the Proliferation Resistance of Civilian nuclear Power Systems

An international task force study, established by the Nuclear Energy Research Advisory Committee to better understand the technical attributes of nuclear non-proliferation.

\section{TRISO}

Tri-structural isotropic

A type of micro fuel particle containing an oxide or oxycarbide kernel or fuel meat, surrounded by four layers of three isotropic materials - porous buffer layer of carbon, inner layer of dense pyrolytic carbon, ceramic layer of silicon carbide, and outer layer of dense pyrolytic carbon.

TRU

Transuranic

The elements beyond uranium in the periodic table that can be produced in nuclear reactors, which are neptunium, plutonium, americium, curium, berkelium, and californium.

\section{TWR}

Traveling Wave Reactor

A variant of the sodium cooled fast reactor being designed by Terra Power, LLC to achieve a selfsustaining breed-and-burn stationary wave. The concept involves a fissile igniter and a breeder zone with fuel shuffling but no external fuel supply over the reactor life-time.

UNF

Used Nuclear Fuel

A definition for fuel that has had at least one life in a nuclear reactor that is intended for further use in the nuclear fuel cycle.

\section{UOX}

Uranium Oxide

An LWR fuel technology comprised of enriched uranium oxide. In this report, if this acronym appears by itself it is in reference to a ${ }^{235} \mathrm{U} / \mathrm{U}$ enrichment of $\sim 4.2 \mathrm{w} / \mathrm{o}$ and a burnup of $50 \mathrm{MWth}$-day $/ \mathrm{kg}$. 
A suite of aqueous reprocessing technologies designed to partition uranium based used nuclear fuel into a pure uranium, transuranic (plutonium with minor actinides) fuel sreams and potentially individualized (sub-partitioned) fission product waste streams. The intent of sub-partitioning fission products into separate streams is to enable waste forms that are tailored to better meet the chemical and radiologic disposal needs of reprocessing wastes.

\section{Vented fuel}

A generic descriptor for technologiesdesigns that allow that collect gaseous and volatile fission products to be injected directly into the primary coolant during the course of irradiation, as opposed to collection and retention inside the cladding. 
Technology Insights and Perspectives

September 30, 2010 



\section{TECHNOLOGY INS IGHTS AND PERSPECTIVES FOR NUCLEAR FUEL CYCLE CONCEPTS}

\section{INTRODUCTION}

The number of reactor and recycle concept technologies being proposed has grown significantly. The purpose of this report is to provide comparative information that can be used to better understand the inherent characteristics belonging to different fuel cycle approaches and technology families. The categories of fuel cycle characteristics discussed in this report are as follows:

- Nuclear resource utilization. The primary characteristics depend on general mass flow calculations, thermal efficiency and energy production and consumption considerations for process flow sheets. More work has been done on uranium utilization than on thorium utilization.

- Radioactive waste. The primary characteristics depend on reactor physics and chemical separations calculations that are representative of the reactors and recycle facilities in a proposed fuel cycle.

- $\quad$ Fuel cycle safety. The primary characteristics previously studied in the area of fuel cycle safety indicators are those of the reactor type(s) involved in a particular fuel cycle option. However, the balance of the fuel cycle must also be considered. For both reactors and fuel cycle facilities, design level information is required to make risk informed assessments of the systems overall safety.

- Proliferation resistance and physical protection. This report draws on existing evaluation methodologies to frame the proliferation resistance and physical protection characteristics of a fuel cycle as an integrated system of technologies.

Several concepts in this report are evolving designs. The reader is cautioned that continuing optimization of a maturing design may yield improved fuel cycle performances in a single characteristic or in general. Similarly, the contemporary nomenclature to describe advanced concepts is evolving.

Although we recognize their importance, the more in-depth performance categories, such as economics and concept technical maturity, are not addressed in this report due to inadequate concept information, concept evolution, etc.

It is understood that these four categories are broad subject areas with multiple metrics developed over past decades for fuel cycle evaluation (Dixon 2009). This report provides perspectives at a higher level to improve understanding of how fuel cycle approaches and technologies behave.

This report has six chapters. Chapter 2 discusses nuclear resource utilization in terms of uranium utilization efficiency, and also fission energy returned per energy invested in the fuel cycle. Chapter 3 discusses nuclear waste in terms of the radiological source term footprint of the fuel cycle. Chapter 4 discusses fuel cycle safety and especially reactor safety indicators, given the importance of these machines on overall safety. Chapter 5 discusses proliferation resistance and physical protection, providing estimations of possible technology strong points and weaknesses. Chapter 6 provides a summary of key findings.

\subsection{Design Specific Requirements}

The ability to understand fuel cycle options with respect to the four categories of characteristics depends on the availability of details of the technologies and how they would fit together to comprise a fuel cycle. 
Table 1-1 shows the relationship between the four fuel cycle areas and the level of detail required for understanding performance characteristics. We define these levels as follows:

- General Concept information represents an idea that has not yet matured to an actual design of one or more parts of the fuel cycle. The concept is typically graphically depicted by an explanatory sketch.

- Conceptual Design information represents a working point design. The concept is graphically depicted by a rough schematic.

- Detailed Design information represents a standardized design that is approaching readiness for preliminary licensing review. The concept is graphically depicted by technical drawings.

Some characteristics can be assessed with only a general concept. For example, one does not need to have a conceptual design to know that the uranium utilization of an LWR will be less than $1 \%$. The basic physics is adequately clear and the range of LWR-based concepts have been studied sufficiently well that the basic answer is known with confidence. The reader will often see graphs in the report with many data points of concepts of a related type; when these group together, it is a sign that the design details do not matter for that characteristic. On the other hand, quantitative estimates of reactor accident risk cannot be performed without nearly complete design detail that captures initiating events and the technology specific reactor safety functions that mitigate consequences. Of course, if a performance characteristic is very dependent on detailed design, it complicates the search for insights on technology families and fuel cycle strategies.

Table 1-1. Level of information needed to evaluate performance in each fuel cycle area.

\begin{tabular}{|l|c|c|c|}
\hline & $\begin{array}{c}\text { General } \\
\text { Concept }\end{array}$ & $\begin{array}{c}\text { Conceptual } \\
\text { Design }\end{array}$ & $\begin{array}{c}\text { Detailed } \\
\text { Design }\end{array}$ \\
\hline Resource utilization & $\mathrm{X}$ & $\mathrm{X}$ & \\
Radioactive waste & $\mathrm{X}$ & $\mathrm{X}$ & \\
Reactor safety & & $\mathrm{X}$ & $\mathrm{X}$ \\
Proliferation resistance and physical protection & & $\mathrm{X}$ & $\mathrm{X}$ \\
\hline
\end{tabular}

\subsection{Consideration of Distinct Versus Generalized Technologies}

The list of concept technologies considered in this report is not all inclusive. This report is not intended to thoroughly study every possible reactor design perturbation being developed by various industrial teams, or to reevaluate all paper reactors from previous R\&D programs, or to consider any and all unproven university design projects. Despite this fact, significant data has been assimilated in an effort to be representative of every "family" of reactor, fuel and separation technologies in the forefront of current fuel cycle research. In this report, technology families are described by common defining features as is relevant in a particular area of fuel cycle evaluation. Though it is understood that there is extensive overlap between technologies belonging to multiple families, for the purpose of establishing a frame-ofreference for the following discussions, the technology families are loosely defined as follows:

- $\quad$ Breed and Burn: A generic descriptor for core designs (and/or fuel management strategy within a reactor core) that enables a self-propagating generation of fissile material with subsequent in-situ burning. The fresh fuel is enriched uranium. Discharged fuel is directly disposed.

- Deep Burn: A generic descriptor for a fuel cycle strategy employing transuranic, fertile-free fuels and reactor engineering optimization to give the highest possible transuranic destruction in a single reactor pass. The phrase "deep burn" is not used for uranium-based fuels. Discharged fuel is directly disposed. 
- Water, Liquid Metal, and Gas cooled reactors: An appropriate categorization of reactors based on similarities in coolant strategies that govern thermodynamic efficiency and safety strategies. Other categorization approaches, such as fast versus thermal reactors, are more appropriate in other areas of characterization of fuel cycles.

- Alternative Separations defined families: Fuel cycles where the separation technology itself, (i.e., online reprocessing or limited separations) is the defining characteristic of the option.

- High Burnup: A generic descriptor for reactor fuels with fuel residence times well beyond the conventional experience base, typically by utilizing advanced materials.

Table 1-2 shows a brief listing of cases for populating the various graphics and discussions in this report. The reader is referred to the front-matter section "Acronyms, Terminology and Use Cases" for a complete listing of all labeling conventions used throughout this report. The source of data used in the following figures and discussion is affected by the required level of design detail. For analyses only needing general concept information, much of the data within the current Fuel Cycle program could be leveraged for the analyses. For conceptual designs such as the Traveling Wave Reactor (TWR), the Fuel Cycle program worked with the concept proponent to better understand the technology specific aspects of the design. Detailed design information was not used in the development of this report, but some design specific information was obtained from subject matter experts internal and external to the Fuel Cycle program. In addition, historic data of operating facilities as well as current vendor data is used to show how past and currently proposed technologies address existing challenges.

Table 1-2. Technology use-cases chosen for each level of design detail within each technology family.*

\begin{tabular}{|c|c|c|c|c|c|c|c|}
\hline & \multicolumn{2}{|c|}{ Physics Defined } & \multicolumn{3}{c|}{ Coolant Defined } & \multicolumn{2}{c|}{ Fuel Defined } \\
\hline $\begin{array}{c}\text { Technology } \\
\text { Families }\end{array}$ & $\begin{array}{c}\text { Breed / } \\
\text { Burn }\end{array}$ & $\begin{array}{c}\text { Deep } \\
\text { Burn }\end{array}$ & Water & $\begin{array}{c}\text { Liquid } \\
\text { Metal }\end{array}$ & Gas & $\begin{array}{c}\text { Alternative } \\
\text { Separations }\end{array}$ & $\begin{array}{c}\text { High } \\
\text { Burnup }\end{array}$ \\
\hline $\begin{array}{c}\text { General } \\
\text { Concept }\end{array}$ & CANDLE & IMF & $\begin{array}{c}\text { CANDU, } \\
\text { PWR, } \\
\text { BWR }\end{array}$ & SFR & MAGNOX & $\begin{array}{c}\text { Fluoride, } \\
\text { AIROX }\end{array}$ & \\
\hline $\begin{array}{c}\text { Conceptual } \\
\text { Design }\end{array}$ & TWR & $\begin{array}{c}\text { DB-MHR, } \\
\text { CONFU }\end{array}$ & & & & Vented Fuel & $\begin{array}{c}\text { Advanced } \\
\text { Cladding }\end{array}$ \\
\hline $\begin{array}{c}\text { Detailed } \\
\text { Design }\end{array}$ & & & NUSCALE & PRISM & MHTGR & MSRE & TRISO \\
\hline
\end{tabular}

* See front-matter section "Acronyms, Terminology, and Use Cases" for a complete listing of all labeling conventions used throughout this report.

The ability to characterize reactor concepts into general categories, e.g., LWR, SFR, and HTGR, stems from the fact that design data exists for these concepts to the extent that they are well understood.

Conversely, technology options that are less explored (e.g., Traveling wave, vented fuel, etc.) do not have sufficient design specific data in order to generalize them into a single category or family of options. This point is exemplified by the consideration of the vast array of small-modular reactor concepts currently being developed by industry and universities. Small modular reactors can be categorized into any column in Table 1-2 depending on their design details.

To show the difficulty of categorizing concepts, note that in some respects an small modular reactors with a specific coolant may share the performance of the column of its coolant; it may share performance characteristics of its fuel or its physics regime; it may additionally have more passive safety features and higher cost in common with other small modular reactors. 


\section{NUCLEAR RESOURCE UTILIZATION}

In this chapter we examine how well different fuel cycle approaches use uranium and thorium resources with specific emphasis on U-235 as the only fissile isotope in nature. We also develop perspectives on the amount of energy required to access and use these resources versus the amount of energy produced. Fissile material (U-235) is moderately abundant today and estimates of resource supply (for a given cost) vary. Because there is only one natural fissile isotope and it is only $0.7 \%$ of uranium, it is acknowledged that fertile material (U-238 and/or Th-232) must be converted to fissile isotopes (i.e., the act of breeding which occurs to some degree by default in any nuclear reactor) in order to achieve any level of resource utilization greater than $0.7 \%$.

\subsection{Uranium Utilization}

The resource utilization efficiency (\%) is defined as the fraction of the original natural uranium or thorium ore that is converted into fission energy. This formulation of uranium utilization is time-period and reactor independent as it assumes no credit for availability of current fissile stocks.

$$
\text { Uranium utilization }(\%)=\frac{\sum_{\text {all reactors }} \text { Mass of heavy metal consumed by fission }}{\sum_{\text {all mines }} \text { mass of natural uranium (or thorium) mined }} \times 100
$$

Generally, the above definition is simply mass utilized/mass consumed. However, the sums over mining and reactors emphasize uranium (or thorium) utilization must be calculated for a fuel cycle, including all reactors included in that fuel cycle and all mining operations.

For once-through fuel cycles where no uranium enrichment is used to concentrate U-235, the utilization efficiency is equivalent to the fraction of initial heavy metal atoms that underwent fission during the single time in the reactor, or burnup. Also, for such a fuel cycle, the rate of resource consumption (tonneHM per GWth-day) is inversely proportional to uranium utilization (GWth-day/tonne of natural uranium). To consider all fuel cycles where enrichment or Pu-239 or U-233 is included, a simple control volume approach is used (Figure 2-1). All reactor and recycle facilities are placed inside of the control volume. Uranium and thorium mines as well as nuclear waste disposal sites are placed outside of the control volume.

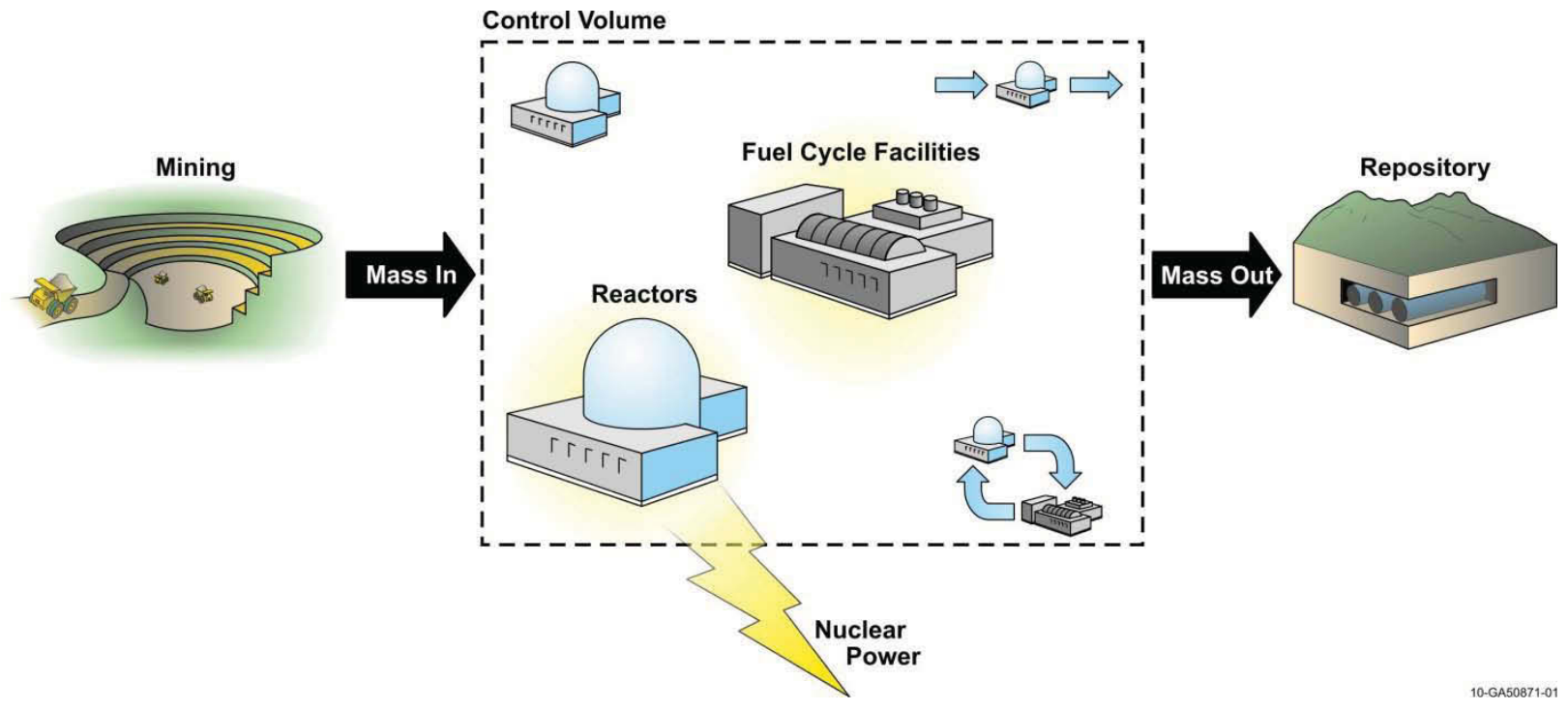

Figure 2-1. Control volume analogy used in calculating resource utilization. 
In this report, the generating capacity of the set of nuclear energy facilities within the control volume (sometimes called a nuclear park) is considered static. This means that, to the extent feasible in a fuel cycle option, there is no net storage of fuel material.

However, there are two cases in which net storage is unavoidable. First, in the current fuel cycle and other fuel cycles with enrichment but no breeding, excess depleted uranium is stored. Depending on the fuel cycle, excess uranium recovered from recycle may also be stored. Second, if breeding is part of the scenario, but there is no growth (static control volume), then excess fissile material that would normally go to startup of new reactors is stored.

The uranium utilization efficiency is plotted against the rate of heavy metal consumption (taken at the point where it is mined) per unit fission energy liberated (Figure 2-2). Perfect utilization efficiency $(100 \%)$ corresponds to no heavy metal mass leaving the control volume. The only mass leaving the fuel cycle in this situation are fission products. The absolute minimum ore consumption, occurring at $100 \%$ utilization efficiency, is directly proportional to the energy released per fission ( $\sim 200 \mathrm{MeV} /$ fission$)$. Converting units, this becomes $\sim 970 \mathrm{GWth}$-day per tonne of uranium or thorium fissioned.

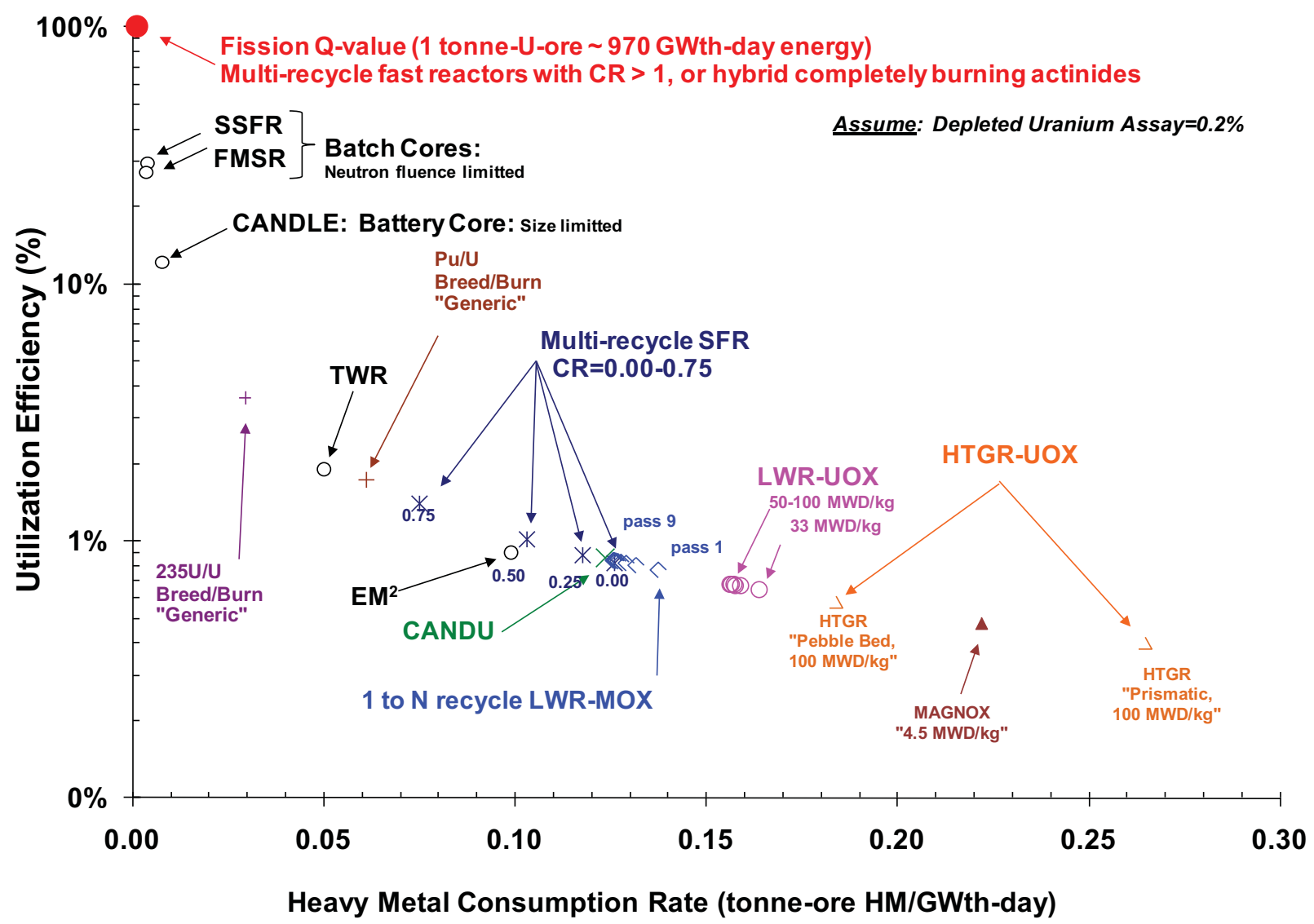

Figure 2-2. Uranium resource utilization efficiency as a function of consumed mass-in natural uranium ${ }^{\mathrm{a}}$

a For more information on the source data used in the calculations for this figure, the reader is referred to the following references: SSFR, FMSR, CANDLE (i.e., $8 \mathrm{~m}$ tall right-circular cylinder with wave propagating from bottom to top), TWR (i.e., standing wave design variant), $\mathrm{EM}^{2}$ (Kim 2010); Multi-Recycle SFR (Hoffman 2006); 1 to N Recycle LWR-MOX (Youinou 2009); CANDU (Ellis 2009); LWR-UOX (Yacout 2008); HTGR "Pebble Bed, 100 MWD/kg" (Boer 2010); MAGNOX “4.5 MWD/kg” (Murphy 2004), HTGR "Prismatic, $100 \mathrm{MWD} / \mathrm{kg”} \mathrm{(Pope} \mathrm{2010).} \mathrm{Isotopic} \mathrm{data} \mathrm{for} \mathrm{these} \mathrm{cases} \mathrm{is}$ catalogued in the "Transmutation Library - 2010" (Piet 2010a). 
Fuel cycles that do not require uranium enrichment such as CANDU and MAGNOX in Figure 2-2 exhibit very low utilization. One original motivation for non-enrichment reactor technologies was plutonium production directly from natural uranium. This does not necessarily imply a plutonium self-sustaining fuel cycle because the production of plutonium is far lower than the consumption of natural uranium.

The reactors with on-line refueling strategies, CANDU and Pebble Bed HTGRs, have greater uranium utilization compared to similar reactor types with a batch process, i.e. MAGNOX and Prismatic HTGR. For example, CANDU reactors achieve nearly twice the burnup as MAGNOX reactors though both reactors begin with natural uranium. Also, Pebble Bed HTGR achieves approximately the same burnup as Prismatic HTGR, but only requires two-thirds the initial ${ }^{235} \mathrm{U} / \mathrm{U}$ enrichment and therefore have higher natural uranium utilization. This is because the excess reactivity of fresh fuel is better matched with reactivity-deficient fuel that is nearly spent. Thus, more excess neutrons that otherwise would need to be absorbed by control mechanisms such as control rods, are instead invested into fuel thus extending their burnup.

All of the once-through enriched $\mathrm{UO}_{2}$ fuel cycles (i.e., current LWR fuel cycle) exhibit utilization in the range of 0.6 to $0.8 \%$, regardless of their discharge burnup. Higher burnup is offset by higher uranium enrichment, which produces more front-end depleted uranium. The higher burnup in these systems is not attained via higher conversion of U-238 to fissile Pu-239. Here again, burnup (and hence uranium utilization) can be slightly extended by increasing the number of batches that reside in the core at any given time for the same reason that on-line refueling extends burnup as explained above. For LWR recycle scenarios such as MOX or IMF, uranium utilization generally increases with the first recycling and then subsequently either increases or decreases slightly with subsequent recycles as they continue to require uranium fissile support (uranium enrichment) to counter the effect of plutonium fissile degradation. The added enrichment for the subsequent reactor passes creates further depleted uranium, thus decreasing utilization.

In general, uranium utilization increases the more the fuel can be burned without the reliance on uranium enrichment. Two generalized fast reactor breed/burn approaches are given that approximate the ideal maximum burnup achievable starting with the lowest possible enrichment $\left({ }^{235} \mathrm{U} / \mathrm{U}\right.$ or $\left.\mathrm{Pu} / \mathrm{HM}\right)$ required to achieve first criticality in the reactor. This maximum burnup corresponds to the time in the irradiation when positive reactivity of the fuel is balanced by the negative reactivity drag of fertile isotopes and fission products. The calculated maximum burnup for this simple zero-dimensional calculation yielded $35-40 \%$ of all initial heavy metal destroyed. The reason that the "Pu/U Breed/Burner" has a smaller utilization than the " ${ }^{6235} \mathrm{U} / \mathrm{U}$ Breed/Burner" point (see Figure 2-2) is that starting with an initial fissile load of $\mathrm{Pu}$ requires that it be first generated in a previous reactor, assumed to be an LWR in this case. The unused depleted uranium created during fuel enrichment in the LWR causes the utilization to go down. The extent of this depleted uranium wastage is the primary driver in differences between the entire breedand-burn concept technologies plotted in Figure 2-2.

\subsection{Deep Burn Concepts}

Figure 2-3 shows the uranium utilization for deep-burn concepts, which are characterized by taking fissile from used fuel and concentrating it in new recycled fuel. From a nomenclature standpoint, we define "deep-burn" to be markedly different than "high burnup," in order to facilitate comparison transuranic burning concepts with breed-and-burn concepts. In deep burn, the idea is to maximize consumption of existing fissile material without creating any new such material.

Because of the intentional consumption of transuranics with zero in-situ breeding, it is not surprising that these deep burn concepts have modest uranium utilization, little better than the reactor that provided the transuranic material. Figure 2-3 shows that DB-MHR and homogeneous LWR-IMF approach 0.8\% versus $<0.7 \%$ for the LWR UOX that produced the transuranic material used in the DB-MHR or LWRIMF. 
Figure 2-3 also shows related concepts in which transuranics from used LWR UOX are repeatedly recycled. These require some means to mix new enriched uranium or fresh supply of bred transuranics into fuel. These include MOX and heterogeneous LWR-IMF such as CONFU or DB-LWR that are a mixture of traditional enriched uranium and concentrated IMF fuels within the same LWR fuel assembly. The uranium utilization starts higher than LWR-UOX but then decreases because the fissile quality of repeatedly recycled transuranics in heterogeneous LWR-IMF or MOX decreases with each successful recycle, thus increasing the dependence on uranium enrichment. With continuing fissile support via uranium enrichment in the system, recovered transuranics can be recycled indefinitely and the uranium utilization reaches an equilibrium that is either slightly above or slightly below that of LWR-UOX.

The DB-MHR and homogeneous LWR-IMF utilization is higher because no enriched uranium support is required to burn greater than $60 \%$ transuranics in a single reactor pass. The homogeneous LWR-IMF data-point represents completely fertile-free IMF concepts assuming a complete LWR is converted to deep-burn operation. From the figure, it can be seen that the transuranic burning potential of DB-MHR and homogeneous-IMF are very similar. We include an SFR $(\mathrm{CR}=0)$ case for comparison. The SFR $(C R=0$, no uranium in the fuel) case has still higher in uranium utilization than DB-MHR because more transuranics are fissioned in a fast reactor with continuous recycle, with no uranium support.

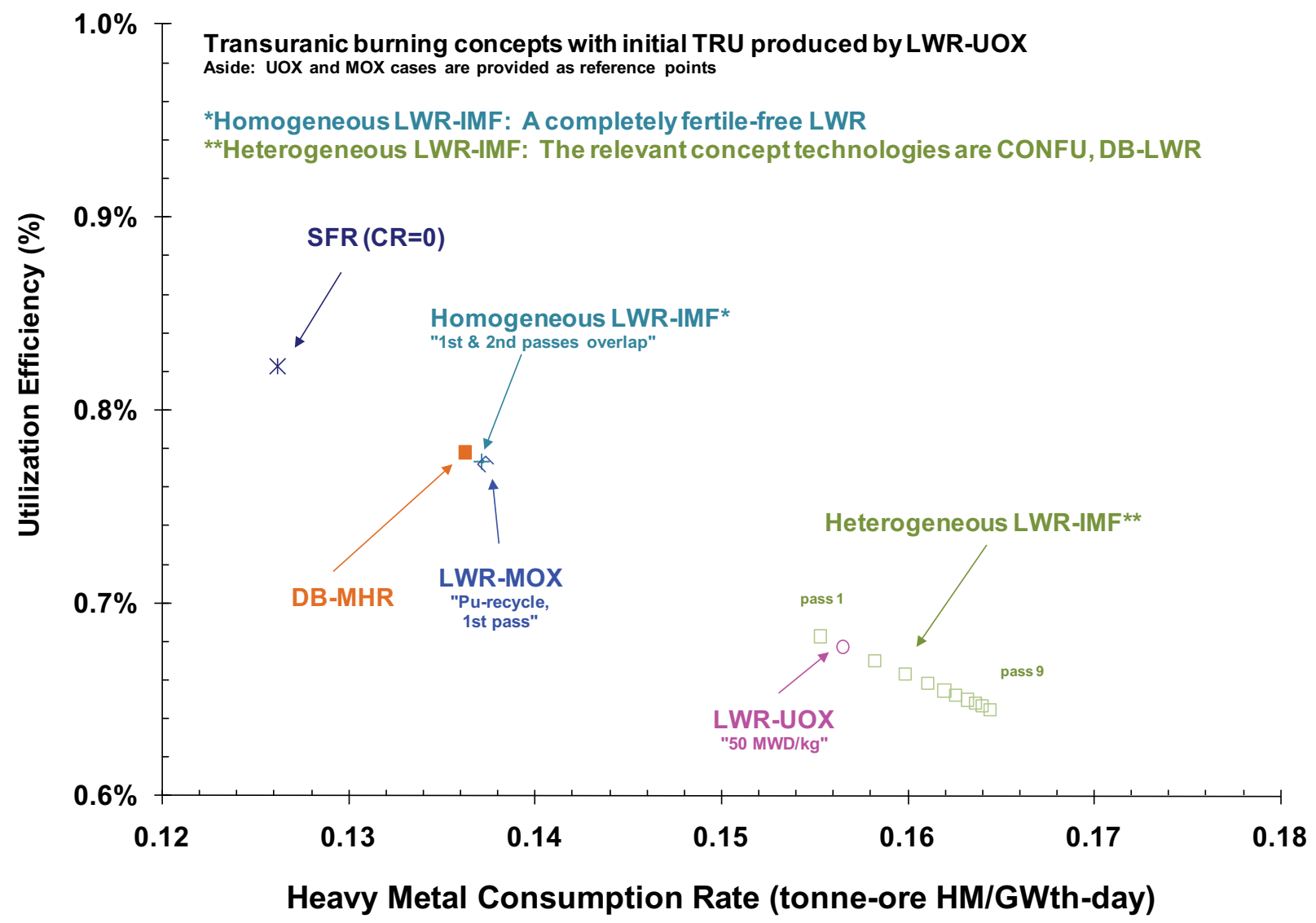

Figure 2-3. Resource utilization efficiency for deep-burn concepts. ${ }^{b}$

b For detailed information on the calculation of the source data used in this figure, the reader is referred to the following references: SFR (CR=0) (Hoffman 2006); DB-MHR (Pope 2010, Boer 2010); Homogeneous LWR-IMF (Hoffman 2005); LWR-MOX (Youinou 2009); LWR-UOX “50 MWD/kg” (Yacout 2008); Heterogeneous LWR-IMF (Pope 2009). Isotopic data for these cases is catalogued in the "Transmutation Library - 2010" (Piet 2010a). 


\subsection{Fuel Cycle Energy Return on Investment}

Energy Return on Investment (EROI) calculations have been used in other disciplines for assessing the life-cycle worth of a given energy option. As an example, EROI has been used to analyze the net positive (or net negative) green-house gas emission footprint of corn-ethanol production for transportation fuels (Hammerschlag 2006). Here, the EROI is defined as the ratio of usable energy produced by reactor cores divided by the energy footprint required to produce the fuel and get it to the reactor. Examples of usable energy are: (1) the electricity produced by nuclear reactors, (2) the enthalpy increase in hydrogen produced using nuclear power, and (3) utilizing nuclear power for process heat. The energy footprint is defined as the amount of energy required to make the nuclear fuel itself. Thus, in this analysis:

- The operational electrical and combustible fuels used for energy inputs that are required in mining, milling, conversion, enrichment, transportation, reprocessing and fuel manufacturing and separation are included. For example, fuels include may be the diesel fuel used by mining trucks, excavation, and transportation equipment. Fuels could also be used for process heat during milling, conversion, etc.

- Embodied energy inputs, such as the energy input required in construction of nuclear power plants and recycle facilities, construction, and operation of a waste repository and transportation costs are not included. Similarly, decommissioning of these facilities is not included. These are excluded due to the variability of facility specific design information that would be required in an adequate assessment of their energy cost. In addition, even with full design information, the accounting to avoid over or under-counting and to ensure consistency for comparison with other industries is a difficult and complex undertaking. Embodied energy inputs are left to future work.

Figure 2-4 shows that the EROI tends to be chiefly dependent on the level of uranium utilization. This is because the invested front-end energy input in transforming uranium resources into fuel is not fully leveraged if much of the original uranium (primarily U-238) is not converted into output fission energy. Full recycle $(\mathrm{CR}=1)$ gives $\sim 100$ times greater uranium utilization than all other options $(\sim 100 \% \mathrm{vs} . \sim 1 \%)$. This is reflected by the EROI for full recycle which is also approximately two orders of magnitude greater than cases other than full recycle in Figure 2-4. 


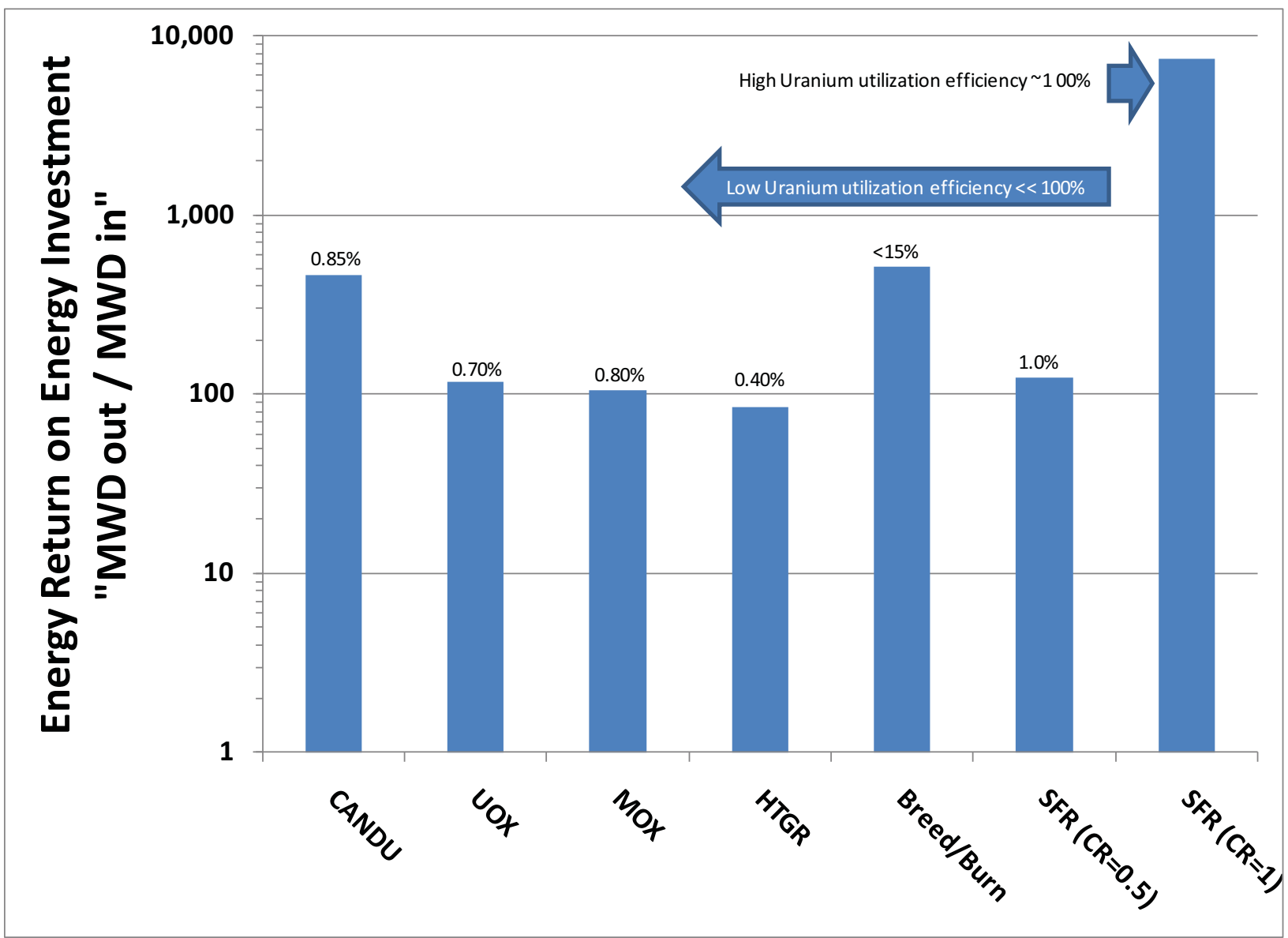

Figure 2-4. Energy return on investment comparison showing uranium utilization differences ${ }^{\mathrm{c}}$

The EROI is also influenced by the efficient use of thermal energy produced or consumed by the fuel cycle. Figure 2-5 shows how the EROI is influenced by thermodynamic efficiency to convert nuclear heat into an energy carrier, such as electricity or hydrogen. Nuclear power plant thermodynamic efficiency improves with increasing reactor outlet temperatures. However, relatively high reactor outlet temperatures $\left(850^{\circ} \mathrm{C}\right.$ or greater for HTGR) are required to achieve a high EROI. Reactor outlet temperatures in excess of $1000^{\circ} \mathrm{C}$ are not considered because thermal efficiency at these temperatures is approaching an asymptotic maximum, mirroring the Carnot efficiency. This is true of both electricity and hydrogen production, including hydrogen production by either high-temperature electrolysis or the sulfuriodine process (O’Brien 2008).

Figures 2-4 and 2-5 show that, when normalized against the useful energy produced, the energy invested in reprocessing and recycling nuclear fuel materials is comparable to the energy required to produce nuclear fuel from mined raw material. Although energy usage is comparable, there are distinct differences in other environmental impacts as well as the nature of the waste forms produced.

c For detailed information on the calculation of the source data used in this figure, the reader is referred to the following references: CANDU (Ellis 2009); UOX (i.e., $50 \mathrm{MWD} / \mathrm{kg}$ ) (Yacout 2008); MOX (i.e., Pu recycle, $1^{\text {st }}$ reactor pass) (Youinou 2009); HTGR (i.e., Prismatic Fuel) (Kim 2004); Breed/Burn (Assume a starting enrichment of 7\% ${ }^{235} \mathrm{U} / \mathrm{U}$ and a burnup of $335 \mathrm{MWD} / \mathrm{kg}$ (S. Bays, Unpublished); SFR (CR=0.5) (Hoffman 2006); SFR (CR=0.1) (Assume an ideal case where all heavy metal undergoes fission yielding: $970 \mathrm{GW}$ th-day/tone) 
The energy intensity of some non-reactor fuel cycle technologies also affect EROI. For example, a significant improvement in total system EROI was achieved by switching from gaseous diffusion to centrifuge-based enrichment. We found little openly available data on the energy requirement for laser enrichment. A recent analysis of enrichment technologies suggest a Moore's Law trend whereby technology leaps (as well as successive generations of the same family) enable progressive increases in performance (Schneider 2010). Therefore, all cases except for gaseous diffusion assume the current generation of gaseous centrifuge with the expectation that laser enrichment will meet this value or improve on it.

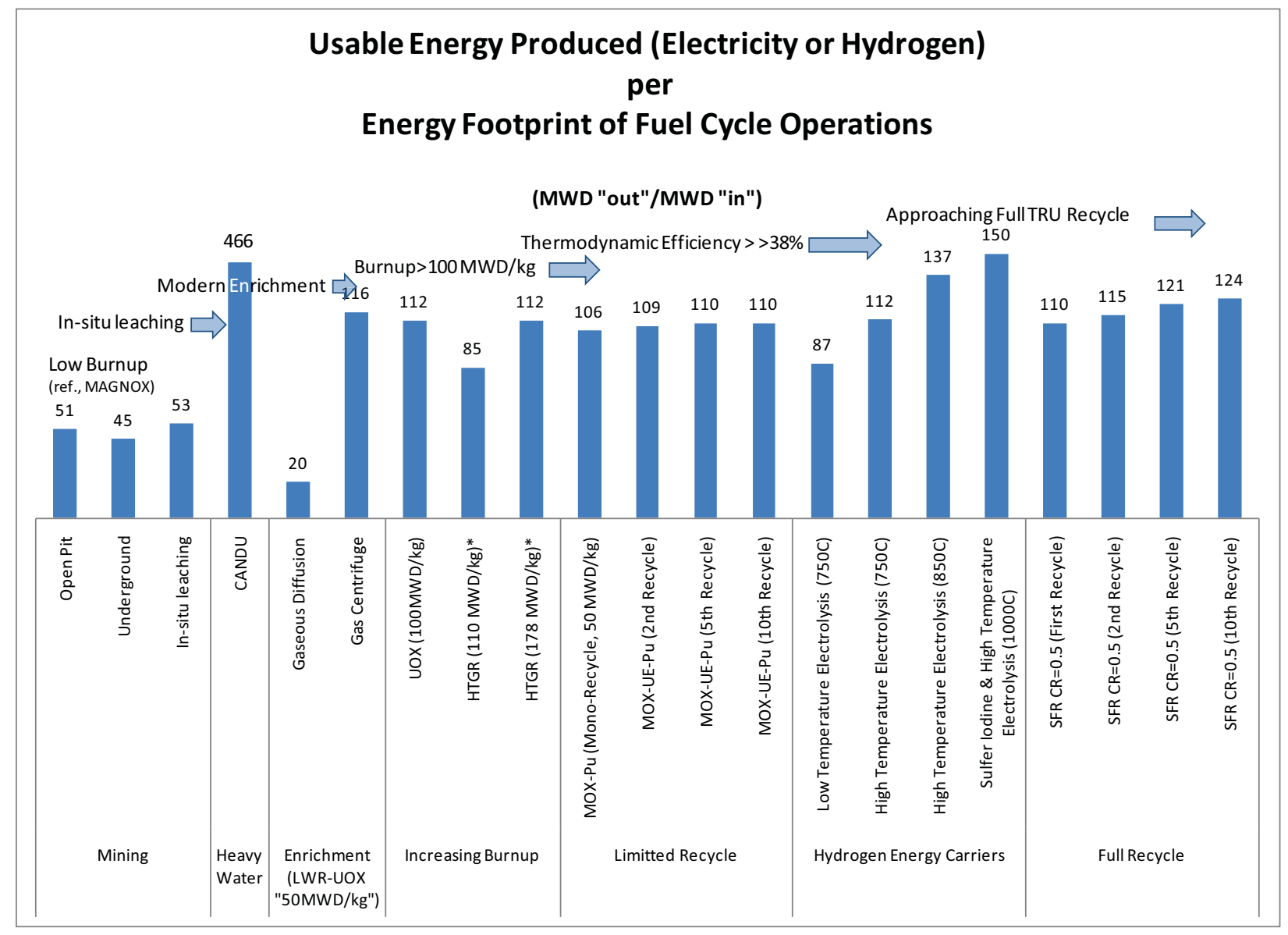

Figure 2-5. Energy return on investment over a wide range of technology options. ${ }^{\mathrm{d}, \mathrm{e}, \mathrm{f}}$

The EROI for UOX fuel burned to $100 \mathrm{MWth}$-day/kg is actually less than $50 \mathrm{MWth}-$ day $/ \mathrm{kg}$. This is due to the additional uranium enrichment because this higher burnup does not utilize energy required to

d HTGR electricity production cases assumed power plant thermal efficiency, $\eta^{\text {th }}=42 \%$ (Tout $850^{\circ} \mathrm{C}$ ).

e Arrows indicate the set of technology assumptions that have been fixed to enable comparisons made to the right.

f For detailed information on the calculation of the source data used in this figure, the reader is referred to the following references: Energy inputs for Mining, Conversion, Enrichment, Fuel Fabrication (Schneider 2010); Energy inputs for Reprocessing (Areva 2009); MAGNOX thermal efficiency assumed: 23\% (Calder Hall), Fuel cycle data (Murphy 2004); CANDU thermal efficiency assumed: 35\% (CANDU-6), Fuel cycle data (Ellis 2009); UOX, MOX (i.e., LWR) thermal efficiencies assumed: 33\%, Fuel cycle data (Yacout 2008, Youinou 2009); HTGR "110 MWD/kg" and "178 MWD $/ \mathrm{kg}$ " with electricity production thermal efficiency taken to be $42 \%$, Fuel cycle data (Pope 2010, Boer 2010); HTGR with High Temperature Electrolysis Hydrogen-to-Thermal Efficiency $\left(1000^{\circ} \mathrm{C}\right)$ taken to be $60 \%\left(\mathrm{O}^{\prime}\right.$ Brien 2008$)$;SFR Thermal Efficiency assumed: 38\%, Fuel cycle data (Hoffman 2006). 
produce the higher enrichment fuel as efficiently as the lower burnup. The break-over point for achievable burnup per invested enrichment is approximately $75 \mathrm{MWth}-\mathrm{day} / \mathrm{kg}$ with an associated enrichment of $6.2 \%{ }^{235} \mathrm{U} / \mathrm{U}$. Similarly, the HTGR at $110 \mathrm{MWth}-\mathrm{day} / \mathrm{kg}$ has a still smaller EROI, demonstrating a still smaller appreciation of front-end energy investment, despite having a higher thermodynamic efficiency ( $42 \%$ as opposed to $33 \%$ ).

From a reactor physics standpoint, the decrease in enrichment utilization for increasing burnup is caused by the higher required enrichment to reach these burnups. In LWR's at current burnup, $\sim 60 \%$ of all the power produced originates from the fission of ${ }^{239} \mathrm{Pu}$ atoms; not the ${ }^{235} \mathrm{U}$. This is due to the in-situ breeding from ${ }^{238} \mathrm{U}$. Higher ${ }^{235} \mathrm{U}$ enrichments, equates to lower ${ }^{238} \mathrm{U}$ concentrations in the fuel, hence less breeding can result.

Higher enrichment is not always required to achieve higher burnup. For example, fast reactors can utilize neutrons more effectively towards breeding than thermal reactors such as LWR and HTGR. Thus, these reactor types can extract more energy from the initial energy investment by producing more fissions from in-situ produced $\mathrm{Pu}-239$. Full recycle of transuranics does not ensure significant gains in EROI. For a symbiotic fuel cycle where fast reactors burn all transuranics produced by LWRs, the energy investment in the required enrichment of the LWRs is translated into plutonium production for the fast reactors. However, transuranic burning fast reactors are intentionally designed not to produce further plutonium. Hence, the continued appreciation of the original front-end energy cost is lost.

\subsection{Breakdown of Fuel Cycle Energy Investments}

Figure 2-6 shows the reciprocal of the EROI values plotted above. Thus the units are invested energy per unit of usable energy produced. Furthermore, the invested energy is further broken down into each fuel cycle process. In all of the cases in Figure 2-6, uranium mining, conversion and enrichment is assumed using current day gaseous centrifuge technologies; mining is assessed at the contemporary industry average ore grade and extraction technology (Schneider 2010).

Note the large energy consumption by the conversion process. Even for modified open fuel cycles where transuranics are partly or completely recycled, the energy input is dominated by conversion. The conversion process energy intensity is primarily due to the two highly endothermic reactions required to convert $\mathrm{UO}_{2}$ into $\mathrm{UF}_{6}$. These reaction energies dominate the energy input requirement of both the dry (U.S. only) or wet (international) conversion processes (Schneider 2010).

$$
\begin{aligned}
& \mathrm{UO}_{2}+4 \mathrm{HF} \rightarrow \mathrm{UF}_{4}+2 \mathrm{H}_{2} \mathrm{O}, \Delta \mathrm{H}^{\mathrm{O}}=-229 \mathrm{~kJ} / \mathrm{mol} \\
& \mathrm{UF}_{4}+\mathrm{F}_{2} \rightarrow \mathrm{UF}_{6}, \Delta \mathrm{H}^{\mathrm{o}}=-233 \mathrm{~kJ} / \mathrm{mol}
\end{aligned}
$$

Keeping in mind that overall invested energy is reduced with decreasing dependence on uranium enrichment, a full recycle strategy (i.e., all ${ }^{238} \mathrm{U}$ is consumed) will have an order of magnitude reduced energy invested. Therefore, as uranium utilization approaches the asymptotic maximum of Figure 2-2, the energy investment associated by all front-end processes tends towards an asymptotic minimum in Figure 2-6. The asymptotic minimum for $100 \%$ uranium utilization then becomes the invested energy in the fuel cycle divided by the full energy payoff that occurs when all mined uranium or thorium undergoes fission. An up-front enrichment energy investment tends towards zero as successive reactor passes produce fission power without the use of this technology. Also, energy consumption due to reprocessing could be higher than enrichment for MOX and low CR SFR.

It is interesting that the CANDU inverse EROI is significantly less than that of the enrichment technologies. This is because this fuel cycle avoids enrichment. More importantly, the CANDU fuel cycle does not require a $\mathrm{UF}_{6}$ conversion step, which is the large energy consumer required as a front-end 
process for enrichment. In the CANDU fuel cycle a wet process is used for converting $\mathrm{U}_{3} \mathrm{O}_{8}$ to $\mathrm{UO}_{3}$ and ultimately $\mathrm{UO}_{2}$.

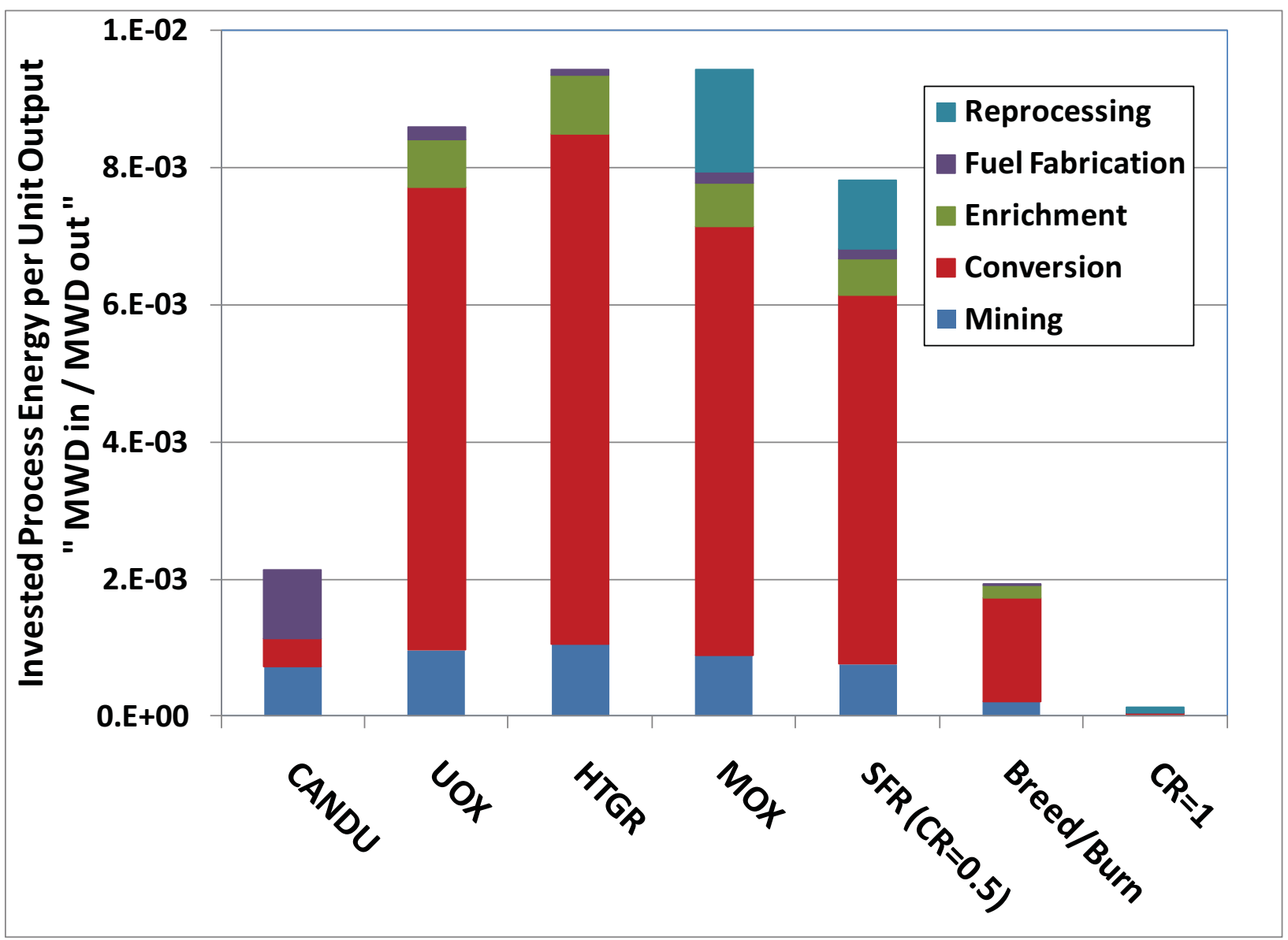

Figure 2-6. Breakdown of energy supplied (electric and combusted fuels) in each fuel productions step per electric energy produced. c,d $^{\mathrm{c}}$

\subsection{R\&D Needs}

In this report, estimations of energy inputs were drawn heavily from existing data corresponding to well established technologies, primarily related to LWRs. Thus fuel fabrication and reprocessing invested energy estimates are based on aqueous reprocessing and LWR fuel fabrication (Schneider 2010). Distinct differences exist between fuel candidates of LWR, SFR and HTGR that require their own determination of fuel manufacturing invested energy. In addition, distinct differences exist between aqueous, electrochemical, and alternative separations families that justify research for differentiating their energy requirements.

Finally, the embodied energy impact associated with facility and infrastructure construction was not included in this study. A comprehensive study of the total levelized life-cycle invested energy has not been performed on the nuclear fuel cycle since the mid-1970s (Rotty 1975). Such a study is necessary for fully understanding which monetary costs of the fuel cycle are associated with energy consumption, apart from which monetary costs are associated with services provided by humans. 
Indeed, a full life-cycle analysis of fuel cycle impacts is overdue. It would include a full assessment of all "major" material as well as embodied energy impacts. Material inputs range from chemicals to concrete and steel to $\mathrm{Zr}$ cladding and deuterated water. 


\section{RADIOACTIVE WASTE}

Radioactive materials are generated in essentially all parts of a nuclear fuel cycle. If they are not re-used, they become wastes that need to be managed and disposed safely. The analyses reported here focuses on used nuclear fuel assemblies that contain unutilized uranium (or thorium), transuranics, and fission products. For the purposes of the following discussion, these three used fuel constituents are considered the fuel "meat". Also discussed are the contaminated or activated cladding and structural materials, because they contain the greatest amounts of radiation, radiotoxicity, and decay heat, after that of the fuel meat. ${ }^{\mathrm{g}}$

Both decay heat and radiotoxicity are important factors in radioactive waste handling, storage, and disposal. Decay heat is important because the decay heat can damage, and impair the ability of the waste form, the waste packaging, and the storage/disposal site to effectively isolate the waste from the environment for up to geological timeframes. Radiotoxicity represents the hazard contained in the waste that must be isolated. Radiation is also an important factor that requires shielding during radioactive waste handling and storage, and that can damage and impair the ability of the waste form and packaging to contain the waste, but it has lesser impact (due to shielding) on a disposal site. Radiation is not specifically included in this analysis, although radiation is related to, and generally decreases over time along with, radiotoxicity; and so results of this analysis that address radiotoxicity also indirectly address radiation.

\subsection{Existing U.S. Radioactive Waste Classification and Disposal}

We start with a summary of existing regulatory waste classification in the U.S for two reasons. First, there is no way to know how much the laws, rules, and regulations will change from now until new fuel cycles are deployed. Second, although some of the existing waste classification rules are source-based instead of characterization-based, there are important technical underpinnings that require attention. In particular, both high-level waste and near-surface burial regulatory documents point to the importance of the two dimensions of long-term hazard and short-to-intermediate-term heat and radiation exposure.

The existing laws, rules, and regulations were written at different times, with different objectives, with different parts of the waste situation in mind, by different people, usually based on then-available technologies and options in mind. Updates may be needed to properly and efficiently regulate new technologies.

\subsubsection{Classification}

The distinction between high level waste (HLW) and low-level waste (LLW) in the Nuclear Waste Policy Act (NWPA 2004) and by the Nuclear Regulatory Commission (NRC) (NRC 2009) is made largely based on the source of the waste, rather than the characterization. Radioactive waste is HLW if it is:

"(A) the highly radioactive materials resulting from the reprocessing of spent nuclear fuel, including liquid waste produced directly in reprocessing and any solid material derived from such liquid waste that contains fission products in sufficient concentrations; and (B) other highly radioactive materials

g Waste streams are radioactive when they contain radioactive contaminants that can either be naturally occurring or generated in a reactor. Radioactivity can also arise from the neutron absorption and subsequent activation of core and fuel structural materials that ultimately must be processed. Radioactive contaminated wastes that result from operating and maintaining nuclear facilities including contaminated (a) process equipment, chemicals, sorbents, and (b) personal protective equipment wastes are generated in all phases of a nuclear fuel cycle, including the front end, fuel fabrication, reactor operations, used fuel separations, waste treatment, and radioactive material handling, storage, packaging, and disposal. These types of waste streams are much larger, but have much lower concentrations of radioactive isotopes, compared to the used fuel meat and activated/contaminated fuel assembly and core materials that come out of reactors. Thus these highvolume, low concentration wastes are not the primary focus of this report. For similar reasons, the uranium ore mining and milling tails and depleted uranium produced by the enrichment process, are not included. 
that the Commission, consistent with existing law, determines by rule requires permanent isolation" or "irradiated reactor fuel;"

LLW is radioactive material that:

"(A) is not high-level radioactive waste, spent nuclear fuel, transuranic waste, or by-product material as defined in section 11e(2) 1 of the Atomic Energy Act of 1954 (42 U.S.C. 2014(e)(2))" and (B) the Commission, consistent with existing law, classifies as low-level radioactive waste."

Some potential waste streams in advanced fuel cycles may not fit obviously into the source-based classifications. Indeed, existing regulations and laws allow the NRC to make determinations for other cases. For example, a radioactive waste can be HLW based on the radioactivity of the material and the judgment of the NRC, if it is:

"...other highly radioactive material that the Commission, consistent with existing law, determines by rule requires permanent isolation.” (NWPA 2004)

Other radioactive waste can be LLW if it is radioactive material that:

“...the Commission, consistent with existing law, classifies as low-level radioactive waste." (NWPA 2004)

We cannot know how the NRC would rule on waste streams from advanced fuel cycles. However, in 1987, the NRC started rulemaking to move from source-based to characterization-based definition of HLW (NRC 1987), but then dropped the effort due to lack of need. At that time, they wrote,

"Wastes which have historically been referred to as HLW (i.e. reprocessing wastes) are initially both intensely radioactive and long-lived. These wastes contain a wide variety of radionuclides. Some (principally Sr-90 and Cs-137) are relatively short-lived and represent a large fraction of the radioactivity for the first few centuries after the wastes are produced. These nuclides produce significant amounts of heat and radiation, both of which are of concern when disposing of such wastes. Other nuclides, including C-14, Tc-99, I-129, and transuranic nuclides, have very long halflives and thus constitute the longer-term hazard of these wastes. Some of these nuclides pose a hazard for sufficiently long periods of time that the term "permanent isolation" is used to describe the type of disposal required to isolate them from man's environment. The commission considers that these two characteristics, intense radioactivity for a few centuries followed by a long-term hazard requiring permanent isolation, are key features which can be used to distinguish high-level waste from other waste categories."

According to NRC definitions, waste that is not HLW but exceeds the criteria for Class C is still low-level waste (LLW) but is called Greater-Than-Class-C (GTCC). ${ }^{\mathrm{h}} \quad$ It is relevant to realize that waste can exceed LLW Class $\mathrm{C}$ in one or two ways.

1. Waste may contain specific long-lived isotopes at concentrations greater than that in Table 1 of 10CFR61. These all relate to long-lived radiotoxicity isotopes, such as C-14, Tc-99, and I-129. 10CFR61 does not currently include several isotopes relevant in advanced fuel cycle assessments (Piet 2010a, Fetter 1988, Fetter 1990).

$\mathrm{h}$ Radioactive wastes in the U.S. resulting from defense-related nuclear activities, that contain greater than $100 \mathrm{nCi} / \mathrm{gm}$ TRU isotopes with half lives greater than 20 years (by DOE definition in DOE 1988), also exceed Class C LLW limits, but are regulated separately as TRU waste (not HLW or GTCC LLW), can be disposed in the Waste Isolation Pilot Plant, and are not included in this report. 
2. Waste may have excessive external radiation and/or heat generation. Table 2 of 10CFR61 limits shorter lived isotopes such as Sr-90 and Cs-137 and specifies that "practical considerations such as the effects of external radiation and internal heat generation on transportation, handling, and disposal will limit the concentrations for these wastes."

In the absence of NRC rulings, this report concentrates on technical characteristics, guided by the technical intent of existing regulations. Both HLW and 10CFR61 rules, explanations by the NRC, as well as analogous foreign documents point to two major characteristics - relatively short-term heat (and external radiation) and relatively long-term hazard from key isotopes.

\subsubsection{Disposal}

Even if we knew the regulatory classification of every possible waste stream from advanced fuel cycle, such classification would not necessarily clarify what types of disposal would be required.

NRC and EPA regulations specify that spent nuclear fuel and HLW require deep geologic disposal. There is no precise technical definition of what disposal options constitute "deep geological" other than the inference that it is deep below ground and is permanent. NWPA and 10CFR60 specify that deep geological disposal must allow a period of retrievability for a minimum of 50 years.

The NRC regulation for near-surface burial (NRC 2001) indicates that Class A, B, and C LLW qualifies for near-surface burial but that other wastes may be deemed in the future to also qualify for near-surface burial.

The NRC has not specified disposal requirements for LLW-GTCC and has only said that if there were a spent HLW disposal site for used fuel/HLW that LLW-GTCC would also be disposed at that site. The NRC could, for example, determine that one disposal approach be used for some wastes that exceeds LLW Class $\mathrm{C}$ because of excessive concentrations of long-lived isotopes in 10CFR61 Table 1 and a different disposal approach for other wastes that exceeds LLW Class C because of excessive relatively short-lived isotopes in 10CFR61 Table 2 due to handling and disposal practicalities.

\subsubsection{Characterization-Based Approaches}

Source-based classification of radioactive wastes, and ensuing requirements for disposal have been identified as an issue for future potential radioactive waste management concepts in the U.S. "This has already created gaps in disposal pathways for wastes and this problem will be exacerbated with alternative fuel cycles... We recommend that an integrated risk-informed waste management system be adopted that classifies all wastes according to their composition and defines disposal pathways according to their risk." (MIT 2010)

Radiotoxicity represents the primary hazard after disposal, and decay heat affects the ability of the waste form, waste package, and disposal site to isolate that hazard from the environment. Together, these affect the risk of environmental impacts from the disposed waste. Waste materials with high long-term radiotoxicity must be isolated from the environment for geological timeframes. High decay heat requires a heat-tolerant and robust system of disposal barriers (the waste form, waste package, and disposal site). Table 3-1 shows how fuel meat, activated structures and contaminated waste streams can be categorized based on the content of isotopes that have high decay-heat and/or high long-term radiotoxicity. 
Table 3-1. Radioactive waste characterization based on decay heat and long-term radiotoxicity.

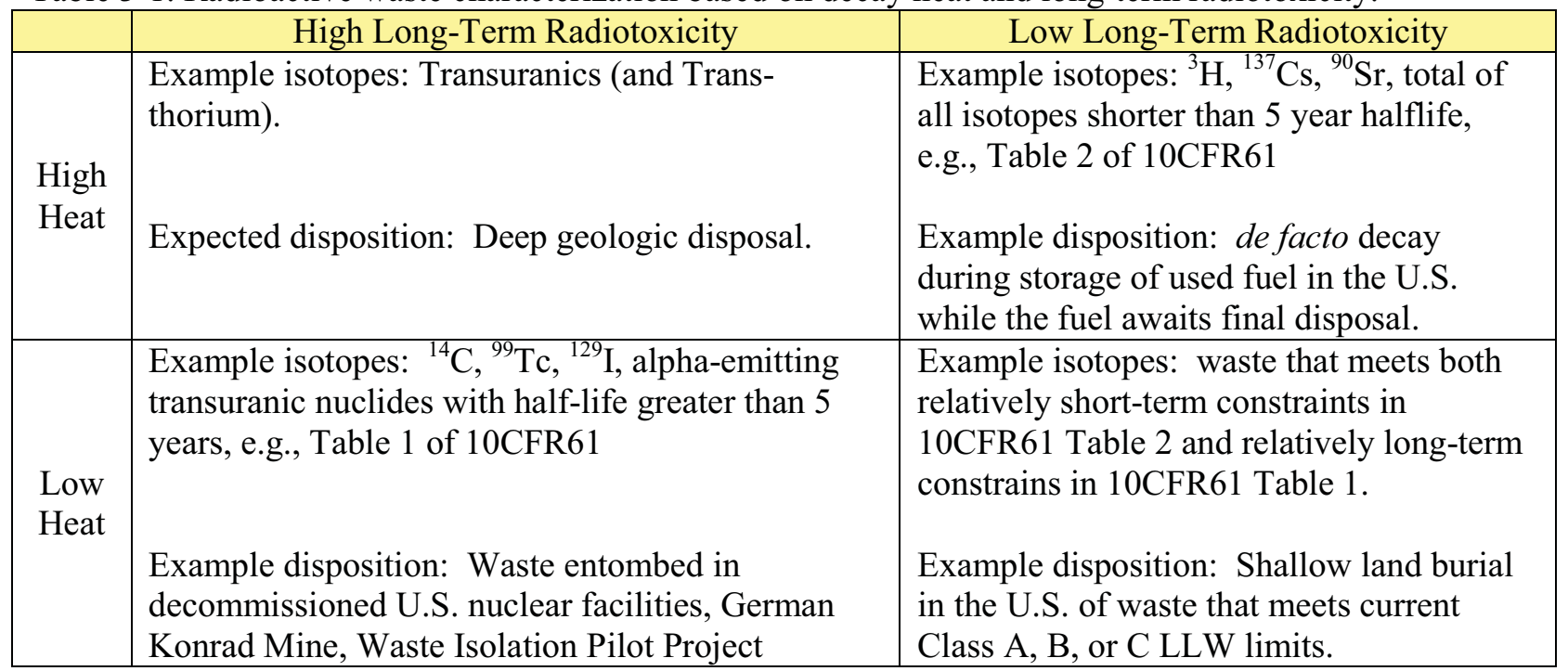

- High longevity/high heat - High long-term radiotoxicity, high decay heat materials (such as spent nuclear fuel, and waste streams from separating used fuels that contain the majority of fission products and TRU isotopes that are not recycled) are those wastes that would require disposal in geologic repository systems that will isolate these wastes from the environment for geologic timeframes. Such repositories do not yet exist.

- Low longevity/high heat - Low long-term radiotoxicity, high decay heat materials include waste streams that contain relatively short-lived fission products such as ${ }^{3} \mathrm{H},{ }^{85} \mathrm{Kr},{ }^{139} \mathrm{Cs}$, and ${ }^{90} \mathrm{Sr}$, which are separated from used fuel (and other, long-lived isotopes) in some potential separations processes. Uncertainty, cost, and risk in how these wastes can be disposed are lower than for high heat, high radiotoxicity wastes. The current de facto decay during storage of used fuel in the U.S. for up to 50 years (and more every year that storage continues) provides a precedent of this approach that has gained public and regulatory acceptance. MIT 2010 recommends storage of used fuel for about 100 years to allow decay of short-lived isotopes.

- High longevity/low heat - High long-term radiotoxicity, low decay heat wastes could include some materials presently classified as GTCC, and waste streams that contain minor actinides that are separated from used fuel but not recycled for some fuel cycle options. These materials may still require isolation for geologic timeframes, but not necessarily in waste forms, packages, and disposal sites that are designed to tolerate high decay heat. Uncertainty, cost, and risk in how these wastes can be disposed are lower than for high heat, high radiotoxicity wastes. Precedents of how these types of wastes are disposed exist in the U.S. and other countries (such as entombment of radioactive materials in decommissioned and buried DOE facilities, and the Waste Isolation Pilot Plant in the U.S., and the Konrad Mine in Germany (Bandt 2003, Sailer 2008).

- Low longevity/low heat - Low radiotoxicity wastes, low decay heat could include waste streams now classified under current regulations as Class A, B, or C LLW. Existing near-surface disposal sites are precedents of safe and relatively low cost disposal of these kinds of wastes in the U.S. and other countries. 


\subsection{Radiotoxicity of Fuel Cycle Options}

The toxicity of any given material is essentially the average of its constituent masses weighted with the relative toxic hazard presented to the human body per constituent. Radiotoxicity is based on the hazard of the material and the pathway by which material enters the human body. The pathways are either ingestion or inhalation. Radiotoxicity values based on inhalation apply when radionuclides can enter the environment through atmospheric releases, which can then be inhaled. Radiotoxicity values based on ingestion apply when radionuclides are assumed to enter the environment through food cycles. Ingestion radiotoxicity is used in this analysis because ingestion, via transport through water to the food chain, is generally considered the most likely means in which humans would be exposed to geologically disposed waste. Water is ubiquitous and is found in tuff, granite, clay, and even salt formations in cracks and fissures.

It is important to be clear what radiotoxicity does and does not convey about radioactive wastes:

- Radiotoxicity indicates the "source term" of the hazard of radioactive waste.

- It is not the dose to which humans could be exposed to.

- It is an indicator of how rigorously and how long wastes must be isolated from humans and the broader ecosystems such that radionuclide release rates are always kept low enough to ensure the doses to humans are within acceptable limits.

- This indicator has been used globally for decades and remains relevant today, especially in the absence of a baseline disposal approach in the U.S.

- Radiotoxicity trends are similar to heat trends as radionuclides decay over time.

The issue with the term "radiotoxicity" is that it can be misinterpreted as actual dose to humans instead of hypothetical dose if all material were ingested in a single point in time. Instead, ingestion toxicity is used to indicate the level of robustness that repository geology and engineered barriers are required to minimize the potential exposure to the environment. Figure 3-1 shows the future radiotoxicity (normalized based on the thermal energy produced) ${ }^{\mathrm{i}, \mathrm{j}}$ as a function of time of various potential illustrative fuel cycles. Five trends are apparent.

1. The LWR and HTGR UOX cases are representative of once-through fuel cycles. Other oncethrough cases with higher or lower burnup follow the same pattern.

2. Single recycle LWR-IMF and HTGR deep burn are representative of low conversion ratio (near zero) options that concentrate recycled transuranic material to more effectively consume it with a single recycle. These two lines are slightly above their corresponding once-through lines at short times (higher relatively short-lived americium and curium isotopes), lower at intermediate times ( $\mathrm{Pu}-239$ consumption), and somewhat higher at the longest times (higher long-lived $\mathrm{Pu}$ isotopes).

3. Single recycle burner and breeder FR cases are representative of modest (0.5) and high (1.0) conversion ratio cases. Single recycle MOX is similar, provided all TRU are recycled. These two lines are little different than LWR and HTGR UOX. Recycling used fuel only once in these

i Radiotoxicity can be expressed in units of the ingestion dose per energy produced (Sv/GWe-year). I t equals the sum over isotopes of the dose conversion factor ( $\mathrm{Sv} / \mathrm{kg}$-isotope) times the mass of isotope per mass of fuel (kg-isotope $/ \mathrm{kg}$-fuel) times the mass of fuel per energy produced (kg-fuel/GWe-year).

j Radiotoxicity values calculated here include recovered uranium from separations. They do not reflect the radiotoxicity of depleted uranium from enrichment of uranium ore. The assumption is made that the radiologic footprint of the front-end of the fuel cycle is significantly less consequential than the back-end and that disposal precedents exist for depleted uranium and uranium mill tailings. 
reactors does not appreciably reduce the radiotoxicity of the discarded waste because most of the TRU isotopes, which have high long-term radiotoxicity, are still eventually disposed.

4. Full recycle LWR-MOX-TRU and burner FR are representative of low to modest conversion ratio sustained recycle. The radiotoxicity of waste is appreciably reduced (by several orders of magnitude) in full recycle cases after about 100 years, when much of the fission products have decayed. These cases represent assume $99.9 \%$ efficient separations and recycling of all TRU isotopes. In addition to $0.1 \%$ of the transuranics, the fission products and unused recovered uranium are included. Most of the fission products decay significantly within about 10,000 years, so the radiotoxicity that remains after about 100,000 years is largely due to the separated uranium that is not recycled.

5. Full recycle without breeding stabilizes after about 100,000 years, with the remaining radiotoxicity largely due to the build-in of radiotoxic decay products in separated uranium that is not recycled. Breeder cases exhibit lower radiotoxicity beyond about 100,000 years because not only are TRU isotopes consumed, but so is the uranium recovered from separations.

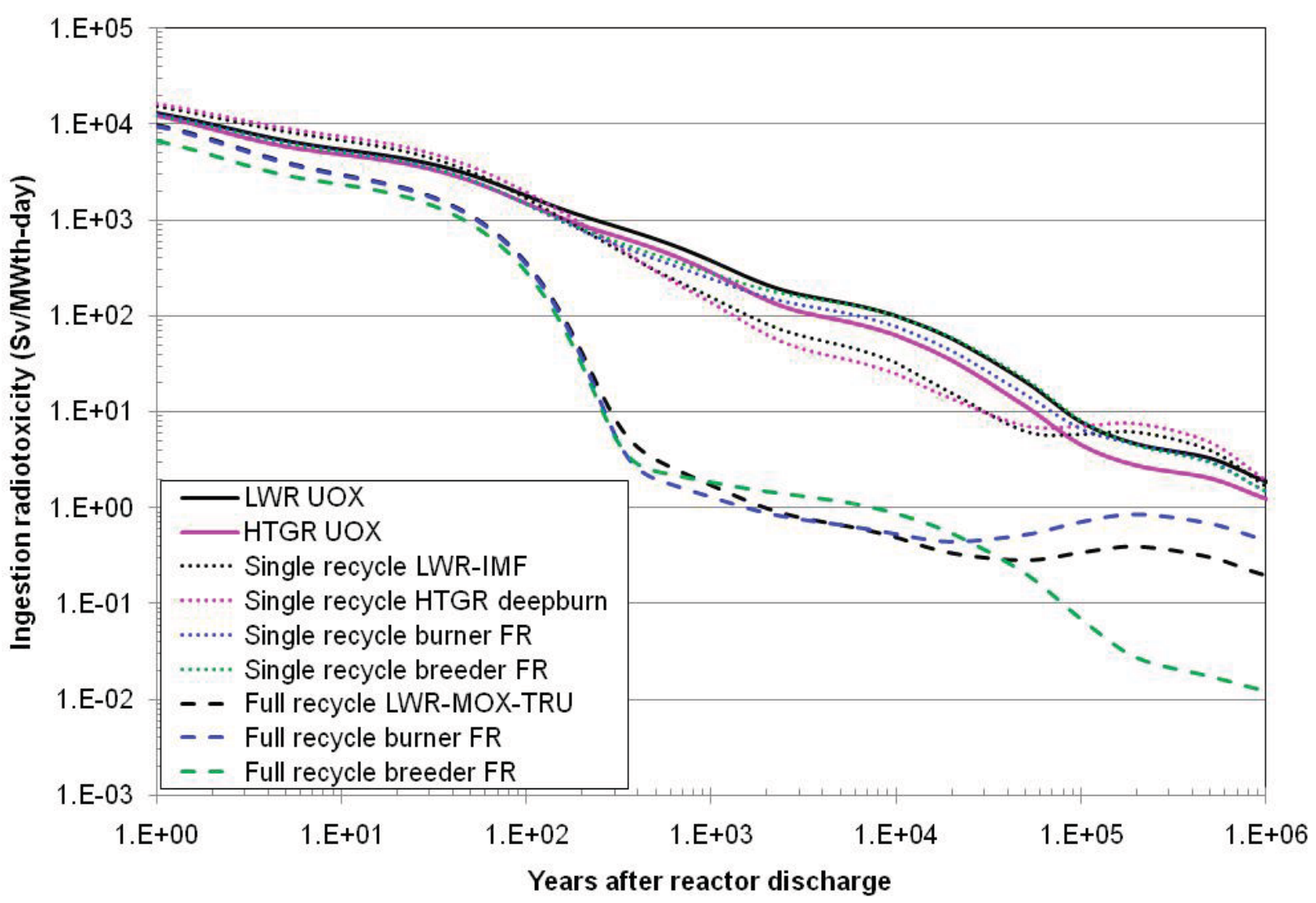

Figure 3-1. Radiotoxicity of waste as function of time after reactor discharge; processing losses are $0.1 \% /$ recycle.

Not shown in Figure 3-1 is the radiotoxicity of uranium ore that gave rise to the waste in the first case. This is not a single line because the amount of uranium ore required per unit energy varies, but basically it is several Sv/MWth-day. So, one can observe the following time periods required for waste to decrease to that of uranium ore. Although this has no regulatory meaning, it indicates the time required before waste decreases to the same inventory-based hazard as the material originally mined.

- Once through or single recycle - over 100,000 years. 
- Sustained recycle of Pu (not shown) - slightly over 10,000 years.

- Sustained recycle of TRU - approximately 1000 years

\subsection{Decay Heat of Fuel Cycle Options}

Figure 3-2 shows decay heat for the same cases as Figure 3-1. The trends are very similar. Prior to $\sim 100$ years, decay heat is dominated by fission products and roughly independent (per energy produced from fission) of the fuel cycle selected. The only options for managing heat in this time period are cooling before processing or separation of the high-heat fission products (mainly $\mathrm{Cs}$ and $\mathrm{Sr}$ isotopes) from other wastes. The "practical considerations" in 10CFR61 relate to this time period.

Once fission products decay after a few hundred years, then the choice of fuel cycle matters. Decay heat comes mainly from TRU between a few hundred years and $\sim 100,000$ years, as the fission products are mostly decayed. Beyond 100,000 years, decay products from uranium tend to dominate. However, heat at such long time periods is not known to be an issue for waste disposal. The greatest reduction of decay heat, beyond 10,000-100,000 years, is only achieved in sustained recycle cases when both TRU and uranium is consumed and not discarded.

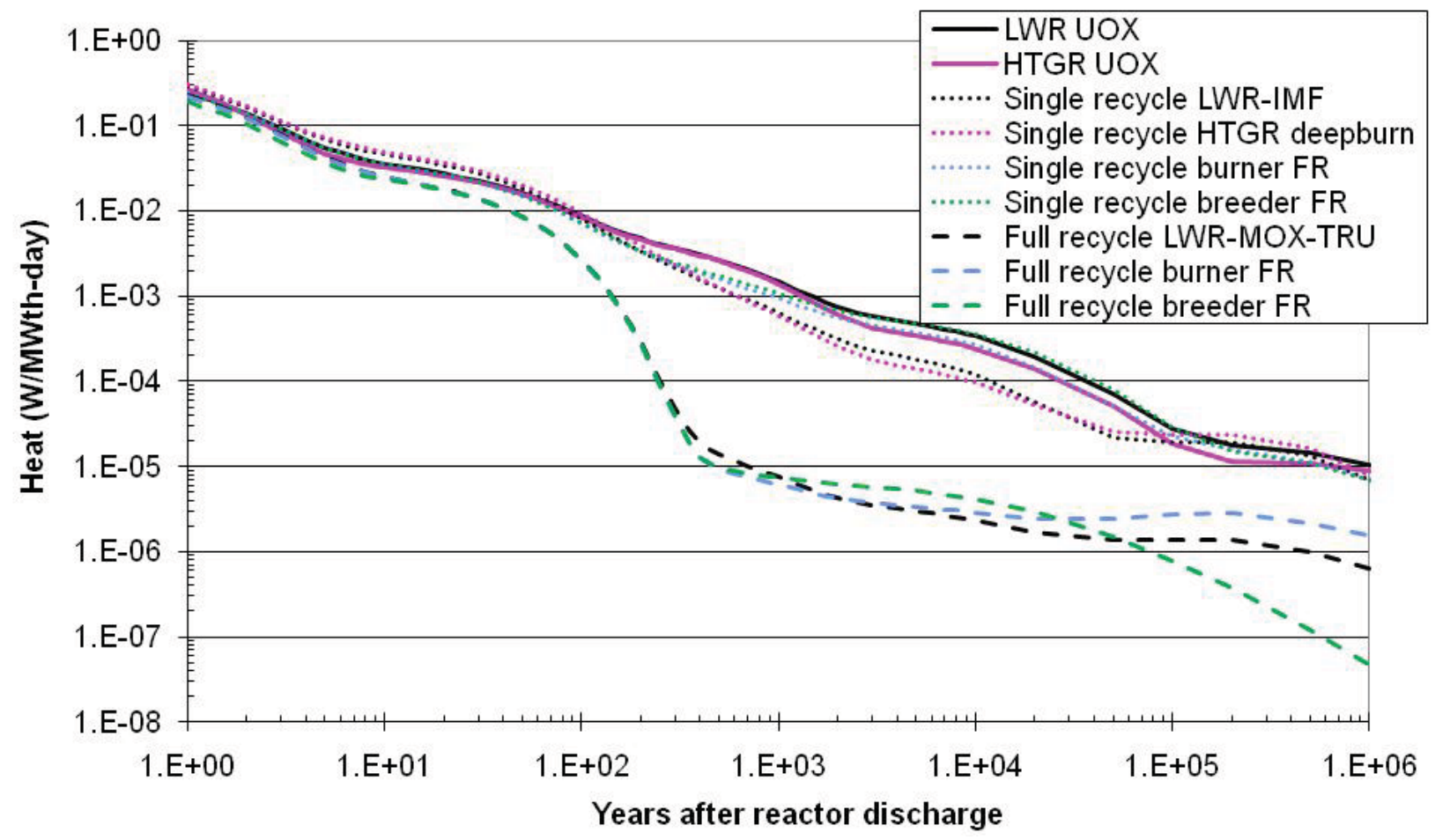

Figure 3-2. Long-term decay heat of radioactive waste from various fuel cycle options.

\subsection{Highly-Radioactive Waste Mass}

Different potential fuel cycles and reactor types use different configurations of fuel contained in fuel assemblies. The fuel material itself in different cases may be uranium, TRU, or Th-based oxides, oxycarbides, carbides, metal alloys, or in the case of molten salt reactors (MSR) fluorides. The fuel assemblies can include Zircaloy and steel cladding tubes assembled into rigid structures for LWRs and FRs; graphite and silicon carbide coatings on fuel kernels, contained inside graphite pebbles or compacts contained in larger prisms for HTGRs; or no fuel assemblies for MSRs. The fuel material (fuel meat) and the activated/contaminated cladding that contains the fuel material are the most highly radioactive 
materials in nuclear fuel cycles. These are the materials that would likely require some type of geological disposal if they are discarded and not recycled.

Figure 3-3 shows the compositions of different fuel designs in terms of mass of heavy metal and constituents that are not heavy metal. All of the oxide fuel cases have a small fraction that is oxygen, less than about 10\%. All of the PWR, BWR and FR - labeled cases have either Zircaloy or stainless steel cladding, and other stainless steel structural components, and so a significant portion of the total mass is zirconium and steel (about 20-30\% zirconium for LWRs, and 70-90\% steel for FRs). The HTGR and MSR cases have 80-97\% carbon. Carbon is included in the HTGR fuels in both the pebble and prismatic formats; the carbon in the MSR case is from reactor core structure that is in direct contact with the molten salt, and requires periodic replacement.

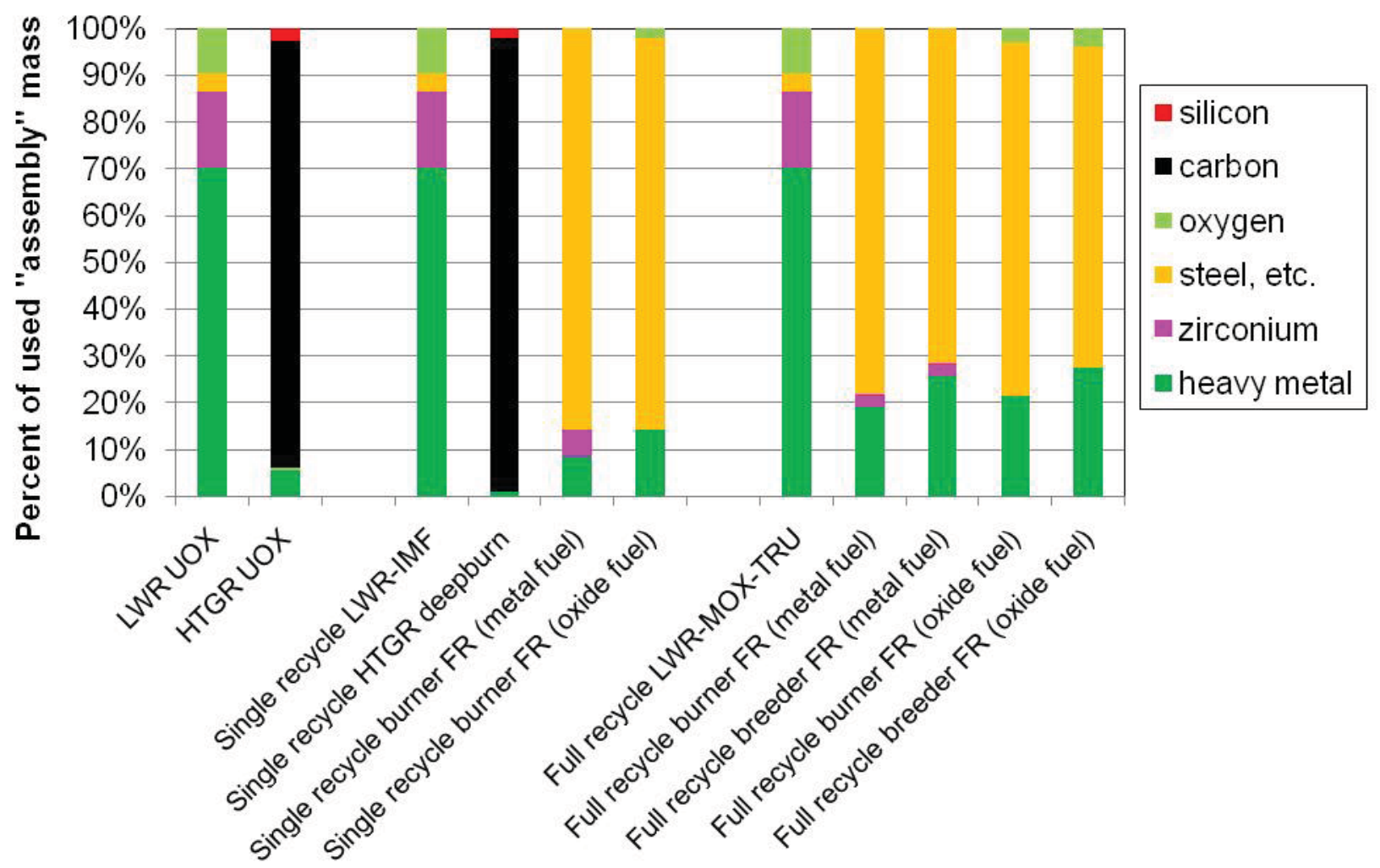

Figure 3-3. Compositions of fuel assemblies for different fuel designs.

Figure 3-4 shows the total mass of fuel assemblies per mass of initial heavy metal for the different fuel designs. The lowest-mass assemblies (for the LWR MOX and $\mathrm{PWR} \mathrm{UO}_{2}$ cases) weigh about 1.4 times more than the heavy metal they contain. The highest-mass cases (the HTGR cases) include up to 100 times more mass of mainly carbon, compared to the mass of heavy metal. Figure 3-5 shows the same mass data normalized to thermal energy production. The variation in fuel assembly mass is decreased by about a factor of ten because the cases with the higher fuel assembly mass ratio to initial heavy metal (the HTGR, FR, and MSR cases) also tend to have higher burnups. The total mass of fuel assemblies normalized to thermal energy production ranges from 0.02-0.03 kg-total/MWth-day for the BWR, LWR, PWR, and FR oxide cases, to almost $0.2 \mathrm{~kg}$-total/MWth-day for the HTGR cases. 


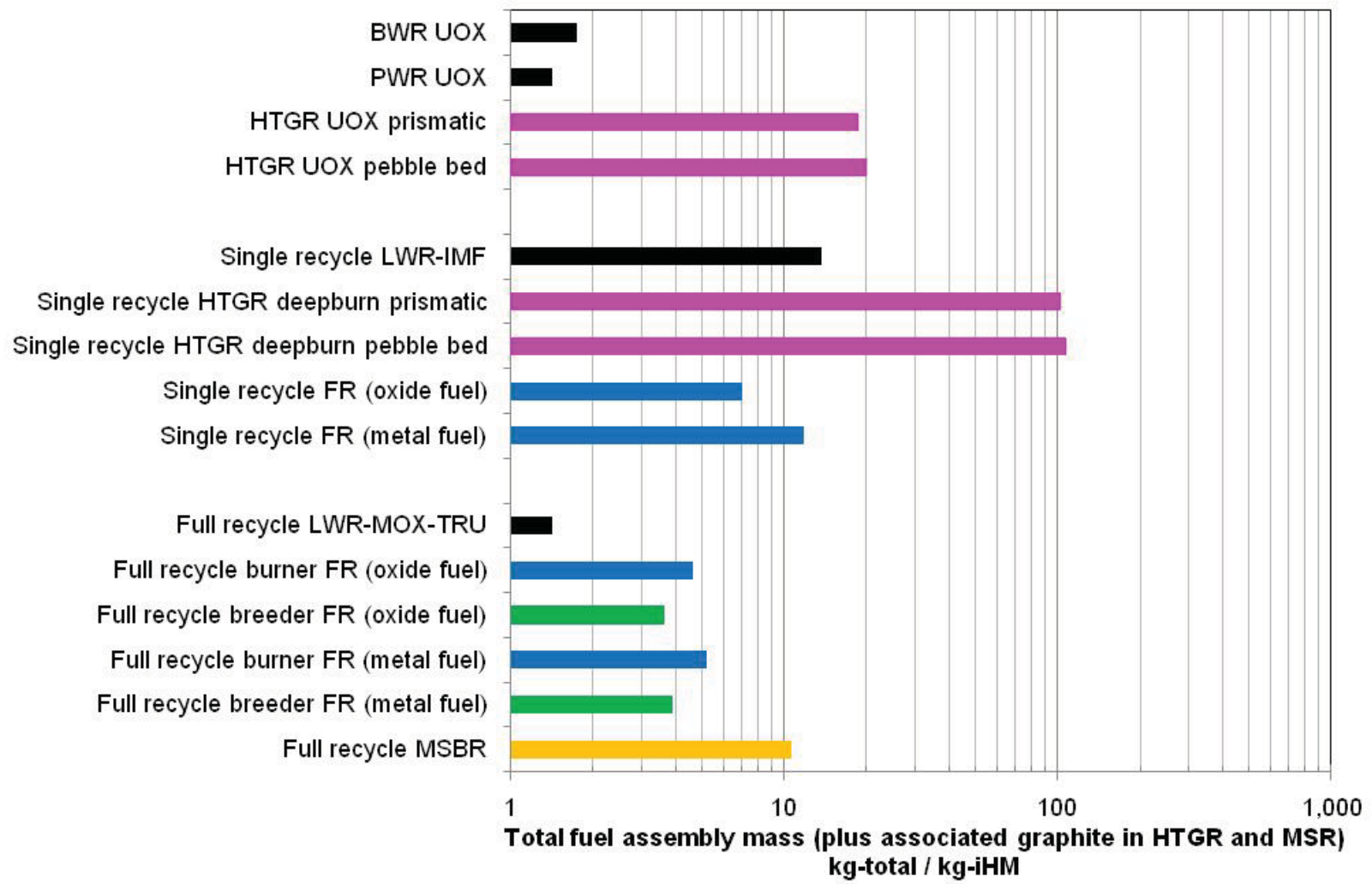

Figure 3-4. Total fuel assembly mass, normalized to mass of initial heavy metal.

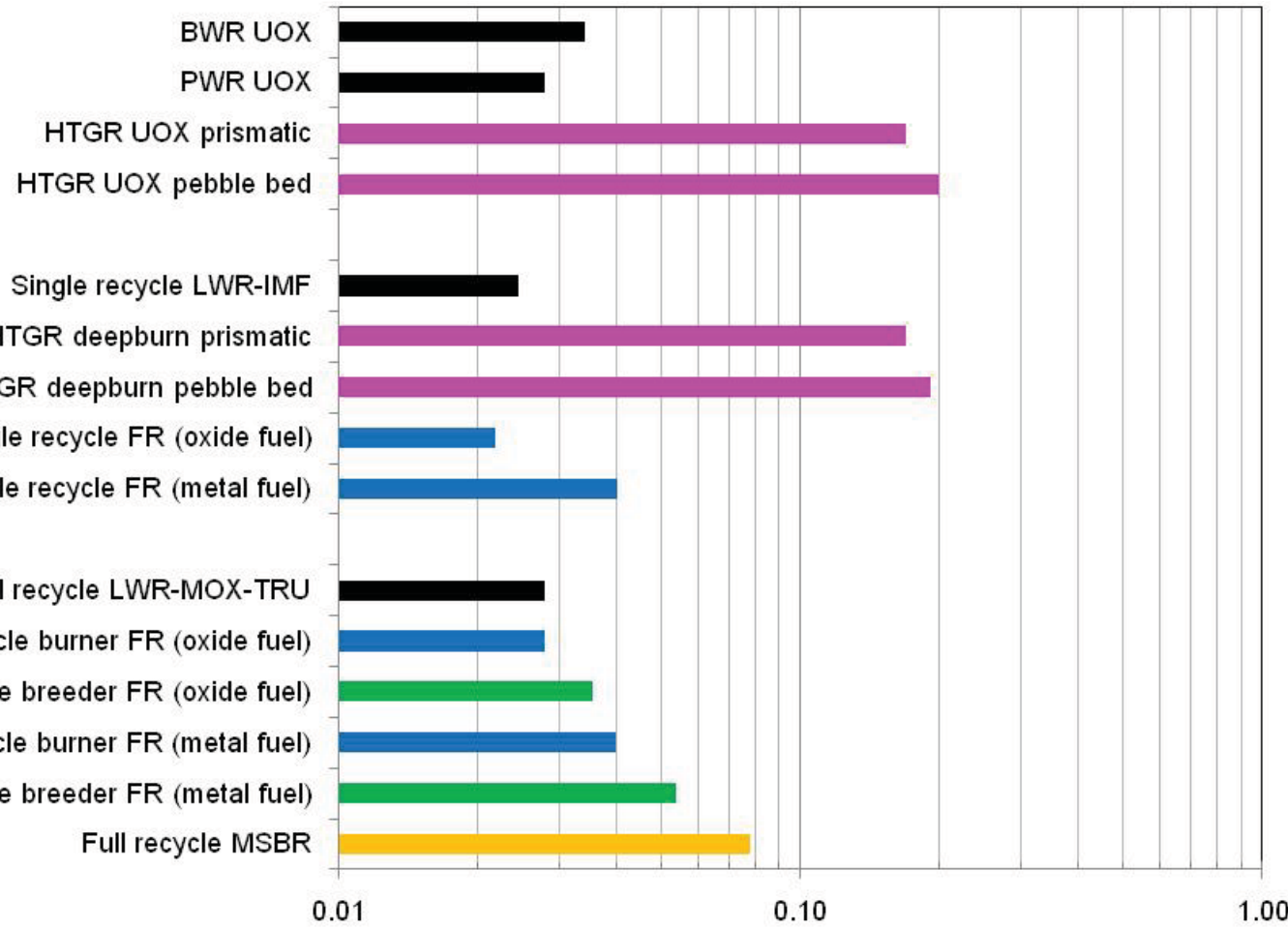

0.10

1.00

Total fuel assembly mass (plus associated graphite in HTGR and MSR) kg-total / MWth-day 
Figure 3-5. Total fuel assembly mass, normalized to thermal energy production.

\subsection{Considering Radiotoxicity and Mass Together}

Depending on handling and disposal approach, disposal of radioactive waste can be limited by three factors:

- Short and long-term decay heat, to avoid overheating the waste form, the waste package, the structures permitting retrievability in the first 50 years, or the rock to temperatures that could change the ability of the system to isolate the waste or changing the flow of water through the rock.

- Radiotoxicity, which is the source term for the dose that the repository system is designed to control.

- Waste mass and volume.

The following discussion and Figure 3-6 attempt to bring together concepts in previous subsections, focusing on (a) the radiotoxicity at 1000 years after reactor discharge and (b) the amount of mass that is both high long-term radiotoxicity and high heat, i.e., lacking disposal precedents. Both the mass and the radiotoxicity of the disposed material are normalized on a thermal power generation basis. (The trends are very similar if instead one graphs at 10,000 years. Analogous graphs at 100,000 or 1,000,000 years would show increasing impact of whether uranium is consumed or not.)

The mass of the disposed material only includes the used fuel meat or waste streams separated from the fuel meat during recycling. The mass of cladding, fuel assembly structural materials, and the waste forms and packaging that would contain the waste, are not included in this first-order analysis, although those masses are important in more detailed analyses that include consideration of disposed waste volume (See Section 3.4).

Several trends and bounding conditions are illustrated in Figure 3-4.

- As burnup (BU) increases, the amount and the radiotoxicity at 1,000 years of disposed waste decreases. For example, the green oval contains all the once through options. As burnup increases from 7.5 to $150 \mathrm{MWth}$-day/kg-iHM across a range of reactor types (CANDU, LWR, HTGR, FR), the disposed waste mass (which, normalized to thermal energy production, is proportional to 1 /burnup) decreases, and radiotoxicity decreases slightly.

- The mass of disposed waste further decreases when used fuel is recycled at least once. The upper blue oval contains all the single recycle options, when all fission products separated from reprocessed fuel are disposed. The reduction of disposed mass is minimal for cases with high transuranic conversion ratio (i.e., high uranium content fuel, thus high uranium content disposed fuel). The reduction of disposed mass is an order of magnitude lower for low transuranic conversion ratios such as for IMF-type fuels (i.e., HTGR deep burn or LWR-IMF concepts).

- Full recycle cases can lower the radiotoxicity of the disposed waste by about two orders of magnitude when the TRU isotopes are recycled. The full extent of the decrease in radiotoxicity is achieved only when all TRU isotopes are recycled, rather than only $\mathrm{Pu}$. The lower purple oval contains all the full recycle options in which all the TRU are recycled, and only the FPs separated during used fuel reprocessing are disposed.

At this point further decreases in the "mass" dimension would require isolating low-heat with high longlived radiotoxicity isotopes from low-heat with low long-lived radiotoxicity isotopes. Such hybrid scenarios would require matching waste characteristics with the repository characteristics. Another consideration is that some low-heat, low-radiotoxicity elements could have economic value in future metal's markets; and some other isotopes may have economic value in other markets; thus not requiring disposal. Still other options include isotopic dilution of long-lived radiotoxic fission products with stable isotopes of the same element prior to disposal. These options are considered transformational disposal 
options but their consideration would greatly expand the fuel cycle option space beyond the scope of this report.

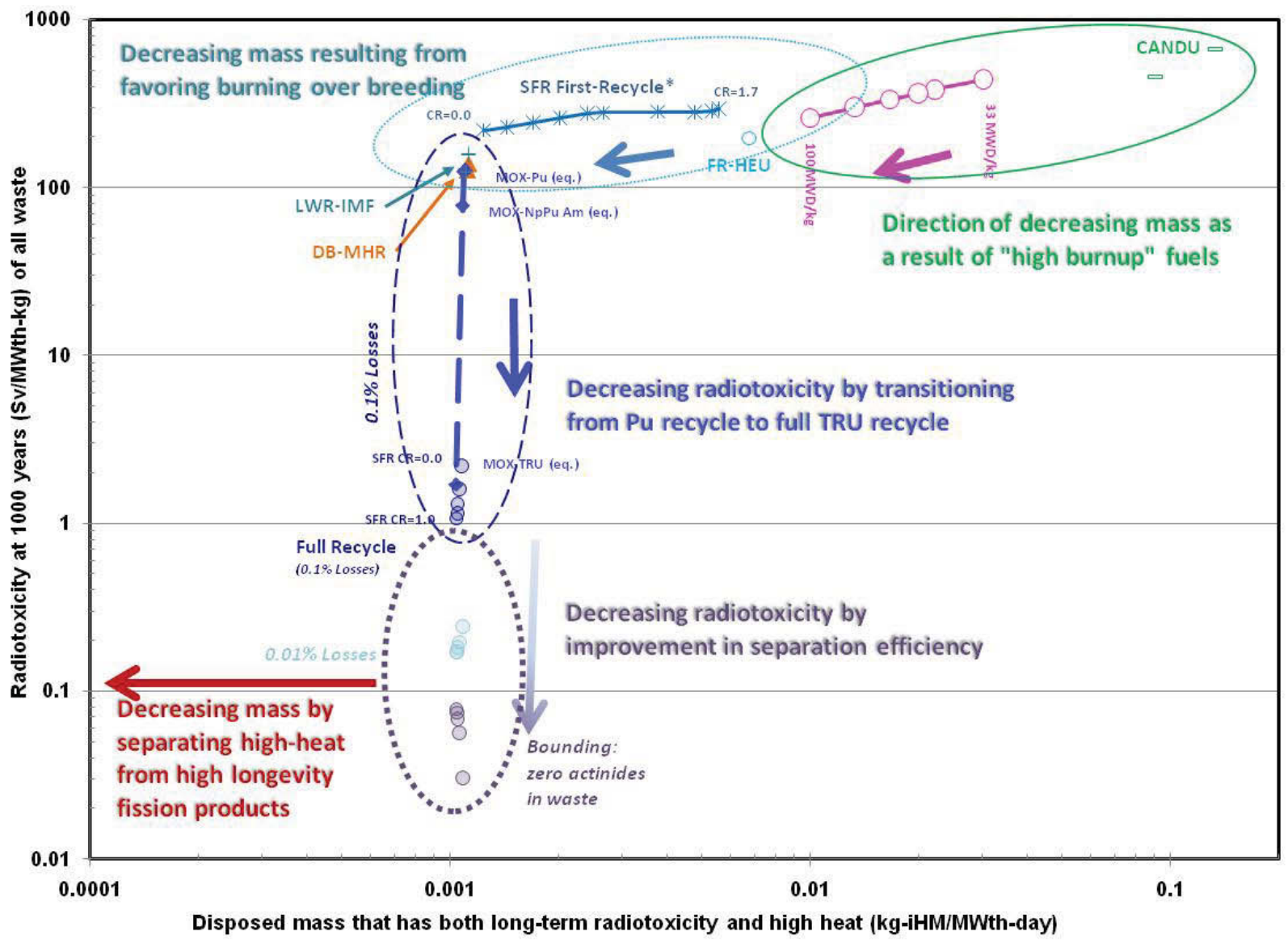

Figure 3-6. Long-term radiotoxicity (taken at 1,000 years) per mass of disposed actinide and fission product constituents of used nuclear fuel. ${ }^{\mathrm{a}, \mathrm{b}, \mathrm{k}}$

\subsection{R\&D Needs}

Uncertainty that exists in several areas of radioactive waste management can be reduced with additional research and development. Research, development, and systems analyses are needed to obtain more complete and quantitative data for essentially all potential fuel cycles, in all areas (from front-end mining to final waste disposition) to enable more-informed technology selection and to provide bases for possible new policies and regulations while ensuring and increasing public safety. This research, development, and systems analysis effort should focus on these areas:

- Fuel cycles that separate and re-use valuable components of used fuel, and treat and dispose waste components of used fuel; separation technologies and efficiencies; requirements of recycle fuel fabrication for recycle reactors; and waste forms designed to tolerate waste heat and radiation and function in a disposal system to isolate the waste from the environment.

$\mathrm{k} \quad$ The SFR cases in this figure represent the first recycle of LWR used nuclear fuel in scenario studies representing eventual full recycle. Thus, for this figure, we assumed that this first recycle SFR used fuel was disposed instead of being recycled for subsequent reactor irradiations. 
- Fuel cycle economic analyses that include all portions of the fuel cycle, addressing the varying impacts of different fuel cycle options on difficult-to-quantify costs and benefits such as the energy and environmental impacts of front end activities (mining, milling, and enrichment), fuel fabrication, reactor operations, separations, waste treatment, and waste disposal, including a quantification of the costs of natural resource consumption and waste disposal.

- Storage of used fuel in existing or new storage sites for longer durations, up to 100 years or longer; impacts of heat, radiation, and time on the forms of the used fuels and how they are packaged; and how to mitigate those impacts to ensure the safety of longer-term storage, and subsequent handling after the storage period.

- Waste management, handling, and repository design and performance for disposing the highhazard, high-decay-heat and high-long-term-radiotoxicity wastes from nuclear fuel cycles, focusing on entire system performance and public safety. 


\section{FUEL CYCLE SAFETY}

Safety and its cousin, reliability, are critical to all nuclear facilities. The Nuclear Regulatory Commission licenses all commercial nuclear facilities deployed in the United States and requires such facilities to meet rigorous safety requirements. Based on the experience of foreign facilities, improvements in maintenance and operation of current U.S. facilities, and improvements from advanced fuel cycle R\&D programs, any future U.S. fuel cycle facilities resulting from FCR\&D research will be at least as safe as current technology.

Per Chapter 1, safety performance is particularly dependent on design details; it is also dependent on maintenance and operation. Indeed, the availability factors for the U.S. reactor fleet have climbed from below $50 \%$ to over $90 \%$ in the past 40 years as maintenance and operation have improved. Off-normal events have correspondingly declined as availability and reliability of systems have increased. Nonreactor fuel cycle facility safety has also improved as evidenced by the fact that most incidents are many years in the past, see examples in (Cadwallader 2005).

Thus, in the safety area, neither design information (even when it is available) nor decades-old experience are necessarily adequate to predict future performance. When there are neither design details nor operational experience, it is difficult or impossible to quantitatively predict the performance of a future system.

On the other hand, safety is too important to ignore during concept selection and development. Historical experience suggests that some types of safety issues are easier to resolve in concept development, detailed design, and/or operation than others. "Easier" can mean lower design cost to add safety systems as a design goes from concept to details, fewer iterations and delays with regulators, easier operation, a more transparent safety case engendering higher trust, less chance for expensive changing during design and construction, less chance of expensive retrofitting during operation, etc.

Regulations are not constant. There is always some chance of a change in regulations during design, construction, or operation. The Nuclear Regulatory Commission has even defined a "backfit" rule for domestic licensing of production and utilization facilities. The Backfit Rule (10CFR50.109): A backfit is a compulsory modification or addition to an existing facility, design and/or procedure as a result of new or changed regulatory policy. The Backfit Rule defines when backfits are justified with provisions to protect commercial licensees from excessive costs that may be caused by gratuitously arising safety expectations (SECY-98-253, Backfit). The stronger the safety case as new technologies evolve, the less chance for backfits later.

\subsection{Hazard Identification and Safety Functions}

Safety assessment and management starts with identifying hazards, safety functions to manage hazards, and approaches to providing those safety functions. In general, one must protect against inventories of hazardous materials and hazardous energy sources. Table 4-1 lists fuel cycle hazards and safety functions. There are three fundamental categories - reduce inventories as much as possible, control or mitigate energy sources, and contain radioactivity at all times. 
Table 4-1. Fuel cycle hazards and protective safety functions.

\begin{tabular}{|c|c|}
\hline Hazardous inventories & Protective safety functions and approaches \\
\hline External radiation & $\begin{array}{l}\text { Minimizing gamma and neutron emitting inventory } \\
\text { Shielding }\end{array}$ \\
\hline Radioactivity that can be ingested & $\begin{array}{l}\text { Minimizing inventory (ingestion radiotoxicity) } \\
\text { Keeping material non-soluble } \\
\text { Out of core - containment barriers } \\
\text { In core - containment barriers of protection } \\
\text { Cladding/coating } \\
\text { Reactor vessel } \\
\text { Reactor containment building }\end{array}$ \\
\hline Radioactivity that can be in inhaled & $\begin{array}{l}\text { Minimizing inventory (inhalation radiotoxicity) } \\
\text { Keeping material in bulk solid form (not gaseous, aerosols, or } \\
\text { particulates, or volatiles) } \\
\text { Containment barriers of protection (see above) }\end{array}$ \\
\hline Chemical toxins & Outside the scope of this report \\
\hline Hazardous energy sources & Protective safety functions and approaches \\
\hline Fission from critical masses & $\begin{array}{l}\text { Out of core - avoidance of critical mass and geometry } \\
\text { In core - proper neutronic feedback } \\
\text { Low excess reactivity } \\
\text { Net negative temperature coefficients } \\
\text { Net negative void coefficients } \\
\text { Etc. }\end{array}$ \\
\hline Decay heat & $\begin{array}{l}\text { Minimize heat-producing inventory } \\
\text { Thermal properties } \\
\text { Out of core - engineered countermeasures } \\
\text { Heat conduction, convection, radiation } \\
\text { In core - engineered countermeasures } \\
\text { Reactor vessel auxiliary cooling system } \\
\text { Direct auxiliary cooling system } \\
\text { Emergency core cooling system } \\
\end{array}$ \\
\hline $\begin{array}{l}\text { High temperatures during } \\
\text { operations }\end{array}$ & $\begin{array}{l}\text { Minimize operating temperatures } \\
\text { Materials that tolerate high temperatures } \\
\text { Normal and off-normal cooling systems }\end{array}$ \\
\hline High pressures during operations & $\begin{array}{l}\text { Minimize operating pressures } \\
\text { Vent pressures when desired } \\
\text { Contain pressures }\end{array}$ \\
\hline Combustion during operations & $\begin{array}{l}\text { Minimize use of combustible materials } \\
\text { Prevent source of oxidizers } \\
\text { Fire prevention and mitigation systems } \\
\text { Cooling systems }\end{array}$ \\
\hline $\begin{array}{l}\text { Fires and mechanical impacts } \\
\text { during transport }\end{array}$ & $\begin{array}{l}\text { Minimize transport } \\
\text { Containment protecting against fire and mechanical impacts }\end{array}$ \\
\hline
\end{tabular}

Several inventories are not reducible. Per energy released from fission, there must be fissionable material and there must be fission products. To first order, the radiotoxicity and decay heat of fission products are the same regardless of which actinide is being fissioned. 


\subsection{Fuel Cycle as a Whole}

Ultimately, the fuel cycle must work as an integrated system, both in theoretical equilibrium conditions and as each part of the system grows, evolves, or shuts down. Although each part of the system must meet regulatory requirements at all times, it is also possible for advantageous changes in one part of the system to create disadvantageous changes in another.

For example, consider the option of venting fuel during reactor operation as embodied in the $\mathrm{EM}^{2}$ concept. This would have several effects, as follows:

1. Decrease in-core inventory of volatile fission products, precisely the ones most likely to be released during accidents.

2. Provide another path for accidental escape of material from the core.

3. Reduce or eliminate the need for subsequent high temperature processing of used fuel.

4. Reduce the inventory of volatile fission products if the used fuel must be transported elsewhere before disposal or separation.

Effect 2 is disadvantageous and would have to be factored into the entire reactor safety case, possibly causes increased costs for containment barriers. Effects 1, 3, and 4 appear advantageous; two of these are away from the reactor, possibly reducing costs at the reactor and other facilities. The point is not whether fuel venting is a good idea, but rather ultimately such decisions are ideally made from the perspective of the fuel cycle as a whole while still ensuring each facility meets regulations.

Another example is potential co-location of facilities. Co-location of separation, fabrication, waste treatment, and/or reactors reduces transportation of radioactive materials but also creates the possibilities of common cause initiators, e.g., earthquakes or loss of external electrical power, or off-normal events cascading from one facility to another. This can only be analyzed from the perspective of the fuel cycle system as a whole.

Nonetheless, the safety of the entire system is likely dominated by the safety of the reactors, because they are more numerous than geologic repositories or recycling plants and because their fuel has a power density several factors of 10 higher than during other parts of the fuel cycle.

- With the once-through strategy, there will be at least one repository per 100 nuclear energy plants. (Each plant is assumed to be $\sim 1$ GWe capacity in this illustration.)

- With a single recycle, there may be slightly fewer repositories than once-through and perhaps one or more recycle plant per 100 nuclear power plants. (Each recycle plant is assumed to be $\sim 2000$ tonnes-fuel/year in this illustration.)

- With sustained recycle, there could be one repository independent of the number of nuclear energy plants. There will be either about one large centralized recycle plant per 100 nuclear energy plants or decentralized recycling at each nuclear energy plant site.

This means that a complete assessment of fuel cycle safety must include the impact of new recycle fuel types on reactor operation.

\subsubsection{Probabilistic risk assessment (PRA)}

Risk incorporates the concepts of the frequency and consequence of events, typically written as

$$
\text { Risk }=\sum_{\text {events }}(\text { frequency of event }) x(\text { consequence of event })
$$


The energy sources potentially available to drive an off-normal event can be relevant to both frequency and consequence. The radioactive inventories tend to primarily manifest impacts on the consequence dimension, except when they are themselves the energy source as in decay heat and criticality events.

For any facility in any industry, PRA is a quantitative, systematic approach for answering the following three fundamental questions:

1. What could go wrong?

2. How likely is each undesired event to happen?

3. What are the consequences if an undesired event happens?

PRA is not in competition with deterministic methods; it incorporates deterministic methods because they are part of answering all three questions.

Once all known failure paths are identified, hierarchical relationships (or trees) describing events and faults can be constructed. Performance reliability data for equipment, systems, human response, internal and external events can then be applied to these trees. In aggregate, these provide the answers to question 2. If all the protective barriers between the nuclear fuel and the environment are breached, information regarding evacuation, weather and aerial dispersion models are used to answer question 3 . Public health consequences are not addressed in this chapter as these indicators goes beyond design-specific detail; requiring reactor site-specific and local-population information. Such detail is useful for assuring public health and safety but not required for the following discussion of reactor fleets in the context of the fuel cycle.

The NRC increasingly tends to require PRAs for nuclear facilities. Indeed, its Regulatory Guide 1.174 is part of 10CFR50, which applies "domestic licensing of production and utilization facilities."

- Regulatory Guide 1.174: Provide guidance for using PRA to request changes in a facility's licensing basis while still meeting the minimum requirements of risk-informed regulations. Specifically, the guidance prescribes acceptability ranges that bound the permitted relative change in risk (e.g., CDF) per proposed change in the licensing basis. The guidance does not propose hard safety limits but suggests using relative improvement (or degradation) of risk for supporting decision making (RegGuide1.174).

The emphasis on PRA means that the R\&D program for any new nuclear technology must eventually address both the frequency and consequence dimensions. The regulator will tend to use precedents, conservative estimates of consequence, and conservative interpretation of failure frequencies of the most analogous components to those in a proposed new facility. It is the responsibility of those proposing a new technology to provide the safety case, evidence for off-normal behavior of radioactive inventories, and arguments for reasonable estimates of failure frequencies.

Table 4-2 characterizes the types of public health and safety impacts as a grouping of consequences and relevant probabilities. Here we emphasize that in non-reactor facilities, some of the chemicals handled could pose a higher hazard than nuclear materials. For example, ammonia and hydrogen fluoride are required in large quantities in the conversion process for decomposition into hydrogen and fluorine feed materials. From examining the historical trend in facility safety events, the highest consequence events occurred in the 1950's and 1960's. It should also be stressed that as operational experience is gained, general safety performance (or instances of off-normal reportable events) gradually improves (Cadwallader 2005). 
Table 4-2. Frequency-consequence matrix contrasting the radioactive source term intensity with probability that a member of the public will be exposed.

\begin{tabular}{|c|c|c|}
\hline High Consequence & $\begin{array}{c}\text { Low Frequency } \\
\text { Large radioactive release } \\
\text { Large inhalation radiotoxicity } \\
\text { Large core inventory }\end{array}$ & High Frequency \\
\hline Low Consequence & $\begin{array}{c}\text { Inconsequential to total risk, } \\
\text { but can still generate headlines }\end{array}$ & $\begin{array}{c}\text { Small, slow pipe leaks - effluent release } \\
\text { Pressurized pipe breaks - containment } \\
\text { pressurization and radioactivity mobilization } \\
\text { Minimum health consequence }\end{array}$ \\
\hline
\end{tabular}

Fundamentally different facility designs can have different hazards and thus will have widely varying defense-in-depth approaches for ensuring public safety. The variance in possible accident initiators, protective measures and outcomes suggests that new licensing methodologies will require two approaches:

- A technology specific evaluation of the concept's key safety characteristics and their suitability to protect against accident types unique to that particular reactor family. Ultimately, a design-level defense-in-depth analysis is necessary to fully develop a preliminary licensing basis. This approach can guide both deterministic safety evaluations and PRAs for a specific design.

- A technology neutral consideration of the fundamental public safety concerns and assess the concept's ability to meet a pre-defined "Acceptable Risk" per "Event Probability" curve. This approach allows for equitable comparisons of accident frequency contrasted with accident severity over a wide range of advanced designs (NUREG-1860).

\subsubsection{Transportation}

Transportation of radioactive materials has been extraordinarily safe, but nonetheless transportation attracts considerable public concern. Conceptualization of new fuel cycles should include consideration of how much transportation will be required and ways for transportation risk to be minimized.

The frequency dimension of transportation pertains to the number of transportation shipments, the length of transport between sites, and the amount of material per shipment. This can be reduced in three ways:

- Increase fuel burnup (MWth-day/kg) so that less mass has to be transported per unit energy produced.

- Co-locate facilities

- Mitigative features of transport casks and shipping arrangements

The consequence dimension of transportation pertains to the hazard per mass (gamma and neutron field, inhalation radioactivity, decay heat, etc.) and mitigating features of transport casks.

Consider for example the characteristic of gamma and neutron energy $(\mathrm{W} / \mathrm{kg})$, a consequence indicator. When this is multiplied by the frequency indicator of $1 /$ burnup ( $\mathrm{kg} / \mathrm{MW}$ th-day), the result is gamma and neutron energy per energy released in fission (W/MWth-day). Thus, the proper indicator is not burnup by itself, but rather the hazard level of material (W of gamma and neutron emission in this example) per fission produced. Although the energy of neutron emission is lower than that of gamma emission, neutrons are more difficult to shield and therefore the two external radiation sources should be considered separately. 
For example, Figures 4-1 and 4-2 show the gamma and neutron emission as a function of conversion ratio for fast reactors starting with used UOX fuel. The green lines are the first recycle in metal or oxide fueled fast reactors; the black lines are the equilibrium recycle. In the first recycle pass, there is little impact from conversion ratio as TRU content in fuel and burnup generally compensate. That is, as TRU content increase, burnup increases, so that $\mathrm{W}$ of gamma or neutrons per burnup are roughly constant as all the feed material (from UOX separation) is the same.

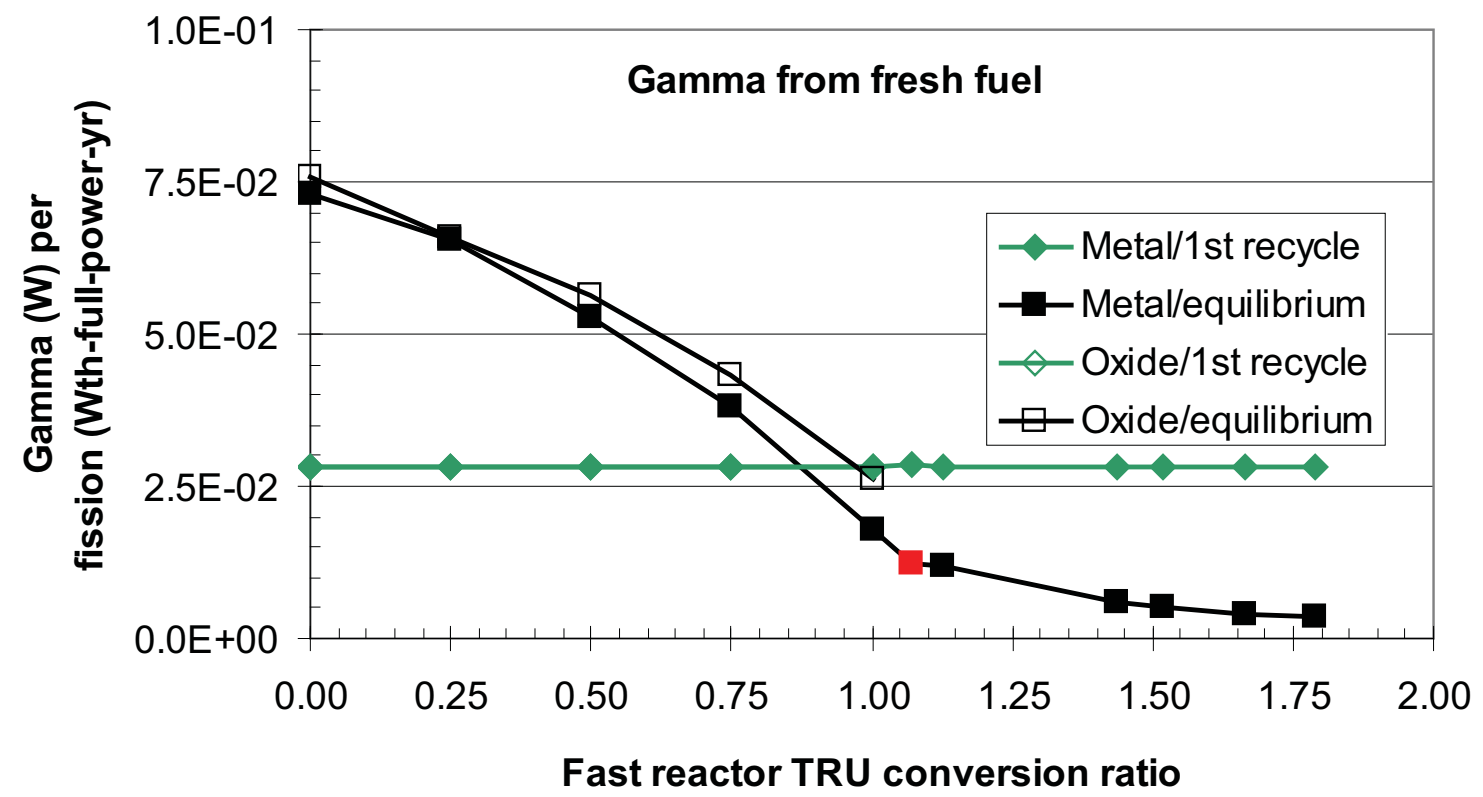

Figure 4-1. Gamma emission from fresh fast reactor metal fuel as function of fast reactor TRU conversion ratio (Bays2009).

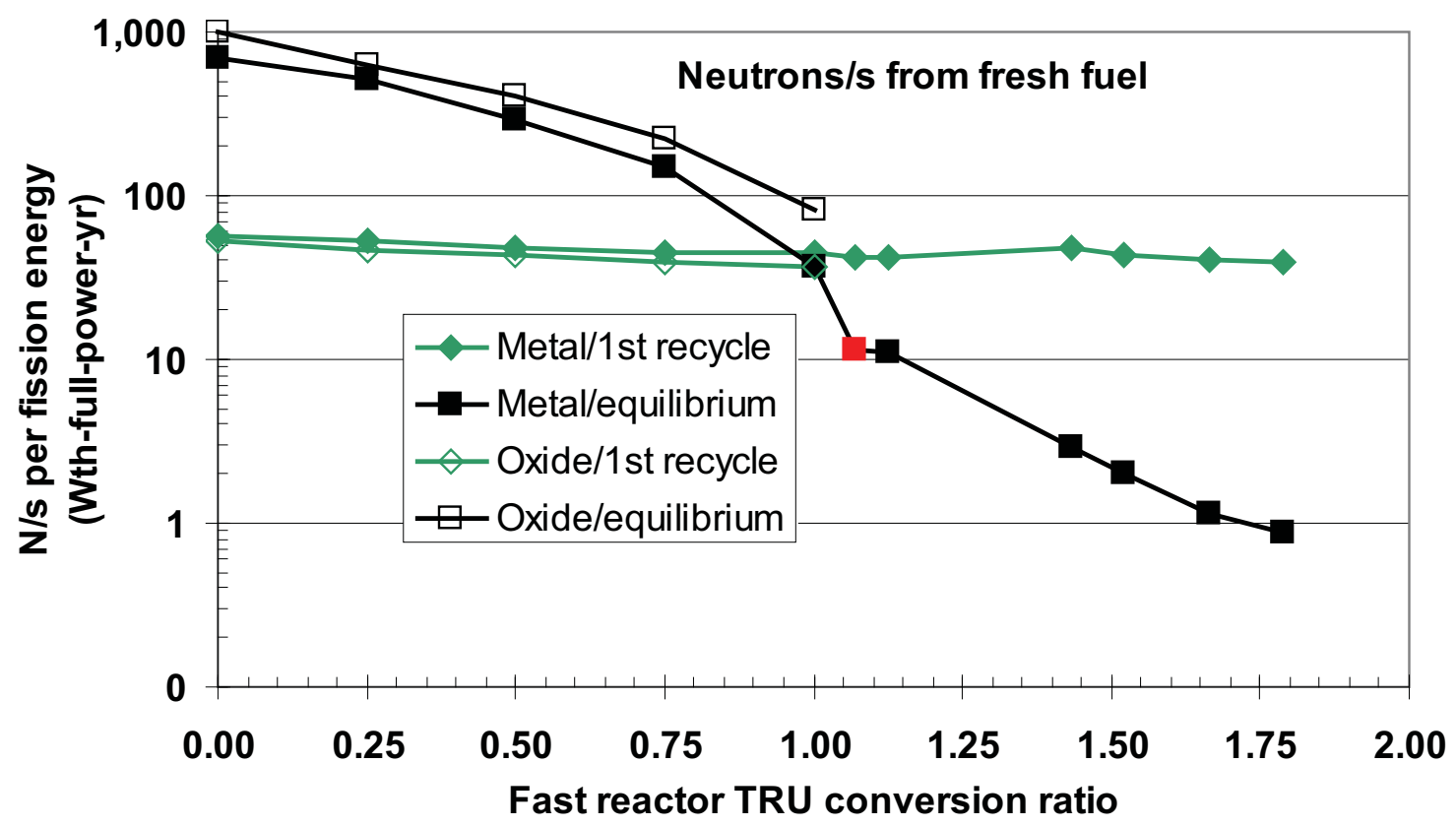

Figure 4-2. Neutron emission from fresh fast reactor metal fuel as function of fast reactor TRU conversion ratio (Bays2009). 
As the systems evolve toward equilibrium, the heat, gamma, and neutron emission increases relative to first recycle for decreasing conversion ratio. In multi-recycle schemes, it is not adequate to consider the hazards from the first recycle only; they may subsequently increase (burner reactors) or decrease (breeder reactors).

The bright red data point in the three Figures at $\mathrm{CR}=1.07$ denotes the case for which recycling of isotopes stopped at Cm-246. The impact on neutron emission is unsurprisingly the largest, about a factor of two away from the pattern, whereas heat and gamma are a factor of 1.2-1.3 away from the line connecting $\mathrm{CR}=0.00$ and $\mathrm{CR}=1.13$. This example shows the importance of performing calculations to the top of the actinide chain, Cf252.

\subsection{Fuel Cycle Facilities Other than Reactor}

Off-normal events at U.S. fuel cycle facilities (other than reactors) have been surveyed and summarized (Cadwallader2005). The report covers both commercial and noncommercial facilities. There have been a very wide range of technologies with many types of off-normal incidents but no major accidents impacting the public.

The report does not derive any generic trends but one can see in what technologies incidents have or have not occurred. For example, "There has never been a criticality incident during the fabrication of LEU power reactor fuels in the U.S. Most fuel fabrication activities utilize $\mathrm{UO}_{2}$ powder so criticality is controlled by maintaining sub-critical quantities of uranium dioxide in favorable geometry containers while excluding moderator. This double contingency of geometry/volume control and moderator control maintains safety in the facilities. " On the other hand, there have been three criticality events involving aqueous separation of used fuel: inadvertent transfer of uranyl nitrate solution from a geometrically safe storage tank to a waste collection tank, inadvertent lifting of uranyl nitrate solution "from a geometrically safe section of an evaporator from a geometrically safe section of an evaporator to the upper, vapordisengager section that was not geometrically safe," and incorrect chemistry control leading to unplanned concentration of uranium solution.

Table 4-3 lists some of the hazards in candidate separation technologies. Most, if not all, candidate separation technologies involve mobilization of are gaseous and volatile fission products and the presence of high temperatures during at least one part of the process. This is not a discriminator but is a common $\mathrm{R} \& \mathrm{D}$ need to continue to search for techniques that maximize recovery and minimize cost.

Table 4-3. Illustrative hazard identification of candidate separation technologies.

\begin{tabular}{|c|c|c|c|c|}
\hline $\begin{array}{l}\text { Separation } \\
\text { technology }\end{array}$ & $\begin{array}{l}\text { Radioactive } \\
\text { inventory }\end{array}$ & \multicolumn{2}{|c|}{$\begin{array}{l}\text { Hazards before separation, as fuel is } \\
\text { being disassembled }\end{array}$} & $\begin{array}{c}\text { Hazards during } \\
\text { separation options }\end{array}$ \\
\hline Aqueous & \multirow[t]{4}{*}{$\begin{array}{c}\text { Nil } \\
\text { difference, } \\
\text { normalized } \\
\text { per fission } \\
\text { energy } \\
\text { produced }\end{array}$} & \multirow[t]{4}{*}{$\begin{array}{l}\text { Gaseous } \\
\text { fission } \\
\text { products }\end{array}$} & $\begin{array}{l}\text { If voloxidation, high } \\
\text { temperatures and volatile } \\
\text { fission products }\end{array}$ & $\begin{array}{l}\text { Soluble, possible to leak } \\
\text { to environment, leaks } \\
\text { stay liquid in } \\
\text { environment (rather than } \\
\text { freezing). }\end{array}$ \\
\hline AIROX & & & \multicolumn{2}{|c|}{ High temperatures and volatile fission products } \\
\hline Electrochemical & & & \multirow[t]{2}{*}{ Mechanical cutting } & High temperatures \\
\hline Melt refining & & & & $\begin{array}{l}\text { during separation, } \\
\text { volatile fission products. }\end{array}$ \\
\hline
\end{tabular}

\subsection{Reactor Safety as Part of the System}

Given that the highest stored-energy component within the fuel cycle is the reactor, the attention to reactor safety in this report is justifiable. The reactor core tends to have the highest overall combination of temperature, pressure and radiation intensity than any other component in the fuel cycle. 
Unfortunately, most discussion of reactor safety narrowly addresses what are considered severe accidents. However, given the variability in initiating events and mitigating safety characteristics for the full gamut of advanced concepts, the dominating risk may not be in the high-consequence/low probability area. Furthermore, the non-reactor fuel cycle technologies (mines, mills, enrichment, fuel fabrication, transportation) have their own specific safety issues.

\subsubsection{Hazard reduction}

To first order, the inventory of fission products per unit fission energy is the same among options. The exception regarding in-core inventories is the concept of fuel venting, noted above.

The mass of transuranic elements is a different situation. As explained in more detail in Chapter 5, the amount of transuranic elements varies from $\sim 1 \%$, e.g., LWR UOX fuel, to $\sim 100 \%$ in low conversion ratio concepts such as HTGR-deep burn or LWR-IMF.

For example, LWR MOX at $\sim 10 \%$ transuranics has been criticized as having a higher accident source term than LWR UOX because of the buildup of TRU isotopes (Lyman2000). Fortunately, in this case, there are data and even a regulatory position to indicate that this is not a problem. Figure 4-3 graphs the release fractions as a function of elemental atomic number (NRC1995) as graphed in (Piet2006). The TRU all have low release fraction, 0.005 and 0.006 . In contrast, the volatile fission products, Xe, I, Cs have maximum release fractions well over 0.1 . These, of course, dominate reactor accident consequences, not the TRU.

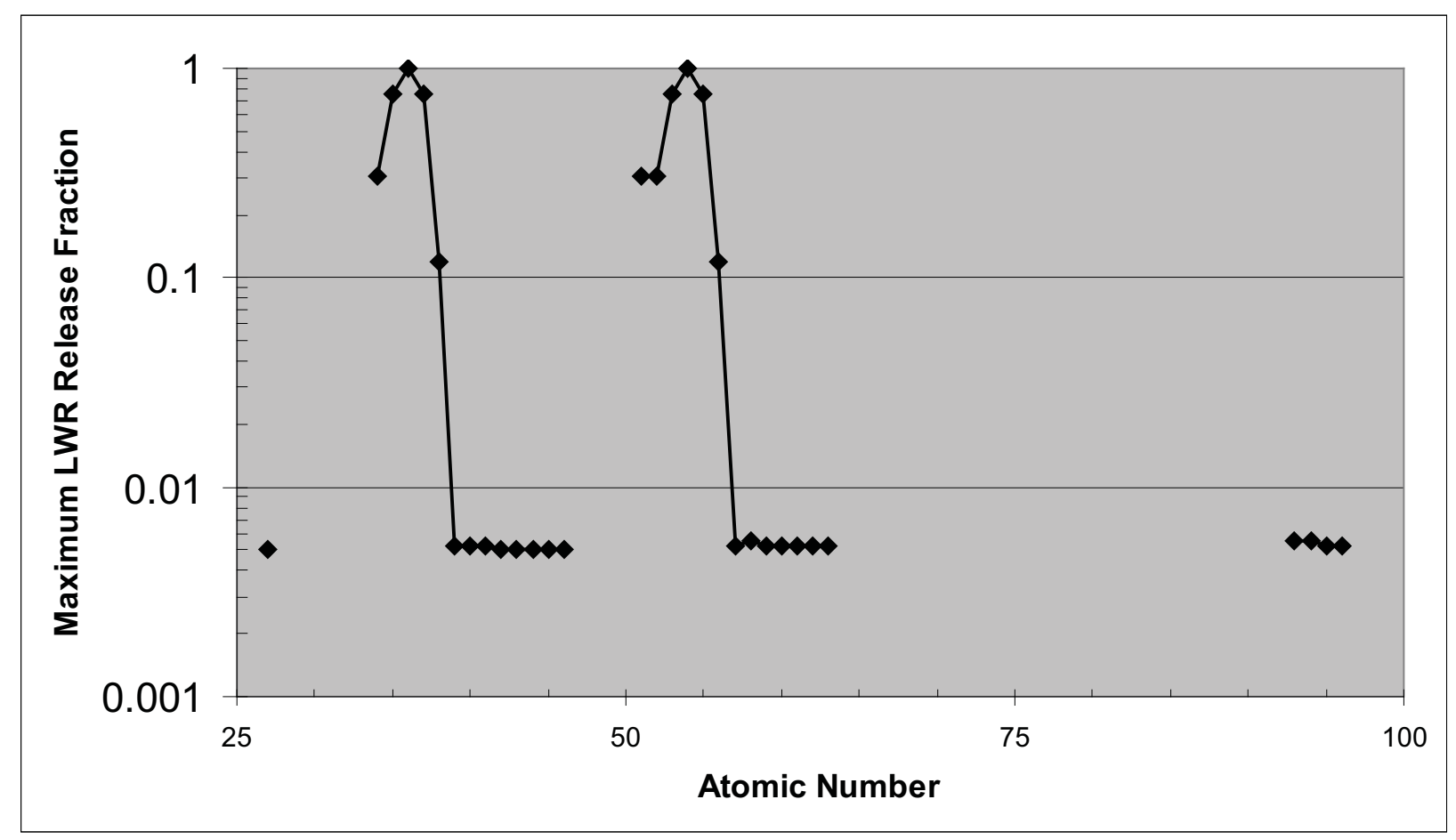

Figure 4-3. Maximum LWR release fractions, data from (NRC1995), as graphed in (Piet2006).

Energy sources do vary significantly among concepts. Table 4-4 lists three energy source indicators that must and are considered in reactor safety design. 
Table 4-4. Energy source indicators for candidate reactor options.

\begin{tabular}{|l|l|l|l|}
\hline Reactor option & $\begin{array}{c}\text { Light Water } \\
\text { Reactor (LWR) }\end{array}$ & $\begin{array}{c}\text { Very High Temperature } \\
\text { Reactor (VHTR) }\end{array}$ & $\begin{array}{c}\text { Sodium Fast Reactor } \\
\text { (SFR) }\end{array}$ \\
\hline $\begin{array}{l}\text { Coolant stability, single- } \\
\text { phase can be easier to control }\end{array}$ & Two-phase fluid & Single-phase fluid & Single-phase fluid \\
\hline $\begin{array}{l}\text { Lower coolant pressure } \\
\text { (MPa) has safety benefits }\end{array}$ & 15 & 9 & 0.1 \\
\hline $\begin{array}{l}\text { Coolant is chemically inert, a } \\
\text { safety benefit }\end{array}$ & Moderately & Yes & No \\
\hline
\end{tabular}

\subsubsection{Reactor safety functions and countermeasures}

Deterministic assessment is a necessary tool as part of a PRA and in some regulatory approaches for establishing a design basis for a given concept. A design basis is the technology specific attributes that protect against core damage. PRAs are also technology specific but require further understanding of initiators, protective measures (or defense-in-depth) to generate a hierarchy of event tree and fault tree relationships. Before this level of detail is reached, it is helpful to understand the central safety characteristics of a general concept that suggests the mechanisms by which future designs of this reactor family would be made safe.

Figure 4-4 contrasts four central safety characteristics with general reactor concepts. The figure gives examples of specific safety mechanisms commonly used to protect against accidents and radioactive release. All reactors utilize each of the four basic safety characteristics to varying degrees. Some reactor families rely on a single safety characteristic as the central feature. However, leveraging all safety characteristics without greatly increasing design complexity can decrease risk without incurring excessive cost. 


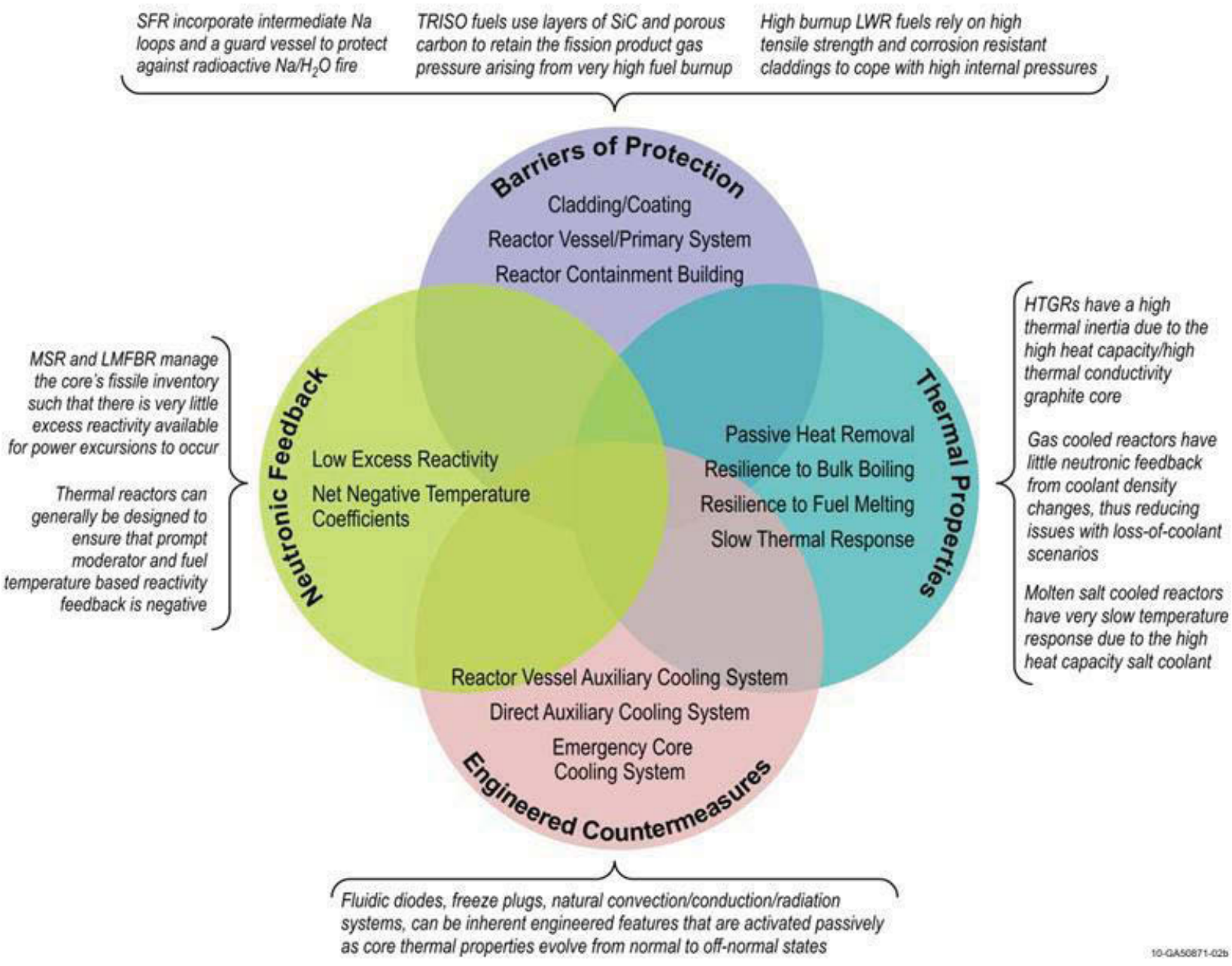

Figure 4-4. Fundamental safety characteristics used in reactor design with relevance to advanced concepts.

All reactors have to provide the four fundamental safety characteristics. Once the inherent and passive safety features of a concept are identified - those that are "built-in" to the concepts physics, heat conduction, thermal inertia, etc. - then active engineered systems are added to provide the required level of safety of the power plant.

Molten Salt Reactor Example: The MSRE safety report (MSRE 1964) describes the maximum credible accident as a release of the molten fuel from the reactor vessel and fuel-circulation system into the reactor cell. MSRE was designed and operated prior to the widely adopted application of PRA. The report goes on to say that "The pressure produced by the release of salt into the secondary container depends on the reactions with the environment. The oxygen content of the cell atmosphere will be kept low enough (by purging with nitrogen) to prevent fires and explosions." Overall, the analysis is limited by possibly overly conservative engineering assumptions on the amount of salt that is released from the reactor primary circulation system and the amount of water in which the escaped fuel salt would come into contact. 
The report does identify that contact of molten salt with water would produce hydrofluoric acid and that part of the acid would be dispersed as vapor in the reactor cell. It is important to identify the possible entrainment of tritium produced by neutron reaction with ${ }^{6} \mathrm{Li}$ in the salt that would become entrained in the vaporized hydrofluoric acid, which was not addressed in the report. The report concluded that the acid itself would be a minor corrosion concern for the plate-steel containment vessel. The defense-in-depth for this accident scenario was focused on the obvious threat of a low probability radioactive release through a penetration in the containment vessel caused by corrosion, pressurization, etc. However, this worse case perspective neglects the potentially higher probability issue of tritiated hydrofluoric acid depositing and impregnating the steel containment structure with tritium, which would not be recoverable due to the high permeability of hydrogen in steel.

\subsubsection{Risk-based goals}

Generally, core damage is associated with severe accidents. However, this brings into question the context of what constitutes as "severe". Not every reactor operations mishap or regulatory noncompliance results in reactor core damage. Consider that the highest probability for core damage reported from the PRISM preapplication safety evaluation report (PSER) is $2.1 \times 10^{-8}$ (PRISM). This provides assurance that the reactor itself has a low probability of a major event. However, this metric does not capture higher probability but lower consequence sodium fire's which do not cause core damage. Sodium fires have occurred at nearly all SFR plants (IAEA 1999, Guidez 2008). Furthermore, higher probability but lower consequence events are not limited to reactors. The 2004-2005 leak of radioactive nitric acid from a small fractured feed pipe at Great Britain's Thermal Oxide reprocessing plant that went undetected for months and caused the facility to be shut down for 18 months until the leak could be cleaned up is a further example of major industrial accidents which have had little to no harm to humans but had major operational ramifications.

The existing licensing framework in the U.S. is built around LWRs. At the same time there is interest in the U.S. in future gas-cooled reactors (e.g. NGNP), and sodium cooled fast reactor. How are they to be licensed in a regime of LWR licensing criteria? Is NRC ready to license different reactor technologies?

Currently, there is an effort to capture all levels of radioactive release with all likelihoods of failure. Recently, the NRC has suggested a frequency-consequence curve based on current regulatory, industry best-practices and professional standards set by the technical community (PRISM). The frequency consequence curve proposed by NUREG-1860 is provided in Figure 4-6. In this curve, public and occupational exposure is emphasized. However, the selection criterion of frequency thresholds for each dose range would benefit from an event-initiator frequency investigation for a range of advanced reactor options. 


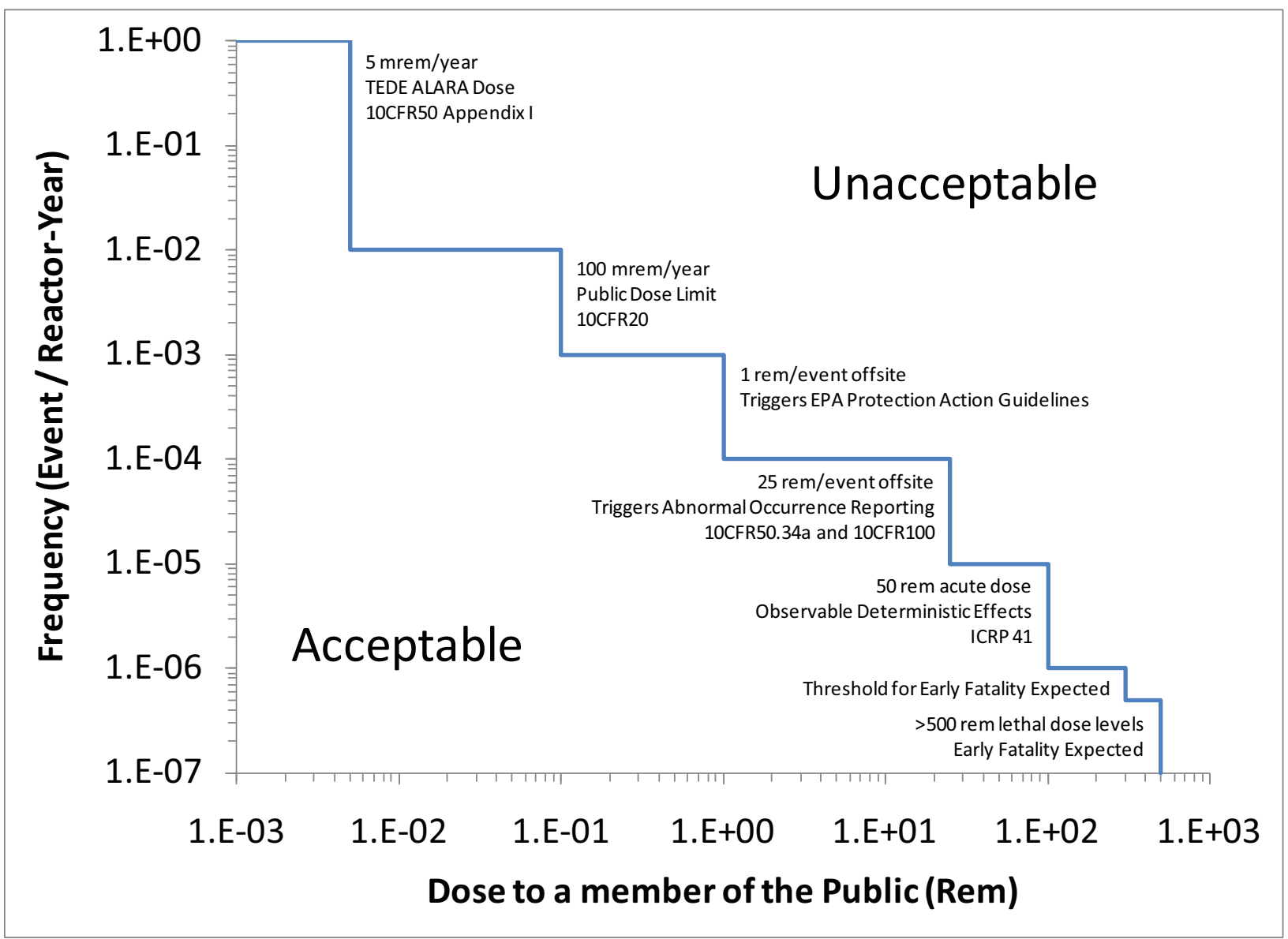

Figure 4-6. The frequency-consequence curve for a risk-informed and performance-based regulatory structure for future plant licensing (NUREG-1860).

\subsection{R\&D Needs}

From a regulatory standpoint, licensing of new concepts is a process of using available funding and staffing to: (1) explore new policy and (2) implement the licensing process on radically unfamiliar technologies. Clarifying how the fundamental safety characteristics address public health and safety concerns will reduce the amount of regulatory effort needed to evaluate new concepts. To accomplish this clarification, future effort should be made to work with reactor concept proponents to establish the fundamental safety characteristics for their conceptual design.

The emphasis on PRA means that the R\&D program for any new nuclear technology must eventually address both the frequency and consequence dimensions. The regulator will tend to use precedents, conservative estimates of consequence, and conservative interpretation of failure frequencies of the most analogous components to those in a proposed new facility. It is the responsibility of those proposing a new technology to provide the safety case, evidence for off-normal behavior of radioactive inventories, and arguments for reasonable estimates of failure frequencies.

Co-location of facilities, e.g., separation and fuel fabrication, is one of the ways that the potential risk of future may be reduced. Although the radiological risk from transportation has been shown to be low, public concerns are high and any industrial transport involves common daily transportation risks.

Most, if not all, candidate separation technologies involve mobilization of gaseous and volatile fission products and the presence of high temperatures during at least one part of the process. This is not a 
discriminator but is a common $\mathrm{R} \& \mathrm{D}$ need to continue to search for techniques that maximize recovery and minimize cost.

Although high-actinide fuels in LWRs (MOX) have been criticized for increasing the accident source term relative to uranium oxide fuel, data indicate that this is not actually a problem. However, this illustrates the need for having off-normal fuel performance data in addition to data for routine operation. 


\section{PROLIFERATION RESISTANCE AND PHYSICAL PROTECTION}

Evaluation of proliferation resistance and/or physical protection requires knowledge of: (a) what technologies are involved in the commercial fuel cycle, (b) the tendency for a nation-state to continuously use the technology for civilian practice, and (c) the ability of the international community to safeguard the technology and nuclear materials that it produces. Nuclear technologies and the supporting infrastructure can be designed to promote safeguards by ensuring material accountability. Hence, proliferation resistance technology is partly contingent on the safeguards-by-design approach for facilities.

Barriers to acquisition of a nuclear weapon/explosive are called "proliferation resistance" for a host nation of nuclear facilities and "physical protection" for a subnational or terrorist group (PRPP2006). An evaluation methodology should include the four stages toward a weapon - (1) diversion (if host nation) or theft (if subnational), (2) transportation, (3) transformation, and (4) weapon fabrication and indicate how the various indicators are to be combined (Cleary2007, Metcalf2009).

The four stages are relevant to both proliferation resistance and physical protection. No single indicator spans all four stages and both PR and PP. Furthermore, different indicators pertaining to the same underlying characteristic of a fuel cycle may exhibit different preferences. Figure 5-1 conceptualizes the importance of three different indicators associated with which transuranic elements are in fresh fuel.

- International safeguards (purple oval) pertain to proliferation resistance but not physical protection. The objective is to detect host country diversion of material. International safeguards do not directly address transportation, transformation, or weapon fabrication. Rather, they are focused on material accountability. It is easier to measure the amount of a transuranic mixture that is plutonium, without the other transuranics, because the other transuranics have higher gamma and neutron emission, which can mask signatures of plutonium. So, from this perspective, plutonium fuels are easier to safeguard than fuels with a mixture of transuranic isotopes.

- The next indicator in the figure is "detect theft or transport". This is relevant to the first two stages and therefore is shown as straddling the line separating "diversion or theft" from "transportation." From this perspective, transuranic fuels are preferable to plutonium (or uranium) fuels because of higher radiation emission.

- The final indicator (grey oval) in the figure is "FOM-1 attractiveness metric" which pertains to an overall material attractiveness figure of merit (FOM) recently published (Bathke 2009). FOM-1 is relevant to host country threats; FOM-2 is relevant to subnational threats. These FOM depend on several factors, including which transuranic isotopes are present. From these two indicators, proliferation resistance and physical protection is increased as non-plutonium transuranic elements are included. One may argue that "detect theft or transport" is a subset of FOM-1 and 2, which is why "detect theft or transport" is shown mostly within the grey oval for FOM 1 and 2.

Thus, for a single issue (Pu vs. transuranic recycling) there are (at least) two indicators that have different preferences. These can only be resolved by decision makers weighting one consideration higher than the other, or R\&D reducing Pu safeguard measurement advantage over transuranics. 


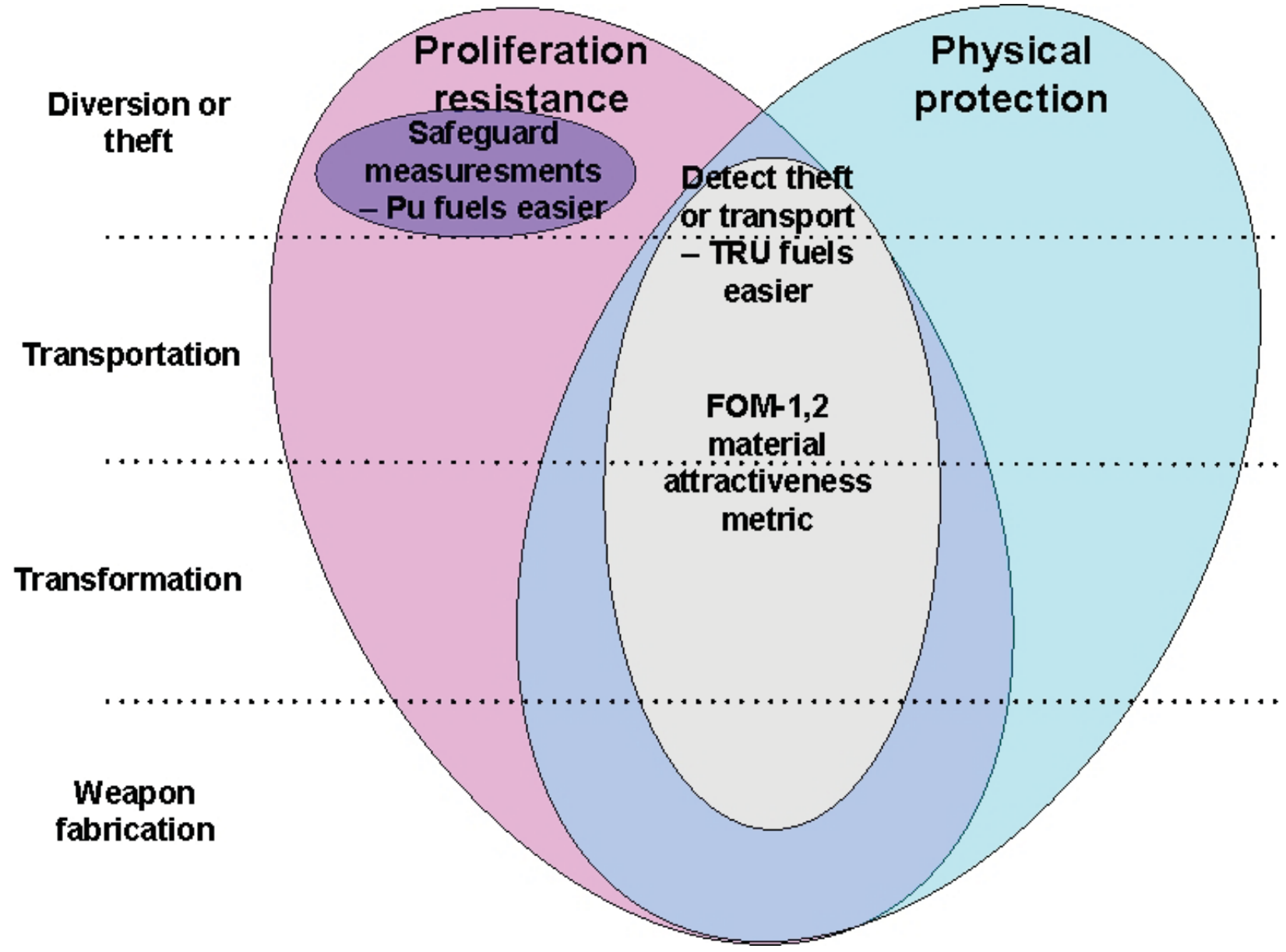

Figure 5-1. Proliferation Resistance and Physical Protection for four stages toward a weapon.

The Generation IV PR\&PP methodology includes consideration of the following threats (Peterson 2009). For PR treats, target identification considers:

1. Nuclear material that can be diverted (diversion threats)

2. Equipment and processes that can be misused to process undeclared nuclear materials (misuse threats), or

3. Equipment and technology that can be replicated in an undeclared facility (clandestine facility threats)."

"For PP threats, target identification considers:

1. Nuclear material to be protected from theft,

2. Information to be protected from theft, or a

3. Set of equipment to be protected from sabotage."

Addressing the above list of threats requires far more than safeguarding material, which only covers the first one or two of the six threats. Indeed, methodologies vary to the degree that they consider the above considerations. They also vary to the degree they can be used at early stages of concept formulation. We searched existing methodologies and identified several useful indicators. We made no attempt to combine or weight these indicators. Figure 5-2 shows a loose mapping of the indicators in this report into the areas of proliferation resistance (against host country diverts material) and physical protection (against subnational group steals material) and the four stages of material acquisition, transport, transformation of 
material, and weapon fabrication. The fundamental point is that there is no single methodology that meets the needs of this report, nor did the authors attempt to create a new methodology. (Efforts are underway elsewhere in the FCR\&D program toward new methodologies.) Furthermore, a preference for a fuel cycle option versus another based on one indicator can be reversed by another indicator; yet both claims may be valid.

\section{Proliferation resistance}

\section{Physical protection}

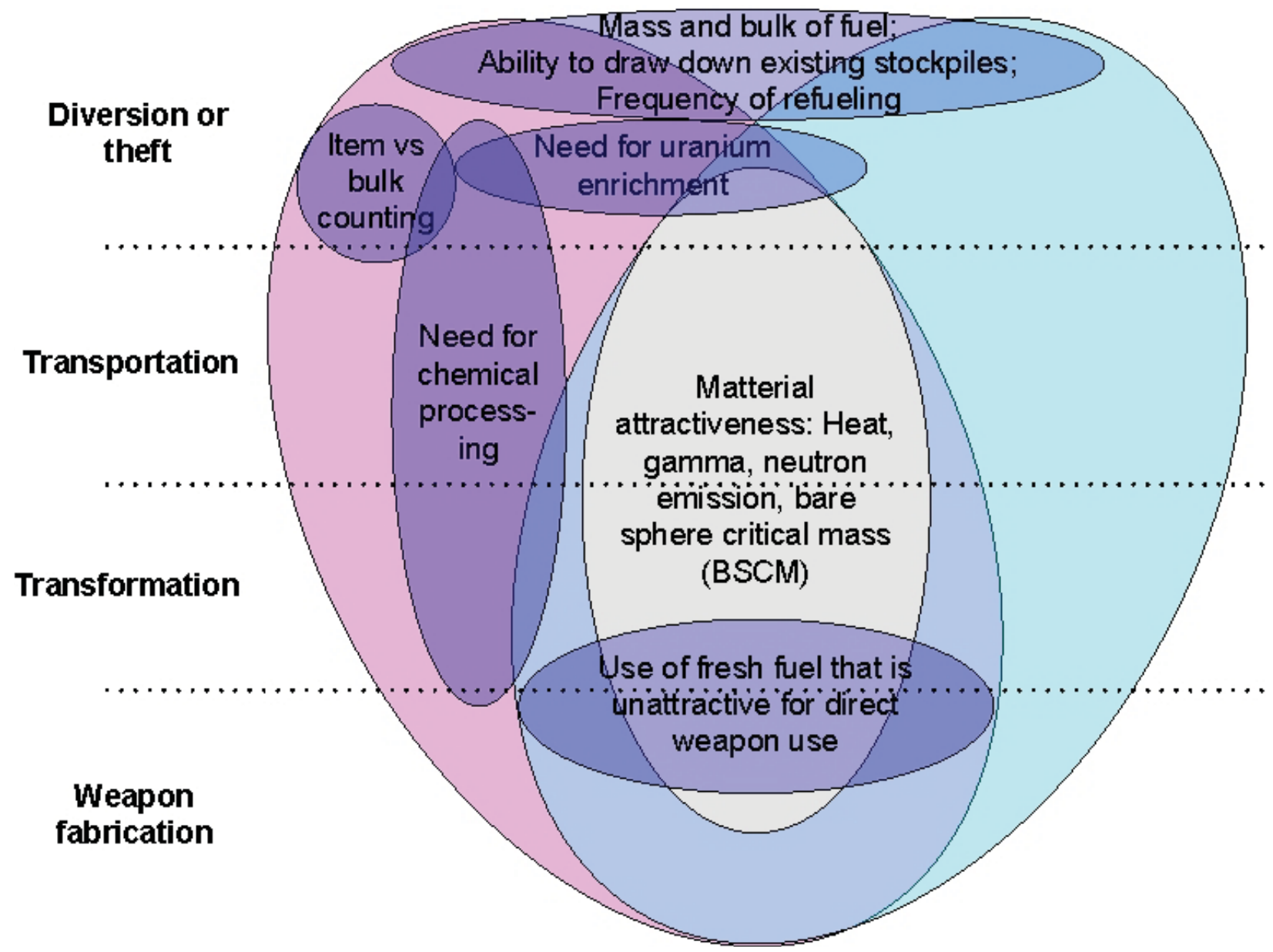

Figure 5-2. Indicators used this chapter, relevant to differing stages toward a weapon; no single indicator covers all four stages and both proliferation resistance and physical protection.

There is one issue - adaptability - that spans both proliferation resistance and physical protection and spans the four stages. Adaptability of technologies and skills is not shown explicitly in Figure 5-2. No assessment would be complete without this consideration as it explains why UREX and COEX get little "credit" relative to PUREX for a host nation threat. Yet, "adaptability" is one of the least explicit topics in existing methodologies. (For subnational threats, UREX and COEX do receive some credit.)

\subsection{Adaptability of Technologies and Skills to Overall Fuel Cycle}

From most engineering perspectives, adaptability of technologies to changing needs and circumstances is an advantage. However, in the proliferation resistance domain, the adaptability of technologies to create high attractive materials (high enriched uranium, plutonium) is a disadvantage. For example, does a fuel cycle "create technical basis for separating weapons-usable material from spent fuel" (Goodman 2009), 
whether or not the fuel cycle actually does such a separation under normal operation? That is, how easy is the technology for misuse? Other ways that adaptability appears in methodologies include "skills, expertise, and knowledge that are necessarily involved" and "the time that may be required to obtain access to weapons-usable materials." (TOPS 2000)

An obvious case is uranium enrichment; if one can enrich to $5 \%$, one can enrich to $95 \%$. Similarly, if one can separate used fuel to produce 50:50 uranium-plutonium, one can separate pure plutonium. Less understood is whether candidate "minimum fuel treatment" approaches, e.g., AIROX and melt refining, can be misused to produce high attractive material. Also less understood is the degree to which fuel fabrication techniques can be misused.

\subsubsection{Need for uranium enrichment}

A fundamental question for all fuel cycle options is whether uranium enrichment is required. Examples of how existing methodologies include the need for uranium enrichment include the following:

- PR\&PP - impacts the "host country capabilities and is a component of "proliferation technical difficulty," "proliferation cost", "proliferation time", and "physical protection resources" in that the more things to guard, the more the expense.

- INPRO - evaluation parameters of 2.1.1 material type and 2.4.1 enrichment

- TOPS - uranium enrichment is an explicit stage of the fuel cycle, what must be evaluated if present.

This report further differentiates (a) whether the enriched uranium needs to be higher than $20 \% \mathrm{U}-235$ or not and (b) whether the enriched uranium is only a one-time need for startup fuel or (c) a continuing need. If the need is only one-time, there is less economic incentive for a country to develop uranium enrichment. Figure 5-3 shows the need for uranium enrichment for different fuel cycles, not individual reactor technologies. Only two types of fuel cycles avoid uranium enrichment on a continuing basis heavy water reactors (if both cooled and moderated by heavy water) and breeder reactors 1 .

Fuel cycles with heavy water reactors (HWR) using recovered uranium or Pu or TRU from used LWR fuel still require routine use of fuel with $<20 \%$ U-235 because the original LWR fuel requires enrichment.

Of course, for an individual reactor, the frequency of fuel loading is important, see section 5.6. For example, a breed-and-burn concept only requires uranium enrichment for its infrequent fuel loading. ${ }^{\mathrm{m}}$

1 MAGNOX and other graphite moderated reactors such as Advanced Gas Reactors, Russian RBMK and Cold War era Pu production reactors (e.g., the Hanford reactors) were also designed not to require uranium enrichment. However, we did not consider these reactor technologies as options since there is currently no apparent demand to expand current commercial reactor fleets using these designs.

m Reminder: in this report, breed-and-burn refers to once-through fast reactors without recycle of used fuel. 


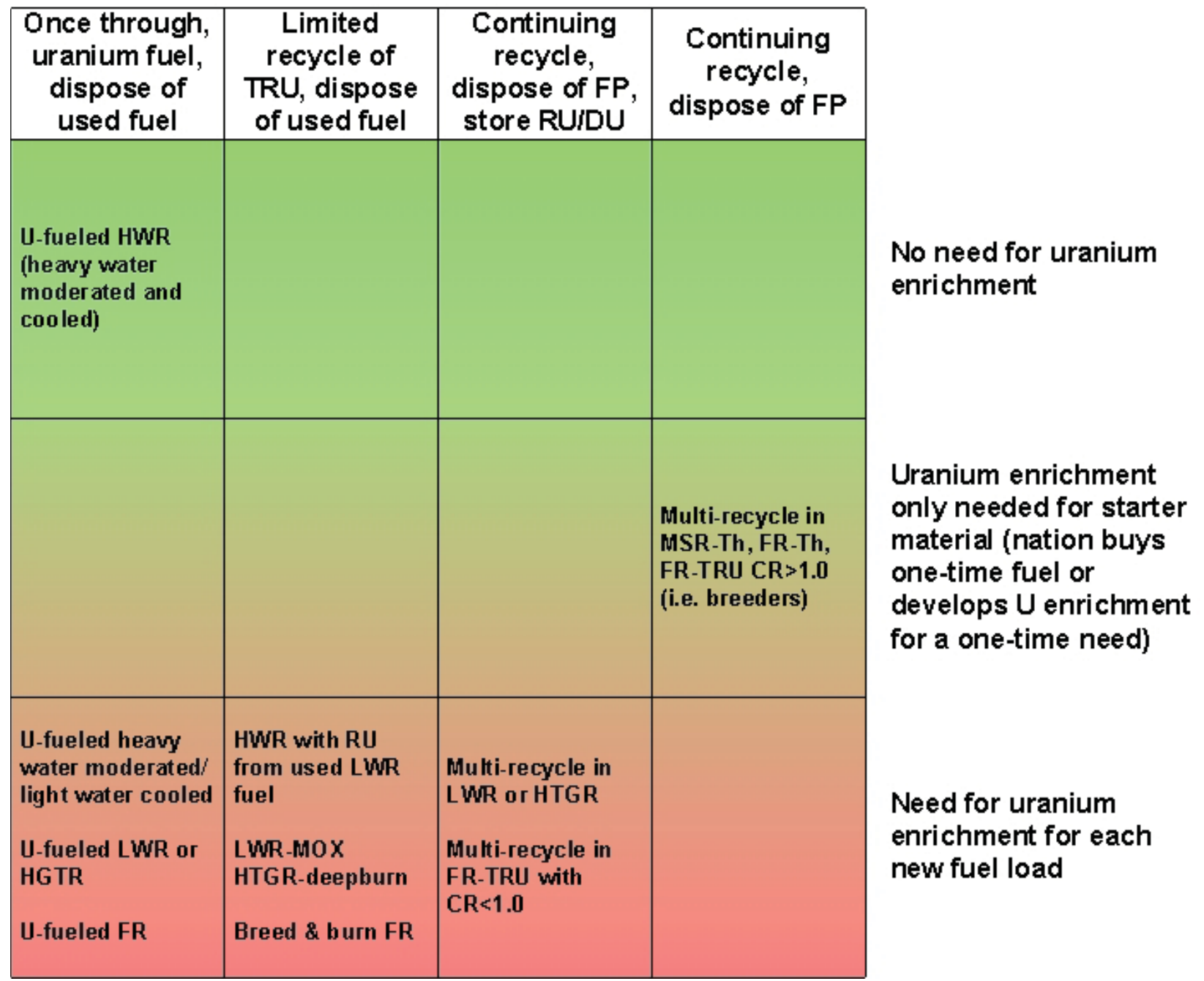

Figure 5-3. Need for uranium enrichment among fuel cycle options; an indicator in essentially all evaluation methodologies.

\subsubsection{Use of fresh fuel that is unattractive for direct weapon use}

All methodologies address whether the fuel cycle uses fresh fuel that is itself unattractive for direct weapon use. Examples of how existing methodologies address this issue include the following:

- INPRO - evaluation parameter 2.1.2: isotopic composition

- $\quad$ PR\&PP - the consideration here of impacting host country capabilities is a component of PR\&PP considerations "proliferation technical difficulty," "proliferation cost", "proliferation time", and "physical protection resources" in that the more things to guard, the more the expense.

- $\quad$ TOPS - under "material barrier", TOPS provides the following classification, Table 5-1. 
Table 5-1. Isotopic Composition Classification (assembled from TOPS 2002).

\begin{tabular}{|c|c|c|}
\hline Resistance to proliferation & Uranium content & Plutonium content \\
\hline Insignificant (-) & $80 \%<\mathrm{U}-235 / \mathrm{U}$-total & \\
\hline \multicolumn{3}{|l|}{ Insignificant } \\
\hline Insignificant $(+)$ & $50 \%<\mathrm{U} 235 / \mathrm{U}$-total $<80 \%$ & \\
\hline Low (-) & & $90 \%<\mathrm{Pu} 239 / \mathrm{Pu}$ \\
\hline Low & & $40 \%<\mathrm{Pu} 239 / \mathrm{Pu}<90 \%$ \\
\hline Low $(+)$ & $35 \%<\mathrm{U} 235 / \mathrm{U}$-total $<50 \%$ & $\mathrm{Pu} 239 / \mathrm{Pu}<40 \%$ \\
\hline Medium & $20 \%<\mathrm{U} 235 / \mathrm{U}$-total $<35 \%$ & \\
\hline High & $\begin{array}{l}1.67 \mathrm{U}_{233}+\mathrm{U}_{235)} / \mathrm{U}_{\text {tot }}<20 \% \\
\mathrm{U}-235 / \mathrm{U} \text {-total }<20 \% \\
\text { U-233/U-total }<12 \%\end{array}$ & \\
\hline Very High & Natural, depleted & \\
\hline
\end{tabular}

Thus, although this topic area is included in all the methodologies studied to date, the exact formulation varies. For our purposes, there are three to four situations of interest: U-233, U-235, Pu, and TRU-based fuels. It is well known that a fresh fuel composition with U-235 enrichment below $20 \%$ is not considered directly weapon usable and identification of fuel cycles on that basis was in the previous section. This has been expanded to U-233 with an enrichment threshold of $12 \%$. Thus, TOPS combines the two uranium thresholds with the expression $(1.67 \mathrm{U} 233+\mathrm{U} 235) /$ U-total $<20 \%$.

There is less agreement on the thresholds for Pu and TRU-based fuels. The most recent study that directly addressed this question defined two figures of merit (FOM), one for national groups and one for subnational groups (Bathke 2009). They find that the plutonium fraction of heavy metal $(\mathrm{Pu} / \mathrm{HM})$ must be $<20 \%$ and the TRU/HM fraction below $25 \%$ to keep material from being attractive for direct weapon use.

Figure 5-4 shows the composition of various cases with lines denoting the criteria of $20 \%$ U235/U-total, $20 \% \mathrm{Pu} / \mathrm{HM}$, and $25 \% \mathrm{TRU} / \mathrm{HM}$. Generally, the only cases exceeding these criteria are thermal reactor fuels with fissile breeding ratio below $\sim 0.25$ (LWR-IMF or HTGR deep-burn) and fast reactor cases with fissile breeding ratio below $\sim 0.75$ ( 0.65 to 0.90$)$.

The degree of required enrichment (U-235/U-total, $\mathrm{Pu} / \mathrm{HM}$, or TRU/HM) depends primarily on the neutron spectrum (thermal or fast), the intended fuel burnup, and the fissile breeding ratio (BR) or TRU conversion ratio (CR). ${ }^{\mathrm{n}}$

Uranium-fueled once through LWRs could achieve $\sim 200$ MWth-day/kg-iHM burnup with U-235 enrichment below $20 \%$; similar numbers would be expected for most other thermal reactors. That is, a burnup of $\sim 200$ corresponds approximately to the dividing line of $20 \% \mathrm{U}-235$. From the uranium enrichment standpoint, fuel cycles that require uranium enrichment to initiate a Pu-based fuel cycle are no different than the current once-through fuel cycle. This is because they still use enriched uranium for the UOX fuel from which Pu or TRU is obtained.

$\mathrm{n}$ Transuranic (TR) conversion ratio (CR) is the production of TRU divided by destruction. Fissile breeding ratio (BR) is the production of fissile isotopes divided by their destruction. In this chapter, we use the fissile breeding ratio as it is the more common outside of the FCR\&D program. 


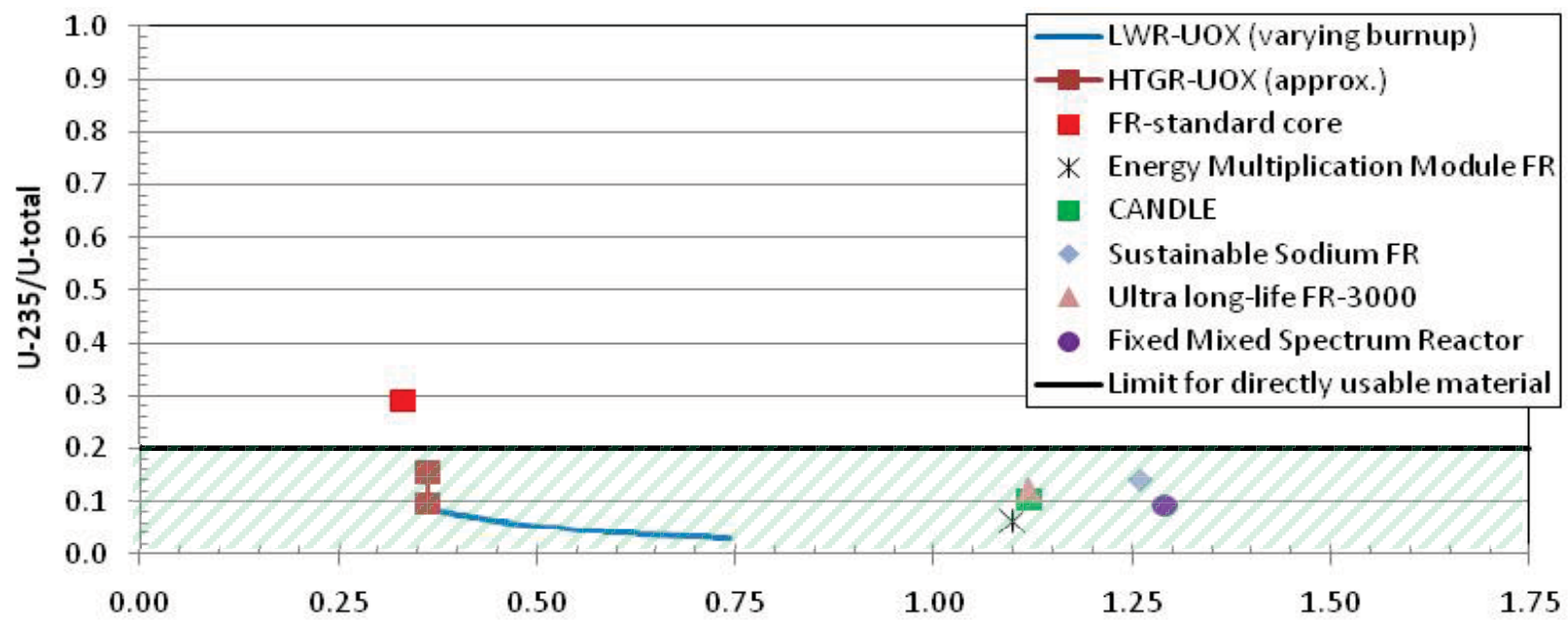

Fissile breeding ratio

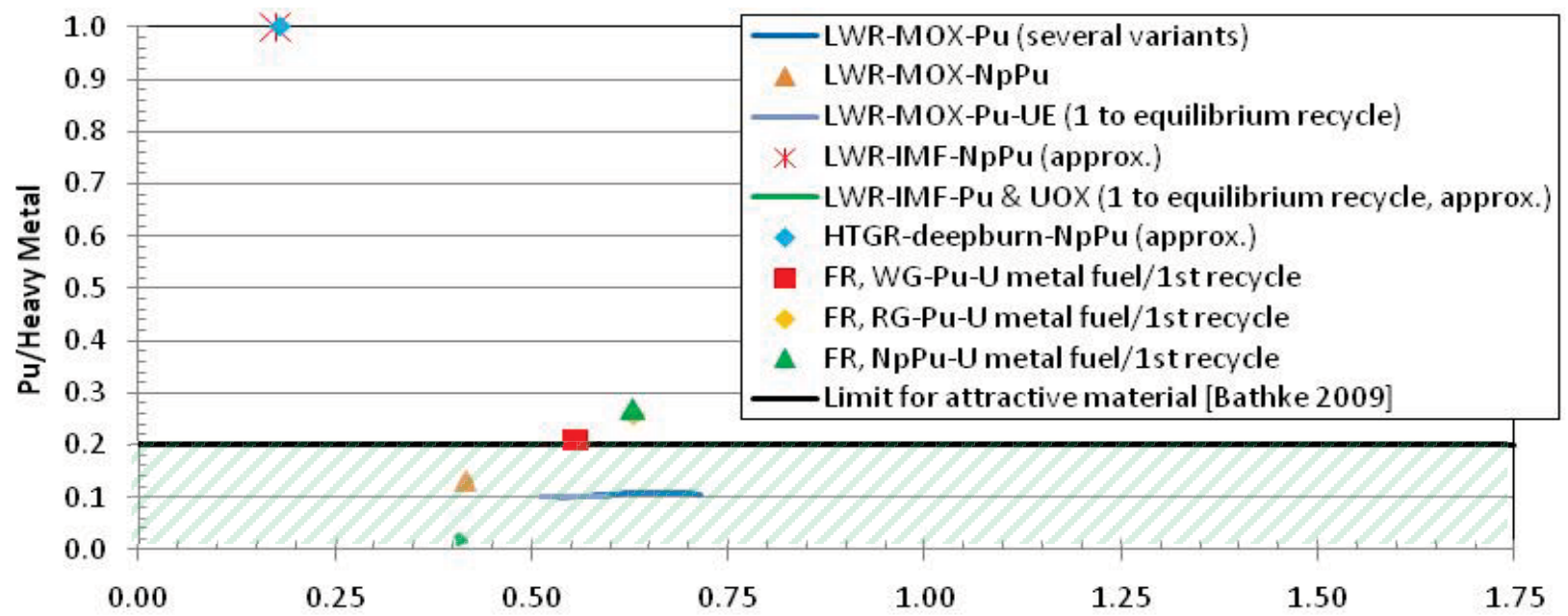

Fissile breeding ratio

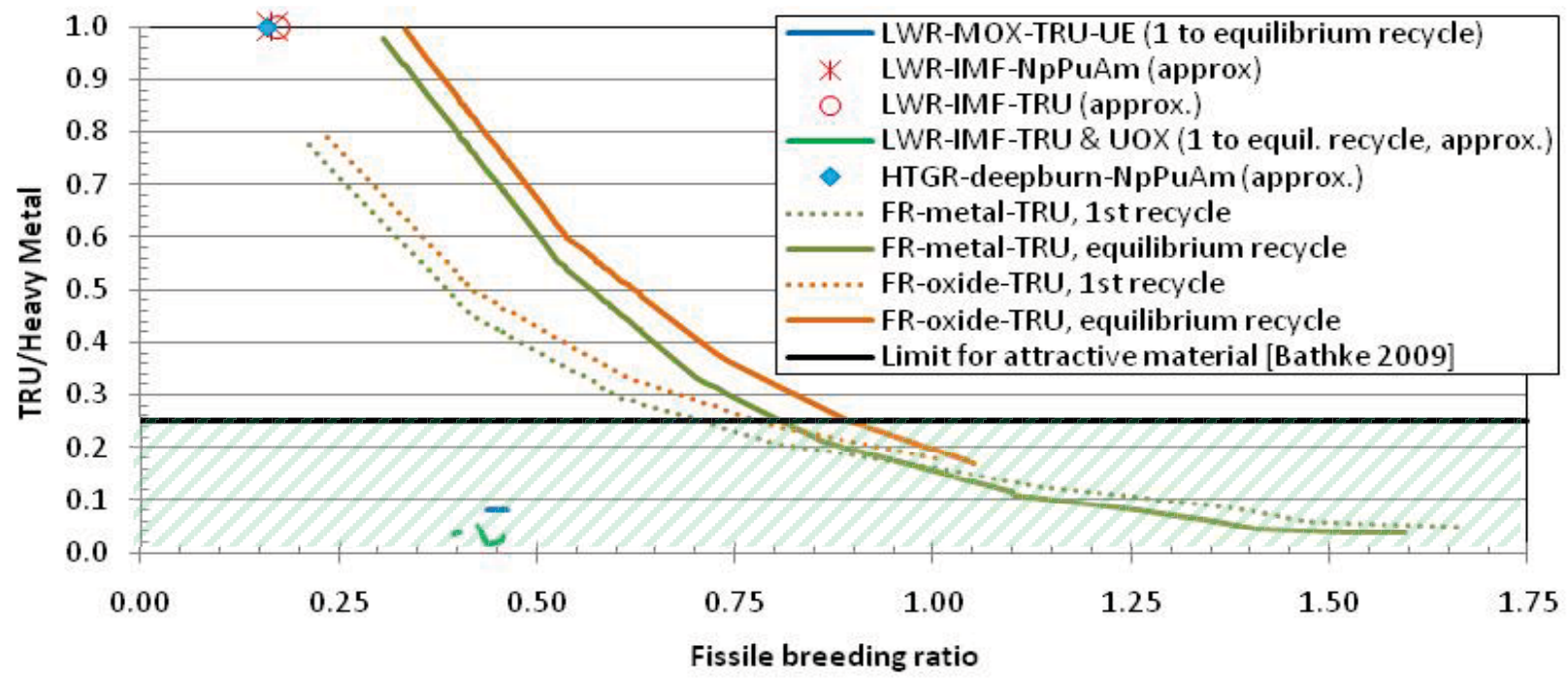


Figure 5-4. Enrichment required, U-235/U-total, $\mathrm{Pu} / \mathrm{HM}$, or TRU/HM, as appropriate; this is a topic addressed by the IAEA and all methodologies but the criteria for Pu and TRU vary.

The exception among thermal reactors is HWR. CANDU HWR reactors operate without uranium enrichment but are limited to very low burnups, about 7.5 MWth-day/kg-iHM. Advanced CANDUs such as the ACR-700 require uranium enrichment as they are light-water cooled/heavy-water moderated; they achieve higher burnups, 20 MWth-day/kg-iHM.

The pattern in fast reactors (FR) is different. Once-through fast reactors with TRU CR below $\sim 0.75$ require U-235 enrichment above 20\%. ${ }^{\circ}$ Modified Open Cycle (MOC) or Full Recycle (FR) with TRU CR over $\sim 0.75$ require U-235 enrichment below $20 \%$. A FR with $\mathrm{CR}>1$ or $\mathrm{BR}>1$ is a "breeder" and only requires enriched uranium once, to start the process with material from used LWR or HTGR fuel. The top part of Figure 5-4 shows several once-through uranium-fueled breed and burn cases: Energy multiplication module, CANDLE, Sustainable Sodium FR, Ultra long-life FR-3000, and the Fixed Mixed Spectrum Reactor. Each is a breeder reactor, albeit a once-through reactor; each has U-235 enrichment below $20 \%$. The values plotted in the figure for these cases are the effective reactor breeding ratio and the U-235/U-total for the starter or igniter zone (Taiwo 2010). In contrast, a one-pass fast reactor that is not a breeder reactor (FR-standard core in the figure) does require U-235 enrichment above $20 \%$.(Ferrer 2007). MSR-Th and FR-Th can also have conversion ratio over 1 and hence only require enriched uranium once.

\subsubsection{Need for chemical processing}

Another fundamental question for all fuel cycles is what chemical processing is required. Some of the ways the need for chemical processing is addressed in existing methodologies include the following:

- TOPS -the "chemical barrier" calls attention to the need for chemical processing to take material into weapon usable form. Pure metals are rated as "insignificant" resistance to proliferation, single compounds such as oxides and nitrides are rated as "low", mixed compounds such as MOX fuel without fission products or other radiation barriers are "medium", and "spent fuel and vitrified wastes" are rated "high" resistance.

- $\quad$ INPRO - three evaluation parameters pertain to the need for chemical processing - 2.3.1: chemical/physical form, 2.4.2: extraction of fissile material, and 2.4.3: irradiation capability of undeclared fertile material (which implies the ability to make fuel or targets).

- PR\&PP - impacts host country capabilities is a component of "proliferation technical difficulty," "proliferation cost", "proliferation time", and "physical protection resources" in that the more things to guard, the more the expense.

All fuel cycles require chemical processing of ore and require chemical processing to make fuel. Therefore, in assessing the need for chemical processing, the question is not "if" chemical processing is required, but what types.

Along these lines, TOPS and INPRO penalize use of metal fuel, but the real issue may be the fabrication technology not so much the fuel form itself. The difference between "fuel form" and "fabrication technology" in assessing fuel cycle options is that fuels are acquired by a reactor host country and fuel fabrication technology may or may not be. Figure 5-5 illustrates the range of need for chemical processing.

o That is, a low TRU CR fast reactor would require high U-235 enrichment. To keep U-235 enrichment below $20 \%$, all of the known once-through FR concepts have CR $>1$, although it appears that a once-through FR with CR slightly below 1 could still keep U-235 below $20 \%$. 


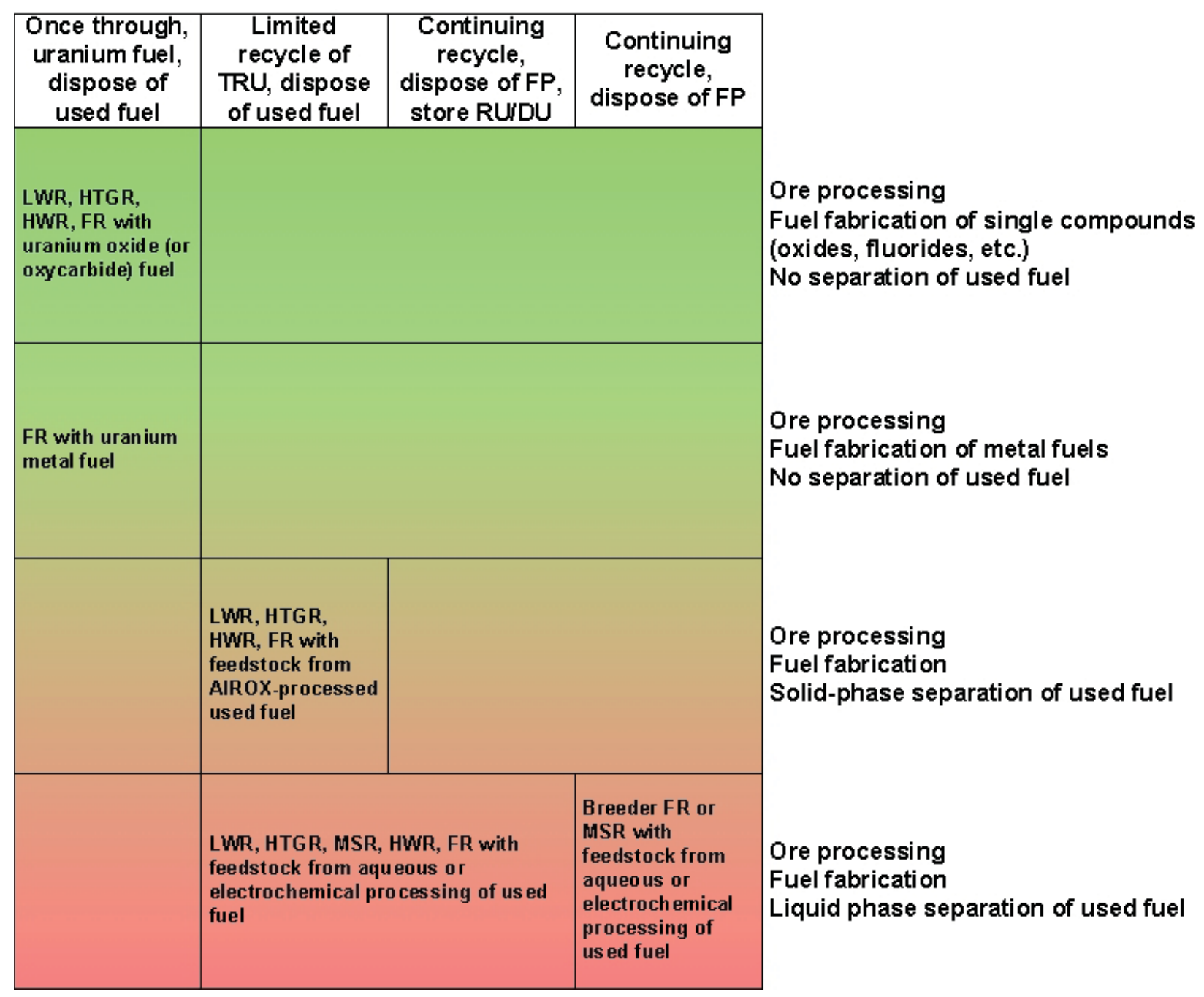

Figure 5-5. Need for chemical processing among fuel cycle options; combining indicators in TOPS, INPRO, and PR\&PP methodologies.

We are unaware of an existing methodology that explicitly differentiates between solid-phase and liquidphase separation of used fuel. However, in considering the potential misuse of separation technologies, which is explicitly in existing methodologies, it appears that the liquefaction (or not) of used fuel would seem to be important.

\subsubsection{Adaptability of specific technologies to make weapon-usable material}

Entering nuclear energy fundamentally changes the industrial capability of a country. The more technological capabilities associated with a fuel cycle imported, the more the change. (In contrast, simply importing fuel and exporting used fuel induces less change.) The preceding indicators address whether fuel cycle options routinely involve material that is attractive for direct use - U235/U-total $>20 \%$, U233/U-total $>12 \%, \mathrm{Pu} / \mathrm{HM}$-total $>25 \%$, TRU/HM-total $>20 \%$ per (Bathke 2009) - and which chemical processing technologies are involved. This subsection considers the next step: how adaptable are the preceding technologies to produce material that is attractive for direct use.

Table 5-2 shows the classification scheme in TOPS for the indicators of "facility unattractiveness" and "skills, expertise, and knowledge". The former indicator is a 5-level scheme; the latter indicator only three. INPRO includes this area of "adaptability" in "extraction of fissile material," "irradiation 
capability of undeclared fertile material," "difficulty to modify the process," "difficulty to modify facility design," and "detectability of misuse of technology or facilities." The PR\&PP methodology does not refer to "adaptability" per se, but it is implied in the structure of the methodology itself, i.e., one starts with identifying the technological capabilities of the host country in question. Technological capabilities then impact the evaluation areas of "proliferation technical difficulty," "proliferation cost", and "proliferation time."

Table 5-2. TOPS Classification Schemes Related to Adaptability of Technologies for Misuse (TOPS 2000).

\begin{tabular}{|c|c|c|}
\hline $\begin{array}{l}\text { Proliferation } \\
\text { resistance }\end{array}$ & $\begin{array}{l}\text { "Facility Unattractiveness" } \\
\text { barrier to proliferation (TOPS 2002) }\end{array}$ & $\begin{array}{l}\text { "Skills, expertise, and } \\
\text { knowledge" barrier to } \\
\text { proliferation (TOPS 2002) } \\
\end{array}$ \\
\hline Insignificant & $\begin{array}{l}\text { Those facilities, equipment, and processes that } \\
\text { routinely use, handle, or produce significant } \\
\text { quantities of directly weapons-usable materials, and } \\
\text { those that can do so with no modifications. } \\
\text { Probably no significant observables }\end{array}$ & $\begin{array}{l}\text { The process, technology, or } \\
\text { facility provide significant and } \\
\text { unique technical expertise } \\
\text { having direct application to a } \\
\text { weapons-development program. }\end{array}$ \\
\hline Low & $\begin{array}{l}\text { Those facilities whose designs lend themselves to } \\
\text { quick, safe, and easy modifications (on the order of } \\
\text { a week) to produce directly usable materials with } \\
\text { reasonable throughputs (a significant } \\
\text { quantity/week). Observables difficult to detect prior } \\
\text { to accumulation of significant quantities of } \\
\text { materials. }\end{array}$ & (not defined) \\
\hline Medium & $\begin{array}{l}\text { Facilities that require considerable engineering } \\
\text { expertise, expense, and time ( } \sim \text { a month) to modify } \\
\text { to produce significant throughputs }(\sim 1 \mathrm{SQ} / \text { month). } \\
\text { Probably observable within the time required to } \\
\text { complete modifications and accumulate significant } \\
\text { quantities of materials. }\end{array}$ & $\begin{array}{l}\text { Existence of skills, knowledge, } \\
\text { and expertise provide support or } \\
\text { insights valuable to a weapons } \\
\text { program, or shortens the time } \\
\text { required to obtain expertise } \\
\text { through training, etc. }\end{array}$ \\
\hline High & $\begin{array}{l}\text { Facilities capable of modification given substantial } \\
\text { time (months to years), money, and expertise, } \\
\text { compounded by difficult safety and throughput } \\
\text { issues, and likely highly observable. }\end{array}$ & (not defined) \\
\hline Very High & $\begin{array}{l}\text { Facilities with little potential or appeal for } \\
\text { modification, through a combination of technical } \\
\text { complexity, cost, detectability, and insignificant } \\
\text { throughput. }\end{array}$ & $\begin{array}{l}\text { Only general industrial skills are } \\
\text { needed to support the } \\
\text { technology or facility and they } \\
\text { are well known and readily } \\
\text { available from a number of } \\
\text { common sources. }\end{array}$ \\
\hline
\end{tabular}

Figure 5-6 provides a simplified scale and examples of technological adaptability. Many of the entries are straightforward. A few cases warrant discussion. 


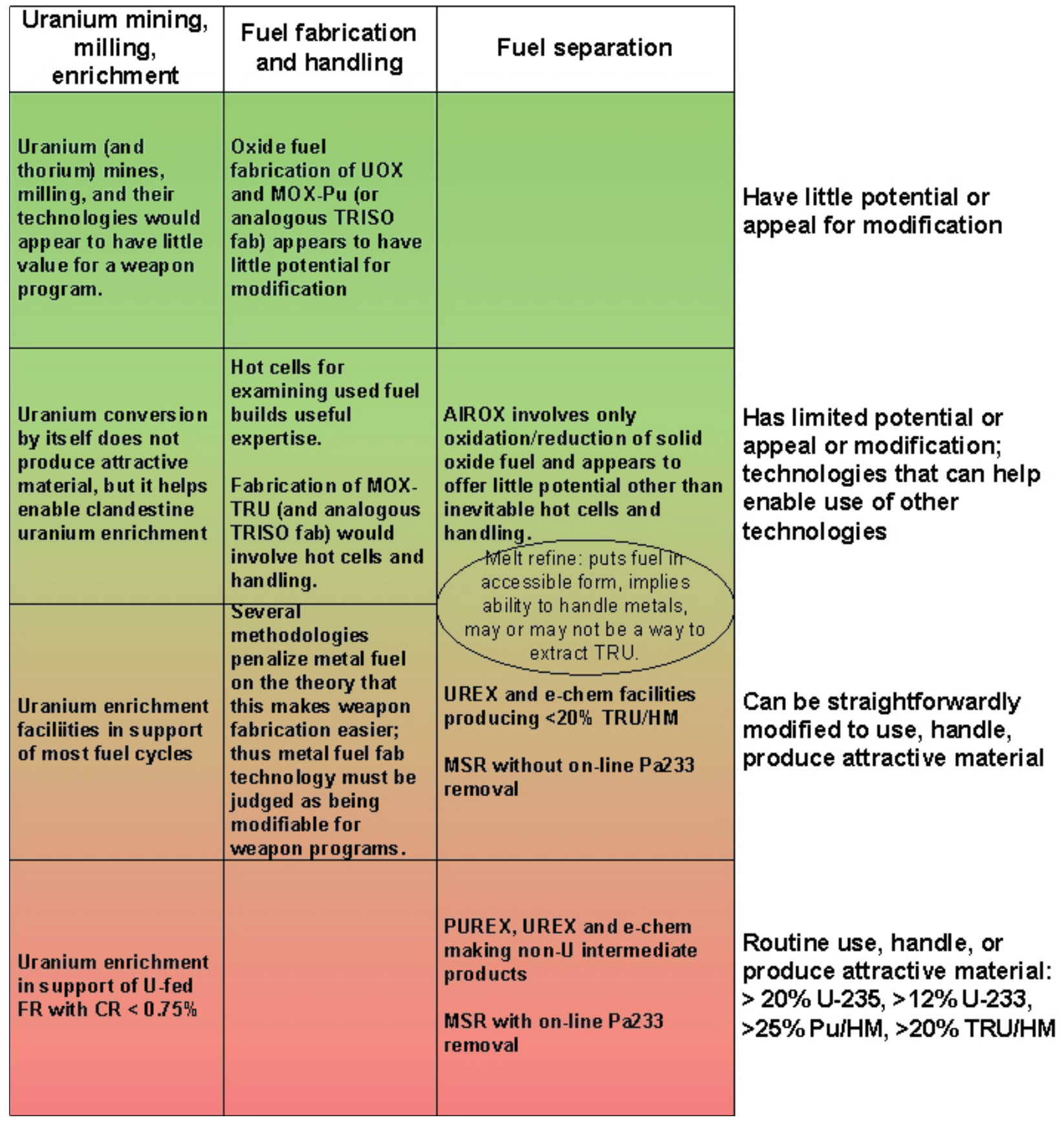

Figure 5-6. Adaptability of individual technologies to make attractive material, combining considerations from several methodologies especially TOPS for clarifying "adaptability" and Bathke2009 for defining criteria for $\mathrm{Pu} / \mathrm{HM}$ and TRU/HM.

AIROX - Passing oxygen and hydrogen (for oxidation and reduction) through oxide fuel has not produced high attractive material; only volatile fission products have been removed. U, TRU and nonvolatile fission products such as the lanthanides were retained in the used fuel. Examination of the free energies of the oxides versus the fluorides suggests that altering the equipment to pass F2 through the used fuel would not produce fluorides of the TRU. Tentatively, we do not see how either a chemical or equipment change would enable an AIROX facility to be adapted to attractive material production. 
Melt refining - Melt refining involves no chemicals other than perhaps oxygen sparging. In the 1960s version of melt refining, the lanthanides were removed from actinides because of the oxygen from the crucible. Today, one would probably design it with oxygen sparging rather than consume the crucible itself. In previous tests, $95 \%$ of the Am was removed from the other TRU and U. We are unaware of a way to separate $U$ from TRU via a melt refining facility. On the other hand, a melt refining approach implies the ability to work with liquid radioactive metals.

Electrochemical (chloride salt) - The free energy of plutonium chlorides versus the others are very close and the designed equipment and chemistry does not produce high attractive material. Data indicates that a higher concentration $\mathrm{Pu}$ stream is possible.

Fluoride volatility (for MSR reactor) - Work for the molten salt reactor showed that U, Tc, gaseous fission products and the noble metals can be removed. Most or all of the Group 1, Group 2, iodine, zirconium, and lanthanides would be retained using fluoride volatility and helium sparging. However, protactinium is removed from the thorium fluoride salts by BeO-ThO2-UO2; Pa233 decays to U233, a very attractive material. If protactinium is not removed, there is no routine use or handling of attractive material; however, the reactor is then a net consumer of fissile material (thereby requiring fissile support) rather than a fissile breeder enabling decoupling with uranium enrichment.

\subsubsection{Adaptability of technologies and skills of fuel cycles}

Having identified the adaptability of specific technologies, we can evaluate fuel cycle options that combine several technologies. The appropriate grade for a fuel cycle option is the lowest among the required individual technologies. Figure 5-7 shows the result. 


\begin{tabular}{|c|c|c|c|c|}
\hline $\begin{array}{l}\text { Once through, } \\
\text { uranium fuel, } \\
\text { dispose of } \\
\text { used fuel }\end{array}$ & $\begin{array}{l}\text { Limited } \\
\text { recycle of } \\
\text { TRU, dispose } \\
\text { of used fuel }\end{array}$ & $\begin{array}{l}\text { Continuing } \\
\text { recycle, } \\
\text { dispose of FP, } \\
\text { store RUIDU }\end{array}$ & $\begin{array}{l}\text { Continuing } \\
\text { recycle, } \\
\text { dispose of FP }\end{array}$ & \\
\hline $\begin{array}{l}\text { LWR, HTGR in } \\
\text { nations with out } \\
\text { enrichment, } \\
\text { without keeping/ } \\
\text { inspecting us ed } \\
\text { fuel }\end{array}$ & & & & $\begin{array}{l}\text { Have little potential or } \\
\text { appeal for modification }\end{array}$ \\
\hline $\begin{array}{l}\text { LWR, HTGR in } \\
\text { nations with out } \\
\text { enrichment, but } \\
\text { with keep ing \& } \\
\text { inspecting us ed } \\
\text { fuel in hot cels }\end{array}$ & $\begin{array}{l}\text { LWR, HTGR, } \\
\text { HWR with AIROX } \\
\text { or melt-r efine } \\
\text { source fuel, } \\
\text { without } \\
\text { enrich ment }\end{array}$ & & & $\begin{array}{l}\text { Has limited potential or } \\
\text { appeal or modification; } \\
\text { has technologies that } \\
\text { can help enable use of } \\
\text { other technologies }\end{array}$ \\
\hline $\begin{array}{l}\text { Once through } \\
\text { (LWR, HTGR, FR, } \\
\text { etc.) because of } \\
\text { enrichment - if FR } \\
\text { with CR > } 0.75 \text { or } \\
\text { LWR with burnup } \\
<200\end{array}$ & $\begin{array}{l}\text { Any } 1 \text {-recycle of } \\
\text { all-TRU in LWR, } \\
\text { HTGR, burner FR } \\
\text { because of } \\
\text { enrich ment }\end{array}$ & \multicolumn{2}{|c|}{$\begin{array}{l}\text { Multi-recycle without non-U } \\
\text { intermediate s eparation products } \\
\text { MSR-Th without Pa233 removal }\end{array}$} & $\begin{array}{l}\text { Can be } \\
\text { straightforwardly } \\
\text { modified to use, } \\
\text { handle, produce } \\
\text { attractive material }\end{array}$ \\
\hline $\begin{array}{l}\text { Once through } \\
\text { with FR CR }<0.75 \\
\text { or LWR with } \\
\text { burnup }>200\end{array}$ & $\begin{array}{l}\text { LWR-IMF or } \\
\text { HTGR-deepburn }\end{array}$ & \multicolumn{2}{|c|}{$\begin{array}{l}\text { Multi-recycle with non-U intermediate } \\
\text { s eparation products } \\
\text { MSR-Th with Pa233 removal }\end{array}$} & $\begin{array}{l}\text { Routinely use, handle, } \\
\text { or produce attractive } \\
\text { material: }>20 \% \text { U-235, } \\
>12 \% \text { U-233, > } 25 \% \text { Pul } \\
\text { HM, }>20 \% \text { TRUHM }\end{array}$ \\
\hline
\end{tabular}

Figure 5-7. Adaptability of fuel cycle options to make high attractive material, consideration the "lowest resistance" in the previous four figures.

All fuel cycles involving domestic enrichment capability and/or traditional used fuel technologies are no better than the third row, "straightforwardly modified."

Fuel cycles involving concentrated TRU material (low uranium content) are in the bottom category. In LWRs, these are called uranium-free or inert-matrix fuels (IMF). In HTGRs, essentially the same class of fuels is called "deep burn."

Historically, those having used fuel in storage for long periods have wanted the capability to examine the condition of that fuel. We therefore assume that a nation that must keep its used fuel for any extended period of time will also have or develop the capability to closely examine that fuel, implying significant hot cell, hot handling, and hot inspection capability.

AIROX has been considered (on paper) for multiple recycles (Majumdar 1992) provided that they are at somewhat lower burnup than the first enriched uranium cycle; the requirement of lower burnup stems from the relatively high fission product retention in recycled material. The feasibility of one or more recycles with separation techniques that do not appear to have the ability to separate U from TRU (e.g. AIROX, melt refining) has not been definitely established. However, recent analysis (Piet 2010b) suggests that AIROX and melt refining with non-breeder fast reactors can achieve, at most, 3 recycles 
using a combination of relatively pure separated material from used UOX-51 (using UREX +1 separation) and impure separated material (from AIROX or melt refining) from used FR fuel. AIROX and melt refining cannot be used to make fast reactor fuel from used UOX-51 because neither technique offers a way to alter the TRU:U ratio (Piet 2010b).

\subsection{Material Attractiveness}

Some methodologies combine the four parameters - heat, gamma emission, spontaneous neutron emission, and bare-sphere-critical mass (BSCM) - into a single figure of merit (Bathke 2009) but most do not. For simplicity, we keep the four physical parameters separate. These four parameters appear throughout the proliferation resistance and physical protection methodologies, for example,

- $\quad$ INPRO - three evaluation parameters (2.1.3: radiation field, 2.1.4: heat generation, 2.1.5: spontaneous neutron generation rate) in the "mass and bulk" topic address material attractiveness. Furthermore, the number of significant quantities (SQ) is used as a metric for inventory.

- PR\&PP - the measure "fissile material type" explicitly includes spontaneous neutron emission rate, heat generation rate, gamma radiation activity, and bare-sphere critical mass (PRPP2005). One or more of these parameters also includes many of the other PR\&PP measures such as detection probability.

- TOPS - all four parameters are mentioned explicitly under "material barriers" and most under "radiological barrier".

The SQ and bare-sphere-critical-mass play similar roles in methodologies. The differences are as follows. The SQ is defined in International Atomic Energy Agency (IAEA) documents only for specific isotopes and cannot directly be calculated. It is used by the IAEA INPRO methodology. The problem is that there is no SQ value defined for many isotopes and mixtures of isotopes relevant to many advanced fuel cycle options. For that reason, TOPS and PR\&PP and other methodologies use the BSCM, defined as the minimum mass $(\mathrm{kg})$ of an isotopic mixture that will go critical without being surrounded by reflectors or neutron multipliers. It therefore is not the minimum mass required to go critical, but it is a commonly used relative parameter. The direct-use isotopes for which it is possible to make an SQ - BSCM comparison are

$$
\begin{aligned}
& \text { U233: } \mathrm{SQ}=8 \mathrm{~kg}, \mathrm{BSCM}=16 \mathrm{~kg} \text { (in TOPS2000) } \\
& \text { U235: } \mathrm{SQ}=25 \mathrm{~kg} \text { if } \mathrm{U} 235 / \mathrm{U} \text {-total }>20 \%, \mathrm{BSCM}=48 \text { (in TOPS2000) } \\
& \mathrm{Pu}: \mathrm{SQ}=8 \mathrm{~kg}(\text { if } \mathrm{Pu} 238 / \mathrm{Pu}<80 \% \text { ), } \mathrm{BSCM}=10 \mathrm{~kg} \text { for } \mathrm{Pu} 238 \text { and } \mathrm{Pu} 239 \text { (in TOPS2000) }
\end{aligned}
$$

There is one key additional difference between SQ and BSCM. The other defined SQs (for indirect use nuclear material) have infinite BSCM: $75 \mathrm{~kg} \mathrm{U} 235$ if U235/U-total $<20 \%, 10$ tonne for natural uranium, 20 tonne for depleted uranium, and 20 tonnes for thorium. Thus, just because an isotope mixture has infinite BSCM, there is no reason to believe the IAEA would not establish an SQ for it as an indirect use nuclear material.

Before examining the values of these four parameters for several cases of interest, note that increased heat can increase proliferation resistance and physical protection; they would seem to have modest penalties on other fuel cycle considerations such as economics.

Gamma and neutron emission have more complicated implications. Increased gamma and neutron emission directly increases resistance and protection throughout the four stages, tending to increase overall proliferation resistance and physical protection. Gamma and neutron emission increase the ability to detect stolen/diverted material in any of the four stages, also tending to increase overall proliferation resistance and physical protection. Yet, the concern has been raised that high gamma or neutron emission makes safeguarding plutonium (first stage only) more difficult even while it makes detection of diverted 
or stolen material easier (also first stage), as discussed in Section 5.1. This suggests an R\&D need: safeguard techniques that provide analogous measurement assurance for high gamma/neutron materials as for uranium or plutonium (Smith 2008). Of course, increased gamma and neutron emission can impose impacts on other fuel cycle considerations such as economics.

Figure 5-8 shows the heat emission per mass of fresh fuels, with several benchmarks added for comparison. On the low side are all the uranium-based fuels, which are below $1 \mathrm{e}-4 \mathrm{~W} / \mathrm{kg}$. On the high side, the IAEA specifies that a plutonium mixture of $80 \% \mathrm{Pu} 238$ is not considered direct weapon-usable; this is about $450 \mathrm{~W} / \mathrm{kg}-\mathrm{HM} .{ }^{\mathrm{p}}$ None of the fresh fuel mixtures studied to date, without impurities, reach $450 \mathrm{~W} / \mathrm{kg}-\mathrm{HM}$. Some of the fuels without uranium (LWR-IMF and HTGR-deepburn) and TRU-based fuels are within an order of magnitude of $450 \mathrm{~W} / \mathrm{kg}-\mathrm{HM}$. Those with uranium are even lower.

Figure 5-9 shows the gamma emission energy (W/kg) for the same cases. ${ }^{\mathrm{q}}$ On the minimum side, the lowest gamma emission is from HEU. On the high side, the "self-protection" criterion standard has been $1 \mathrm{~Sv} / \mathrm{hr}(100 \mathrm{rem} / \mathrm{hr})$ at 1 -meter distance, but this has been recently raised to $5 \mathrm{~Gy} / \mathrm{hr}(500 \mathrm{rad} / \mathrm{hr})$ at 1 meter (Bathke 2009) ${ }^{\mathrm{r}}$. Gamma of 30-yr old UOX is $\sim 0.3 \mathrm{~W} / \mathrm{kg}-\mathrm{iHM}$. None of the cases reach this level of gamma emission. The TRU-U cases and the Pu cases without uranium are the highest, i.e., least attractive for direct weapon use. The higher the uranium fraction (especially without the Pu or TRU), the lower the gamma emission and the more attractive for direct weapon use. Although the threshold line in the figure stems from (Bathke 2009), the concept that higher gamma emission decreases material attractiveness is more widespread.

Figure 5-10 shows the spontaneous neutron emission rate for the same cases. The published FOM-1 (for subnational groups) does not include neutron emission rate as a term. The corresponding FOM-2 (for would-be host nation) does include neutron emission rate, as do several of the proliferation resistance methodologies. For FOM-2, with a BSCM of 10 (for Pu238 and Pu239, one of the lowest), a neutron emission rate of $6.8 \times 10^{5}$ neutrons/second per $\mathrm{kg}$ (or above) would make the FOM-2 to be 1.0 or below, i.e., unattractive for direct weapon use. The Figure shows that the TRU-based fresh fuels tend to be above that derived threshold, which helps explain why Bathke et al (Bathke 2009) find them unattractive for representative compositions. The Pu-based fuels tend to be below the derived threshold and Bathke et al find them attractive. The U-based fuels have the lowest neutron emission.

Figure 5-11 shows the BSCM. Consistent with Figure 5-4, the only cases that have a low (hence undesirable) BSCM are those thermal reactor cases without uranium (LWR-IMF and HTGR-deepburn) and fast reactor cases with transuranic conversion ratio at or below 1.0. Thermal reactor cases with uranium or MOX fuels and fast breeder cases cannot go critical without being surrounded by reflectors or neutron multipliers, i.e., the BSCM is off scale.

$\mathrm{p} \quad$ The heat term in the published FOM-1 (Bathke2009) is $\mathrm{M} \mathrm{h} / 4500$ where $\mathrm{M}$ is the bare spherical mass and $\mathrm{h}$ is the heat in $\mathrm{W} / \mathrm{kg}$. As that term exceeds 1, the FOM-1 falls below 1 and thus the mixture is unattractive for weapon use, regardless of other parameters. FOM-1 falls below 1 for a mixture of 20\% Pu238 and 80\% Pu239. M for both Pu238 and Pu239 is $10 \mathrm{~kg}$. Heat is $450 \mathrm{~W} / \mathrm{kg}$. M h / 4500=1 and the overall FOM-1 falls below 1.0 regardless of other parameters.

q Ideally, this graph would use dose at 1-meter from an appropriate fuel assembly geometry. Due to time and resource limitations to do all the necessary calculations, we instead use watts of gamma energy as a surrogate.

$\mathrm{r} \quad$ The difference between Sv and Gy (or rem to rad) is the relative biological effectiveness or quality factor, which is generally 1 for beta and gamma emission. Dose limits protecting against long term stochastic health effects such as cancer are generally in units of $\mathrm{Sv}$ (or rem); dose levels predictive of effects to equipment are in units of Gy (or rad); short-term effects to people are in units of Gy (or rad) per ICRP-63. 


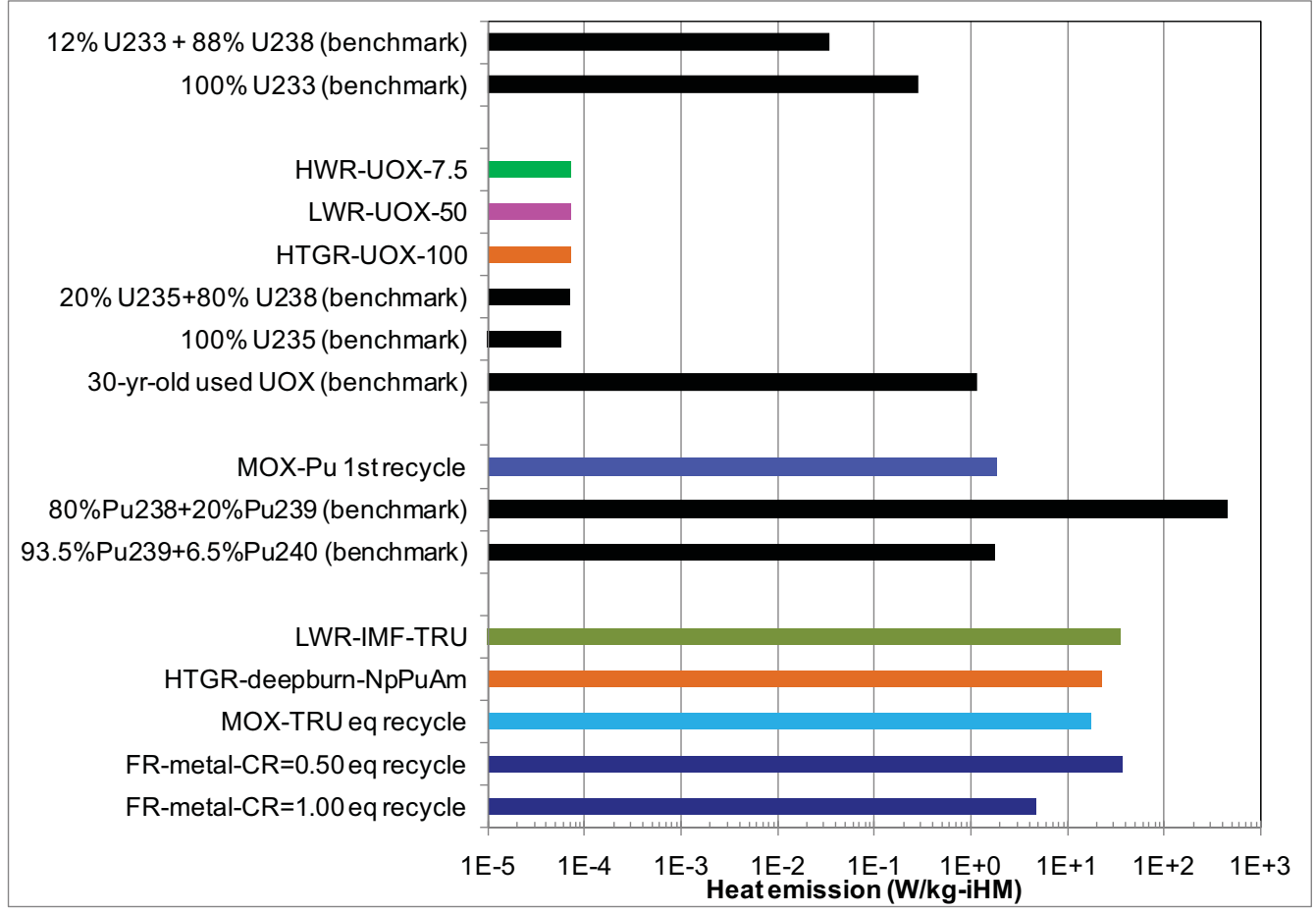

Figure 5-8. Decay heat of fresh fuels. ${ }^{\mathrm{s}}$

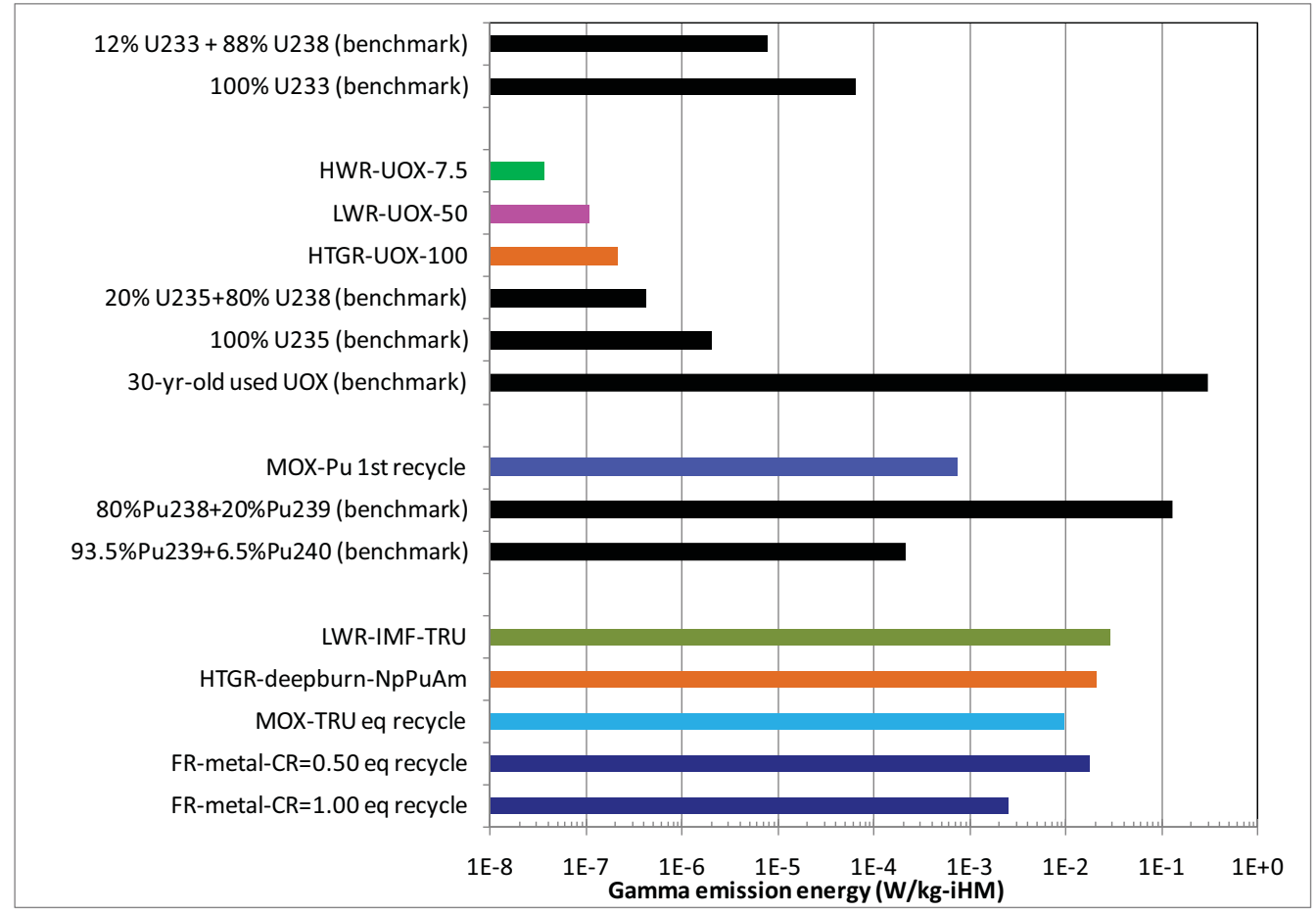

Figure 5-9. Gamma emission of fresh fuels., ${ }^{a, b, t}$

s Note various benchmarks, especially $80 \% \mathrm{Pu} 238(450 \mathrm{~W} / \mathrm{kg})$, which is considered not directly weapon usable by the IAEA.

$\mathrm{t} \quad$ Note the various benchmarks especially 30 -yr old used UOX (so-called self-protecting). 


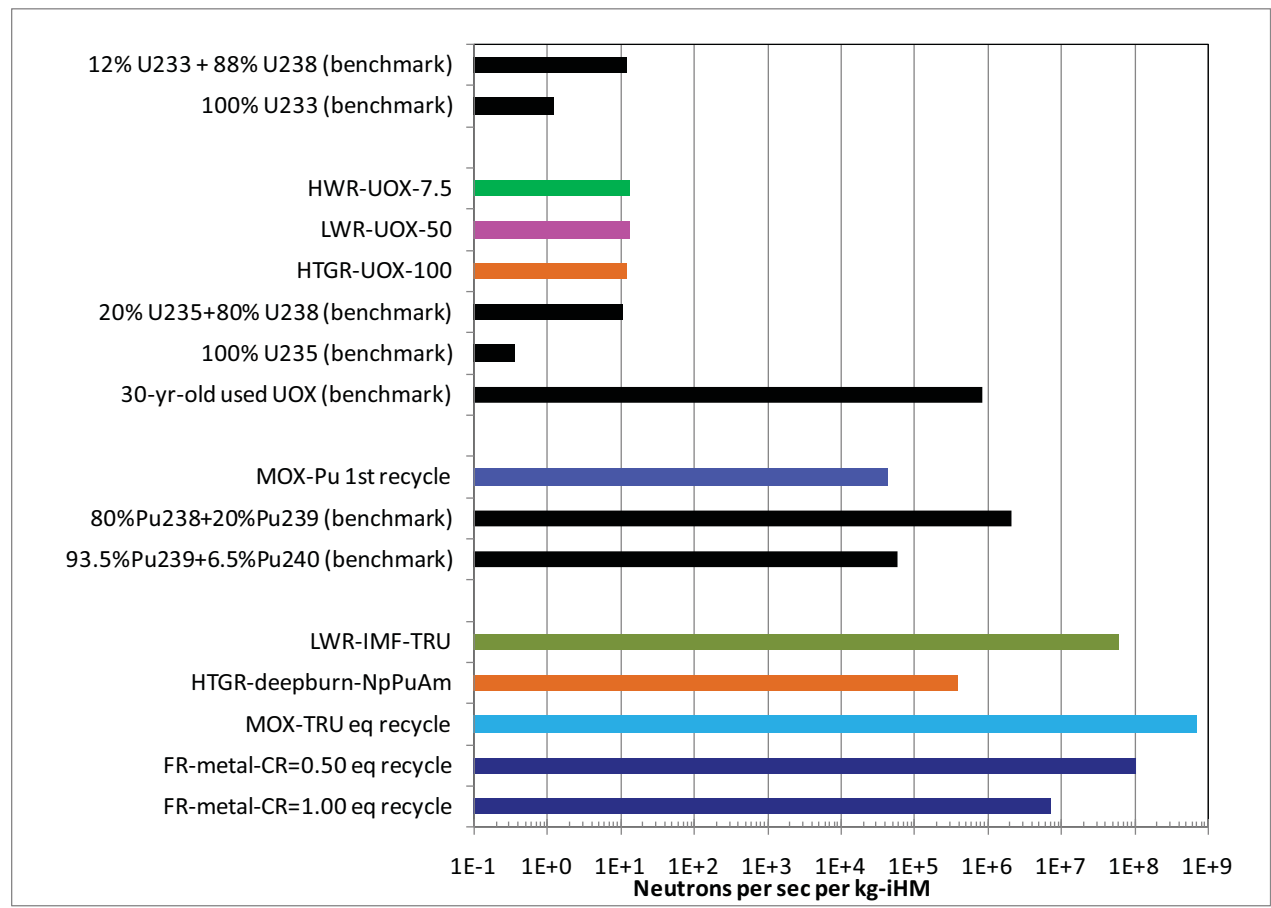

Figure 5-10. Spontaneous neutron emission of fresh fuels. ${ }^{a, b, u}$

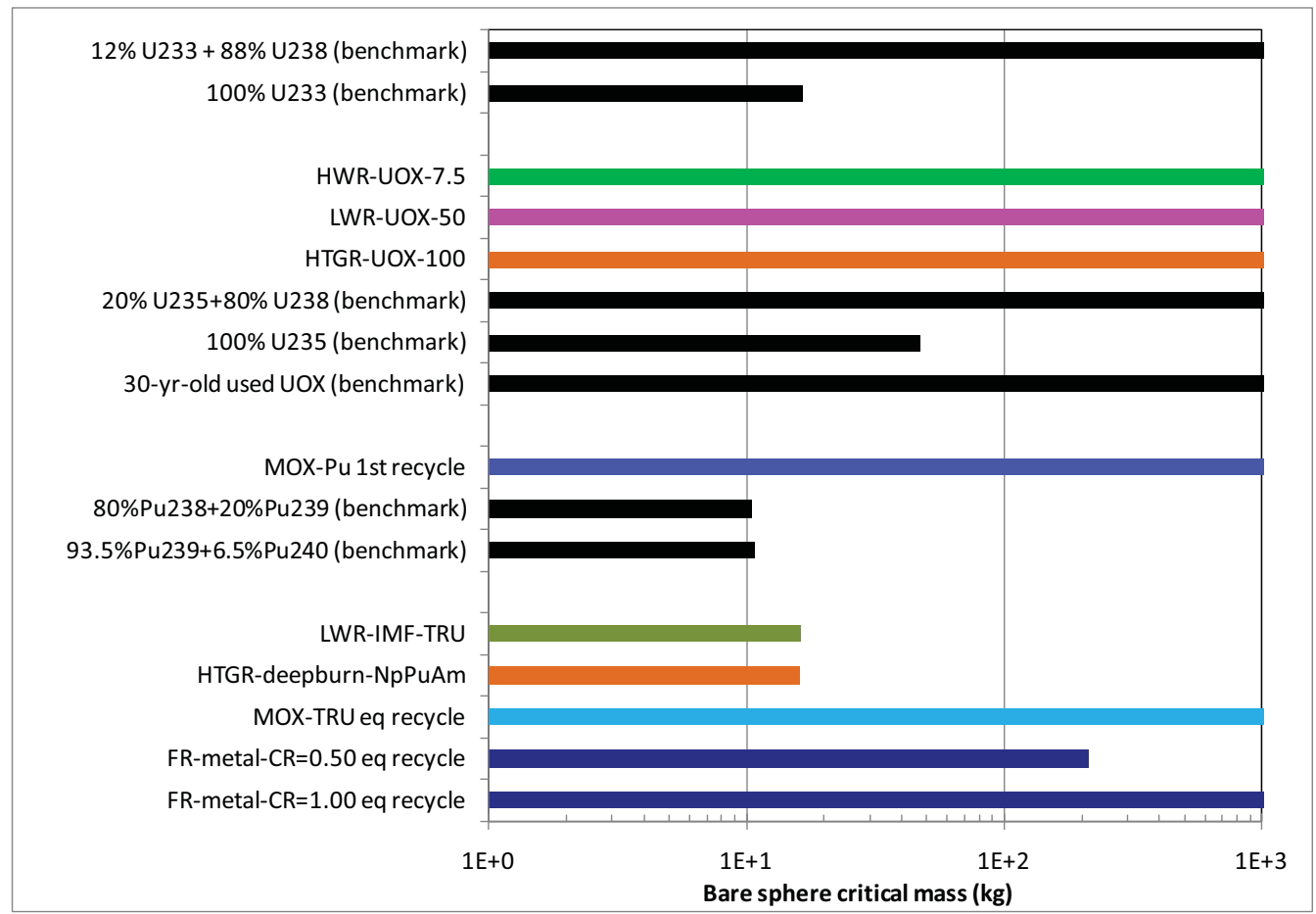

Figure 5-11. Bare sphere critical mass (kg) of fresh fuels. ${ }^{a, b, v}$

u Cases with neutron emission over $6.8 \times 10^{5}$ would be unattractive for use by nation states per FOM-2.

$\mathrm{v}$ Most cases have an effectively infinite BSCM, no amount of the material can go critical without reflectors or neutron multipliers. Those cases are shown with BSCM lines that reach $1000 \mathrm{~kg}$ in Figure 5-11. 


\subsection{Item versus Bulk Counting}

The central challenge in safeguarding material is determining how much is present at any particular point in time. Among other things, this requires determining the number of fuel items - fuel assemblies, pebbles, etc. Counting a discrete number of fuel assembles (or compacts) is considered far easier than fuel in bulk form (liquids, pebbles) (Goodman2009, PRPP 2006, Metcalf 2009, TOPS 2000). A limited number of fuel assemblies is generally considered easier to safeguard than a large number of small pebbles (e.g. HTGR pebble bed) or continuous material flow (e.g. molten salt reactors), see Figure 5-12.

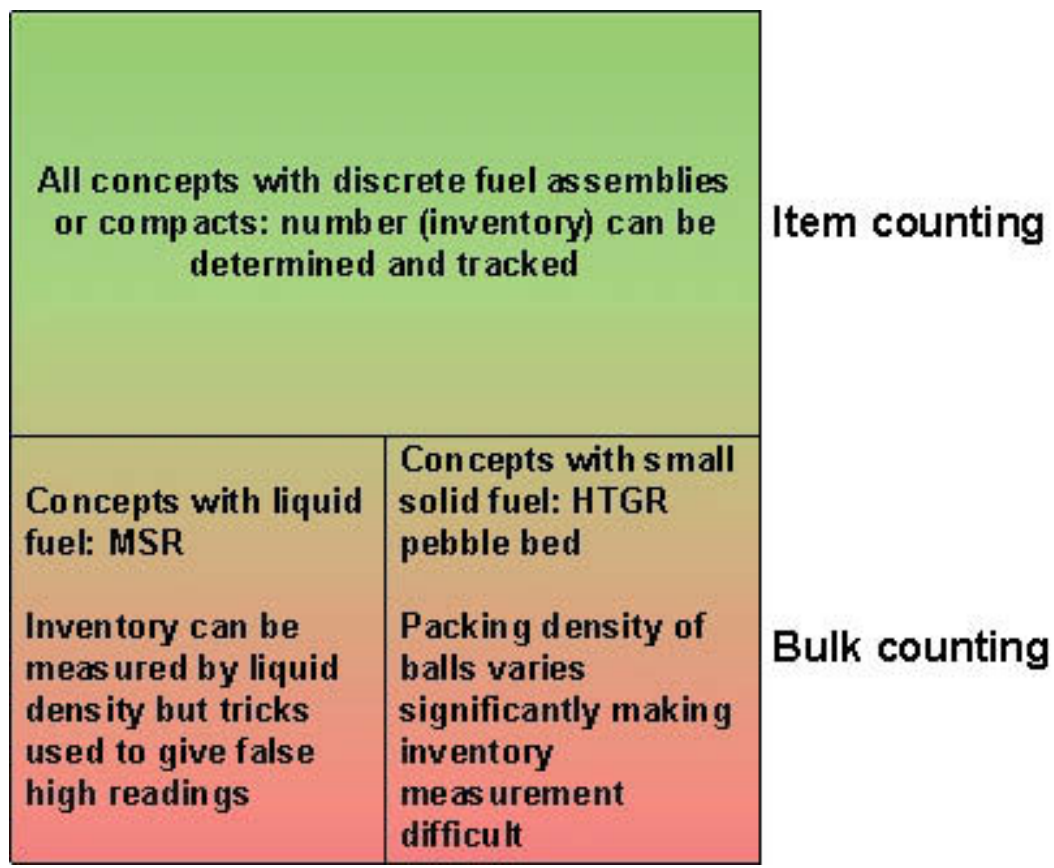

Figure 5-12. Frequency of access to fuel in reactor; inferred by considerations in the TOPS and PR\&PP methodologies.

\subsection{Mass and Bulk of Fuel}

A topic related to refueling access is the mass and bulk of fuel, an indicator in most if not all methodologies. This is the mass that has to be diverted or stolen. It is important to recognize that the smallest physical units to be diverted or stolen from a reactor includes not only the mass of the fuel meat, the mass of "heavy metal", which is thorium, uranium, plutonium, etc., but also the mass of other materials that is part of fuel assemblies or pebbles, etc. The other elements (carbon, silicon, oxygen, zirconium, and constituents of steel) have two impacts - they increase the mass and bulk but they decrease the calculated dose, heat, gamma, and neutron emission. In this report, the latter effect is ignored, partly because of insufficient data and calculational resources and partly because one aspect of material attractiveness is the heat, gamma, neutron emission after fuel meat has been separated from nonfuel material.

Table 5-3 shows the mass of fuel assemblies in various options. All options with the sole exception of the "pebble bed" variant of the HTGR have fuel assemblies over $100 \mathrm{~kg}$ mass, which is large enough that equipment is required to remove and transport the items. The reader is cautioned against assigning a high importance to the values over $100 \mathrm{~kg}$; if methodologies assign a high importance to such values, designers would tend to react by making the fuel assemblies larger. That is, other than the pebble bed (or molten salt reactor, not listed), there are few inherent reasons why fuel assemblies cannot be made somewhat larger if there is deemed to be a major proliferation resistance reason to do so. 
Table 5-3. Mass of Fuel Assemblies in Various Options (Piet 2010c).

\begin{tabular}{|c|c|c|}
\hline & $\begin{array}{c}\text { kg- } \\
\text { iHM/assembly }\end{array}$ & $\begin{array}{c}\mathrm{kg}- \\
\text { total/assembly }\end{array}$ \\
\hline Once through PWR UO2 & 461.3 & 657.9 \\
\hline Once through BWR UO2 & 183.3 & 319.9 \\
\hline PWR MOX & 461.3 & 657.9 \\
\hline PWR IMF-Pu & 37.2 & 530.9 \\
\hline PWR IMF-NpPuAm & 42.7 & 580.8 \\
\hline \multirow[t]{2}{*}{ PWR IMF-TRU } & 42.5 & 578.8 \\
\hline & $\begin{array}{c}\text { kg- } \\
\mathrm{iHM} / \text { assembly }\end{array}$ & $\begin{array}{c}\mathrm{kg}- \\
\text { total/assembly }\end{array}$ \\
\hline Full recycle FR metal $\mathrm{CR}=0.00$ & 29.7 & 349.7 \\
\hline Full recycle FR metal $\mathrm{CR}=0.25$ & 44.9 & 342.8 \\
\hline Full recycle FR metal $\mathrm{CR}=0.50$ & 69.9 & 366.1 \\
\hline Full recycle $\mathrm{FR}$ metal $\mathrm{CR}=0.75$ & 97.7 & 411.5 \\
\hline Full recycle FR metal $\mathrm{CR}=1.00$ & 114.1 & 446.1 \\
\hline Full recycle FR oxide $\mathrm{CR}=0.00$ & 37.7 & 264.9 \\
\hline Full recycle $\mathrm{FR}$ oxide $\mathrm{CR}=0.25$ & 60.6 & 335.6 \\
\hline Full recycle FR oxide $\mathrm{CR}=0.50$ & 91.9 & 426.1 \\
\hline Full recycle FR oxide $\mathrm{CR}=0.75$ & 126.0 & 483.2 \\
\hline \multirow[t]{2}{*}{ Full recycle FR oxide $\mathrm{CR}=1.00$} & 148.6 & 540.0 \\
\hline & kg-iHM/element & kg-total/element \\
\hline Once through HTGR-UO2 prismatic & 7.2 & 134.4 \\
\hline \multirow[t]{2}{*}{ HTGR-deep burn prismatic } & 1.2 & 126.9 \\
\hline & kg-iHM/pebble & kg-total/pebble \\
\hline Once through HTGR-UO2 pebble bed & 0.011 & 0.21 \\
\hline HTGR-deep burn pebble bed & 0.002 & 0.20 \\
\hline
\end{tabular}

\subsection{Reduction of Existing Stockpiles}

This topic is not mentioned in PR\&PP, TOPS, or INPRO, which are focused on evaluation of technologies that may be used in a non-weapon state. However, DOE has indicated that one desirable attribute of fuel cycles and proliferation resistance and physical protection is the ability to reduce existing plutonium stocks (Goodman 2009). We broaden this consideration to all other actinide materials (Figure 5-13). 


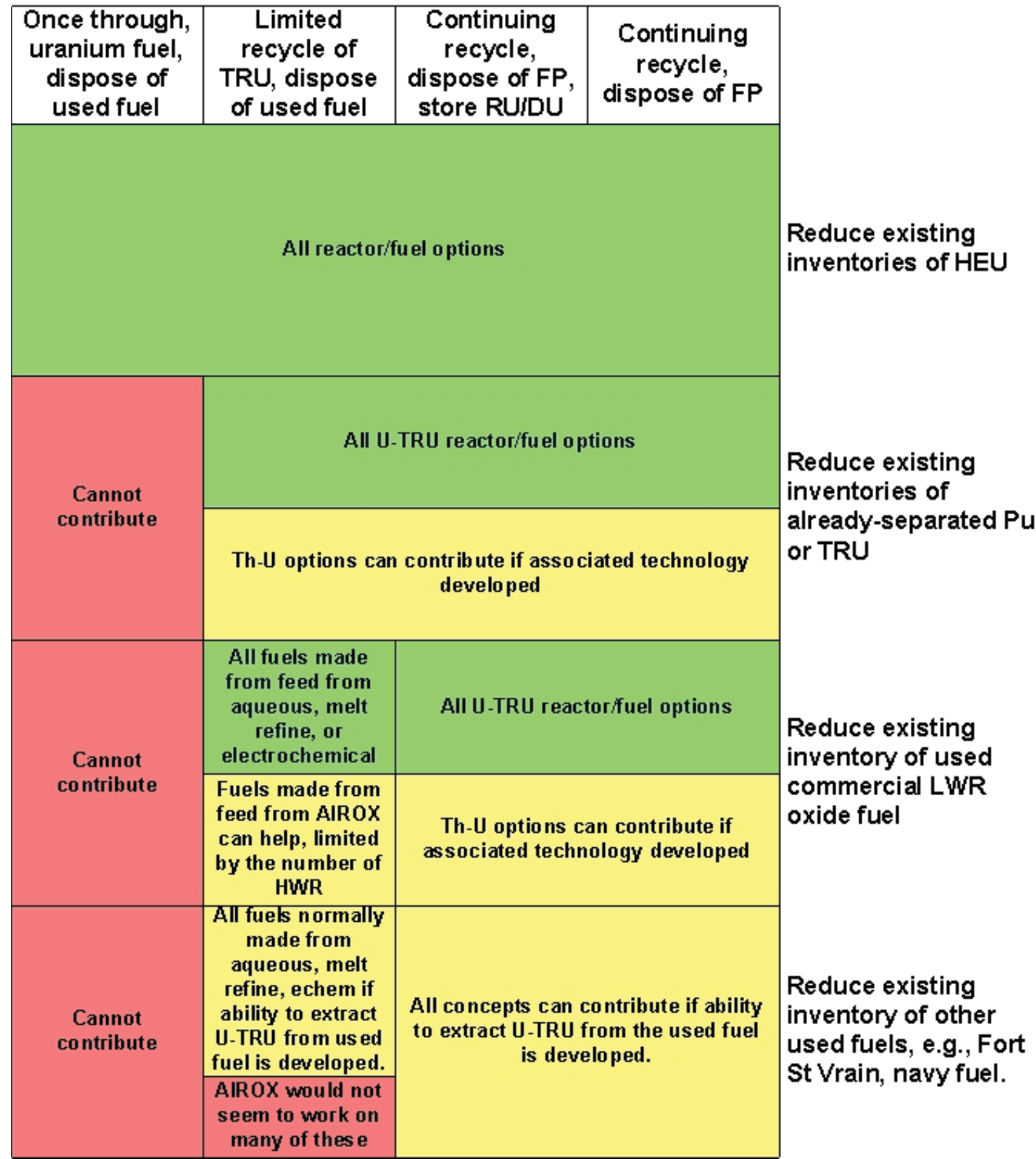

Figure 5-13. Ability of fuel cycle options to reduce existing actinide inventories (Goodman 2009).

\subsection{Frequency of Access to Fuel}

The frequency of routine access to fuel via refueling is logically an indicator for proliferation resistance, but one typically does not find it mentioned as an explicit indicator in existing methodologies. Instead, one can infer it. For example, it is implied by PR\&PP by "detection probability" and "physical protection resources" when one considers fuel cycle options beyond those with the typical 1-2 year refueling time. And it can be inferred in TOPS from "facility accessibility" and "facility unattractiveness." 
The relative importance of this indicator is less obvious for several reasons. First, most reactors have access ports for control rods, safety rods, or diagnostic samples. Of course, the amount of material that can be irradiated stealthily in such ways is limited. Second, as the fuel residence time in reactor increases, one is faced with safeguarding significant amount of material that is removed from a reactor all at once that was made with technology that was many decades old.

Figure 5-14 shows the frequency of access to fuel. This is not "the fuel residence time" unless the number of "batches" is one. For example, the pebble bed concepts consider $\sim 6$ passes through a reactor, for a total fuel residence time of $\sim 3$ years. The evolving designs of Hyperion (8-10 years), traveling wave (34 years), Ultra Long-Life Fast Reactor (49 years), and CANDLE (70 years or more) all have low refuel frequency as an explicit objective.

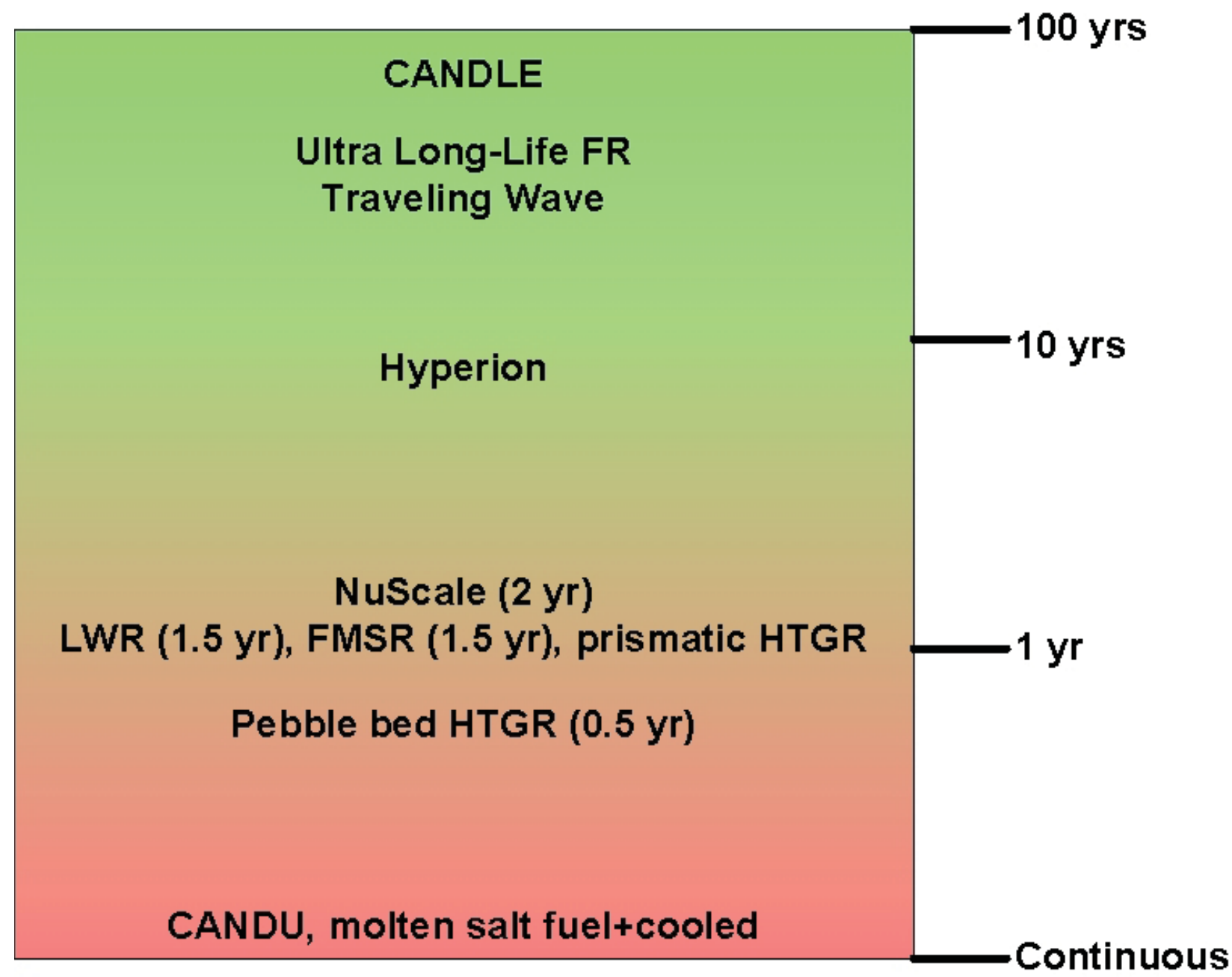

Figure 5-14. Frequency of access to fuel in reactor; inferred by considerations in the TOPS and PR\&PP methodologies.

\subsection{R\&D Needs}

Methodologies are needed that can evaluate fuel cycle systems at an early stage of concept development that also quantify improvement of those options as they mature. The indicators in this Chapter are all motivated by existing methodologies and can be evaluated at a relatively early state of concept development. However, the relative importance of these indicators is not clear. For example, is low frequency of refueling access very important or of only low importance? How important are the material 
attractiveness indicators given the ability of PUREX, already in the literature, to separate plutonium from gamma-emitting fission products, minor actinides, and uranium?

Methodologies are needed that better assess adaptability of technologies. Any adoption of any nuclear fuel cycle changes the technological capabilities of a nation. How can this be better assessed? 


\section{SUMMARY}

Major findings or trends that can be drawn from the trade-off comparisons within this report are given below in numbered format. The findings are replete with asymptotic and step-function behaviors that can only be reached with greatly enhanced performance of existing technologies, the advent of transformational technologies, or a systematic rethink of how fuel cycle technologies should be deployed and operated. The asymptotic behaviors are:

- Uranium utilization is asymptotic with the rate of natural uranium consumption from the environment

- A step reduction in the long-lived radiotoxicity of nuclear waste occurs once a fuel cycle strategy is adopted where only reprocessing wastes are disposed as opposed to used nuclear fuel being disposed.

- The amount of mass requiring disposal is closely tied to uranium utilization. Complete uranium utilization equates into only fission products requiring disposal.

- The relevant proliferation resistance of a fuel cycle system is enhanced with: decreasing reliance on domestic fuel cycle services, decreasing adaptability for technology misuse, enablement of material accountability, decreasing material attractiveness.

Summary of findings in numbered format.

a) Uranium utilization asymptotically increases for decreasing natural uranium consumed from the environment

i) Breed and Burn (with no recycle): Uranium utilization is limited by the buildup of fission products which poisons the chain reaction to the point where the reactor cannot stay critical, thus precluding further irradiation and resultant uranium utilization.

ii) Limited separations: Enables further extension of uranium utilization by separating fission products from the fuel, thus allowing subsequent re-irradiation for an additional finite number of reactor passes, extending the allowable uranium utilization.

iii) Full Recycle: Routinely purges fission products from the fuel, thus allowing an infinite number of subsequent irradiations to achieve complete uranium utilization, or complete burnup of the starting natural uranium resource.

b) The Energy Return on Investment: More energy return is produced per the initial front-end energy investments as more of initial natural uranium resource undergoes fission, hence producing nuclear power.

i) Full recycle provides the ultimate amount of energy returned in the back-end per energy input in the front-end mining, milling and enrichment processes.

ii) High temperature fuels in nuclear reactors enable higher thermodynamic efficiency for electricity or hydrogen production. However, this efficiency gain yields only approximately 1.5 times more energy produced per invested compared to most other fuel cycles, with the exception of full recycle (i.e., EROI 150 instead of EROI 100). Going to full recycle can potentially allow for a two order of magnitude improvement in energy return, related to the uranium utilization (EROI 1000).

iii) The largest energy input into the nuclear fuel cycle is the conversion process. Fuel reprocessing and fabrication processes are not the dominate energy input but do contribute the highest monetary cost. Because fuel recycle monetary costs are at least partly tied to employing a skilled workforce, it may not be appropriate to assume that nuclear recycling is a sunk cost required to attain fuel as is appropriate for coal or uranium mining. 
iv) The maximum potential for the fuel cycle to produce energy is equivalently the reaction Qvalue of nuclear fission, meaning that all natural uranium undergoes fission with creation of bi-product fission products and energy (i.e., $\sim 970 \mathrm{GW}$ th-day/tonne of Uranium consumed from the earth).

c) The expected environmental protection effort required for disposed fuel is a function of the longevity, heat and radiotoxicity intensity characteristics of wastes produced and disposed by the nuclear fuel cycle.

i) Heat and Radiotoxicity of disposed waste is dominated by fission products for the first 1,000 years. Noticeable differences in heat and radiotoxicity between different fuel cycles appear only after 100,000 years and are chiefly dominated by the decay daughters of the actinides.

ii) Radiotoxicity of thorium fuel cycles is as high at 100,000 years as it is at 1,000 years

d) The long-term radiotoxic source term as well as the mass of nuclear waste requiring disposal is chiefly a function of the attained burnup by the fuel cycle on the original natural uranium resource (i.e., $100 \%$ uranium utilization by definition means that all waste is fission product with no actinides being disposed).

i) Ultimately, the minimum long-term radiotoxicity of disposed nuclear waste is limited by the radiotoxicity of fission products. This is essentially the case where the reprocessing separation efficiency is perfect and no actinides are discharged from the fuel cycle as waste. For less than perfect separations, the radiotoxicity is dominated by the amount of transuranics disposed. For limited separations and limited recycle strategies, used fuel assemblies are disposed as spent fuel prior to complete destruction of transuranics; as a result the long-term radiotoxicity is orders of magnitude higher than for complete transuranic recycle.

ii) Ultimately, the minimum mass requiring disposal is limited by the mass of fission products produced per unit of fission energy, equivalently the inverse of the nuclear reaction Q-value (i.e., $~ 0.001$ tonne fission products per GWth-day). A further reduction in disposed mass requires removal of short-lived from long-lived radiotoxic fission products prior to disposal.

iii) The mass (and by extension the volume) of waste requiring disposal does not have a hard upper boundary. The geometry of the fuel form and how it is disassembled during recycling plays a dominate role in the activated and contaminated non-fuel core structures that would de facto require disposal with the fission products and actinides.

e) Stakeholders require assurances that advanced or transformational technologies can be used in a fuel cycle in such a way that once deployed are difficult to be diverted for misuse or nuclear weapons technology proliferation.

i) Reactor technologies that do not require a domestic enrichment or reprocessing capability remove this degree-of-freedom for proliferation. Conversely, fuel cycles that require routine item counting of fuel batches are relatively easier to safeguard than fuel cycles that rarely require inspection (i.e., stealth misuse of reactor instrumentation and control access ports). Bulk accountability of fluids or very small fuel forms also are difficult to safeguard due to the need for a sustained monitoring presence.

ii) The adaptability of reactor and recycle technologies affects the ease at which they can be clandestinely misused. Some technologies can be altered by making simple changes in the process flow sheet such as UREX. Other technologies such as AIROX are not directly amenable to the critical path to weapons production (i.e., they require additional clandestine technology to be developed in order to make use of services or materials produced by the civilian implemented technology). 
iii) The level of compatibility of fuel material with direct weapons use also influences the ease at which it can be diverted to nuclear weapons manufacture. This compatibility is affected by: the chemical form of transported material; the fertile content at any given stage in the fuel cycle; the heat, dose and criticality characteristics of the fissile species if it were separated from the fertile species. Generally, reactor transmutation strategies that drawn-down stockpiles of weapons compatible fuel material increase the intrinsic proliferation resistance of the fuel cycle's overall material inventory. 


\section{REFERENCES}

Areva 2009

Backfit

Bandt 2003

Bathke 2009

Bays 2009

Boer 2010

Cadwallader 2005

Calder Hall

CANDU-6

Charlton 2004

Cleary 2007

Dixon 2009

DOE 1988
Areva NC de la Hague, “Areva Etablissement de La Hague, Rapport environnemental, social, societal, de surete nucleaire et de radioprotection 2008," http://www.areva.com/mediatheque/liblocal/docs/pdf/activites/aval/recyclage/pdf -rapp-la-hague-08-vf.pdf, Accessed: August 2, 2010, (2009)

Code of Federal Regulations, “Backfitting,” 10 CFR 50.109, (2003)

Bandt, Gabriele, B. Posnatzki, K. Beckers, "Final Disposal of Radioactive Waste in Germany: Plan for Approval Process of Konrad Mine and Acceptance Requirements," WM'03 Conference, February 23-27, 2003

C. Bathke, B. Ebbinghaus, B. Sleaford, R. Wallace, B. Collins, K. Hase, G. Jarvinen, K. Bradley, J. Ireland, M. Johnson, A. Prichard, B. Smith, "The Attractiveness of Materials in Advanced Nuclear Fuel Cycles for Various Proliferation and Theft Scenarios," Proceedings of Global 2009, Paris, France, September 6-11, 2009, (2009)

S. Bays, S. Piet, M. Pope, G. Youinou, A. Dumontier, D. Hawn, “ Transmutation Dynamics: Impacts of Multi-Recycling on Fuel Cycle Performances,” AFCISYSA-PMO-MI-DV-2009-000185, INL/EXT-09-16857, September 2009.

B. Boer, "Comparison of PEBBED and SCALE Results for the Depletion of Pebble Fuel," Internal Communication, peb bed.doc, (May 19, 2010)

L. Cadwallader, J. Piet, S. Sheetz, D. McGuire, W. Boore, "Summary of OffNormal Events in US Fuel Cycle Facilities for AFCI Applications," INEEL/EXT04-02257, September 2005.

Nuclear Engineering International - Wallchart 6, "The Worlds Reactors, No. 6, Calder Hall," Available:

http://econtent.unm.edu/cdm4/browse.php?CISOROOT=\%2Fnuceng, Accessed: September 16, 2010, (1956)

Nuclear Engineering International - Wallchart 104, "CANDU 6," Available: http://econtent.unm.edu/cdm4/browse.php?CISOROOT=\%2Fnuceng, Accessed: September 16, 2010

W. Charlton, R. LeBouf, C. Gariazzo, D. Ford, C. Beard, S. Landsberger, M. Whitaker, "Proliferation Resistance Assessment Methodology for Nuclear Fuel Cycles," Nuclear Technology, 157, pg. 143-156, (2007)

V. Cleary, P. Rexroth, G. Rochau, D. Saltiel, D. Grenéche, S. Ng, W. Charlton, D. Ford, D. Giannangeli, "Strengthening the Foundations of Proliferation Assessment Tools," SAND2007-6158, (2007)

B. Dixon, "Fuel Cycle Metrics Review," FCR\&D-SYSA-2010-000025, (2009)

DOE, "Radioactive Waste Management," DOE Order 5820.2A, Washington, DC, September 26, (1988) 
Ellis 2009

Ferrer 2007

Fetter 1988

Fetter 1990

Glassner

Goodman 2009

Guidez 2008

Hammerschlag 2006

Hoffman 2005

Hoffman 2006

Hoffman 2009

IAEA 1999

ICRP-63

INPRO 2003

INPRO2007
R. Ellis, S. Hart, G. Maldonado, "Final Report: CANDU VISION Recipes and Fuel Cycle Analysis," ORNL-AECL I-NERI Project 2008-003-C, (2009)

R. Ferrer, M. Asgari, S. Bays, B. Forget, "Fast Reactor Alternative Studies: Effects of Transuranic Groupings on Metal and Oxide Sodium Fast Reactor Designs," INL/EXT-07-13236, (2007)

S. Fetter, E. T. Cheng, F. M. Mann, Long-Term Radioactivity in Fusion Reactors, Fusion Engineering and Design, 6, 1988, pp. 123-130.

S. Fetter, E. T. Cheng, F. M. Mann, Long-Term Radioactive Waste From Fusion Reactors: Part II, Fusion Engineering and Design, 13, 1990, pp. 239-248.

A. Glassner, "The Thermochemical Properties of the Oxides, Flourides, and Chlorides to $2500 \mathrm{~K}, " A N L-5750$

M. Goodman, "A Nonproliferation Impact Assessment of the GNEP Alternatives," Proceedings of Global 2009, Paris, France, September 6-11, 2009, (2009)

J. Guidez, L. Martin, S. Chetal, P. Chellapandi, B. Raj, "Lessons Learned from Sodium-cooled Fast Reactor Operation and Their Ramifications for Future Reactors with Respect to Enhanced Safety and Reliability," Nuclear Technology, 164, pg. 207-220, (2008)

R. Hammerschlag, "Ethanol's Energy Return on Investment: A Survey of the Literature 1990-Present," Environmental Science and Technology, 40, pg. 17441750, (2006)

E. Hoffman, W. Yang, R. Hill, "Preliminary Report on Blending Strategies for Inert-Matrix Fuel Recycling in LWRs," ANL-AFCI-149, (2005)

E. Hoffman, W. Yang, R. Hill, "Preliminary Core Design Studies for the Advanced Burner Reactor over a Wide Range of Conversion Ratios," ANLAFCI-177, (2006)

E. Hoffman, "FY09 ANL AFCI Transmutation Studies," ANL-AFCI-271, (2009)

International Atomic Energy Agency, "Status of Liquid Metal Cooled Fast Reactor Technology," IAEA-TECDCC-1083, ISSN 1011-4289, (1999)

International Commission on Radiological Protection, "Principles for Intervention for Protection of the Public in a Radiological Emergency," ICRP Publication 63, (1992)

Guidance for the evaluation of innovative nuclear reactors and fuel cycles Report of Phase 1A of the International Project on Innovative Nuclear Reactors and Fuel Cycles (INPRO), "International Atomic Energy Agency," IAEATECDOC-1362, (2003)

"Guidance for the Application of an Assessment Methodogology for Innovative Nuclear Energy Systems - INPRO Manual - Proliferation Resistance - volume 5 of the Final Report of Phase 1 of the International Project on Innovative Nuclear Reactors and Fuel Cycles," IAEA, 2007. 
Lyman 2000

Kim 2004

Kim 2010

Majumdar 1992

Metcalf 2009

MIT 2010

MSRE 1964

Murphy 2004

NRC 1987

NRC 1995

NRC 2001

NRC 2009

NUREG-1860

NWPA 2004

O'Brien 2008
Edwin S. Lyman, “ Public Health Risks of Substituting Mixed-Oxide For Uranium Fuel in Pressurized-Water Reactors," Science \& Global Security, 2000, Volume 9, pp.1-47

T. Kim, T. Taiwo, R. Hill, J. Stillman, "Spent Nuclear Fuel Characterization for a VHTR," Proceedings of Global 2005, Tsukuba, Japan, October 9-13, 2005, (2005)

T. Kim, T. Taiwo, "Fuel Cycle Analysis of Once-Through Nuclear Systems," $A N L-F C R D-308,(2010)$

D. Majumdar, S. N. Jahshan, C. M. Allison, P. Kuan, T. R. Thomas, "Recycling of Nuclear Spent Fuel with AIROX Processing," DOE/ID-10423, (1992)

R. Metcalf, "New Tool for Proliferation Resistance Evaluation Applied to Uranium and Thorium Fueled Fast Reactor Fuel Cycles," Texas A\&M Masters Thesis, (2009)

MIT Nuclear Fuel Cycle Study Advisory Committee, "The Future of the Nuclear Fuel Cycle," ISBN 978-0-9828008-1-2, (2010)

S. Beal, P. Haubenreich, R. Lindauer, J. Tallackson, "MSRE Design and Operations Report - Part V, Reactor Safety Analysis Report," ORNL-TM-0732, (1964)

B. Murphy, "ORIGEN-ARP Cross-Section Libraries for Magnox, Advanced Gas-Cooled, and VVER Reactor Designs," ORNL/TM-2003/263, (2004)

U.S. Nuclear Regulatory Commission, for 10CFR60, "Definition of 'High-Level Radioactive Waste Advance notice of proposed rulemaking,' "Federal Register, Volume 52, No. 39, February 27, 1987.

L. Soffer, S. B. Burson, C. M. Ferrell, R. Y. Lee, J. N. Ridgeley, "Accident Source Terms for Light-Water Nuclear Power Plants," NUREG-1465, February 1995.

U.S. Nuclear Regulatory Commission, Code of Federal Regulations, "Waste Classification," 10 CFR 61.55, (2001)

U.S. Nuclear Regulatory Commission, Code of Federal Regulations, "Disposal of High-Level Radioactive Wastes in a Geologic Repository at Yucca Mountain, Nevada," 10 CFR 63, (2009)

U.S. Nuclear Regulatory Commission, "Feasibility Study for a Risk-Informed and Performance-Based Regulatory Structure for Future Plant Licensing," NUREG-1860, pg. 6-8 to 6-9, (2007)

U.S. Department of Energy, Office of Civillian Radioactive Waste Management, "The Nuclear Waste Policy Act: As Amended," (2004)

J. O'Brien, "Thermodynamic Considerations for Thermal Water Splitting Processes and High Temperature Electrolysis," Proceedings of the 2008 International Mechanical Engineering Congress and Exposition (IMEC2008), Boston, Massachusetts, pg. USA, October 31-November 6, 2008, (2008) 
Peterson 2009

Piet 2006

Piet 2010a

Piet 2010b

Piet 2010c

Pope 2009

Pope 2010

PRISM

PRPP 2006

Regguide1.174

Rotty 1975

Sailer 2008

Schneider 2010

SECY-98-253

Smith 2008

TOPS 2000
Per F. Peterson, "Elements of the Proliferation Resistance and Physical Protection (PR\&PP) Evaluation Methodology, Proceedings of Global 2009, Paris, France, September 6-11, 2009, paper 9298.

S. J. Piet, G. E. Matthern, J. J. Jacobson, C. T. Laws, L. C. Cadwallader, A. M. Yacout, R. N. Hill, J. D. Smith, A. S. Goldmann, G. Bailey, "Fuel Cycle Scenario Definition, Evaluation, and Trade-offs," INL/EXT-06-11683, August 2006.

S. Piet, S. Bays, E. Hoffman, "Description of Transmutation Library for Fuel Cycle System Analyses," FCRD-SYSA-2010-000116, INL/EXT-10-19545, (2010)

S. Piet, N. Soelberg, S. Bays, R. Cherry, D Djokić, C. Pereira, L. Pincock, E. Shaber, M. Teague, G. Teske, K. Vedros, "System Losses Study - FIT (FuelCycle Integration and Tradeoffs," FCRD-SYSA-2010-000140, (2010)

S. Piet, S. Bays, N. Soelberg, "HTGR Technology Family Assessment for a Range of Fuel Cycle Missions," FCRD-SASA-2010-000130, 2010

M. Pope, S. Bays, S. Piet, R. Ferrer, M. Asgari, B. Forget, "Transmutation Performance Analysis for Inert Matrix Fuels in Light Water Reactors and Computational Neutronics Capabilities at INL," INL/EXT-07-12472, rev1, (2009)

M. Pope, "Prismatic VHTR Depletion Calculations for Systems Analysis," Internal Communication, HTGR prismatic.doc, (May 20, 2010)

U.S. Nuclear Regulatory Commission, "Preapplication Safety Evaluation Report for the Power Reactor Innovative Small Module (PRISM) Liquid Metal Reactor," NUREG-1368, pg. A-14, (1994)

Proliferation Resistance and Physical Protection Evaluation Methodology Expert Group of the Generation IV International Forum, "Evaluation Methodology for Proliferation Resistance and Physical Protection of Generation IV Nuclear Energy Systems, Revision 5," GIF/PRPPWG/2006/005, (2006)

U.S. Nuclear Regulatory Commission, “An Approach for Using Probabilistic Risk Assessment in Risk-Informed Decisions on Plant-Specific Changes to the Licensing Basis," Regulatory Guide 1.174, (1998)

R. Rotty, A. Perry, D. Reister, "Net Energy from Nuclear Power," IAEA-75-3, (1975)

Sailer, Michael, "Nuclear Waste Repository Case Studies: Germany," Bulletin of the Atomic Scientists, (2008)

E. Schneider, B. Carlsen, E. Tavrides, "Measures of the Environmental Footprint of the Front End of the Nuclear Fuel Cycle," FCRD-SYSA-2010-000104, (2010)

W. Travers, U.S. Nuclear Regulatory Commission, "Applicability of PlantSpecific Backfit Requirements To Plants Undergoing Decommissioning," SECY98-253, (1998)

L. Smith, A. Dougan, S. Tobin, B. Cipiti, M. Ehinger, A, Bakel, "AFCI Safeguards Enhancement Study: Technology Development Roadmap," PNNL18099, (2008)

TOPS Task Force of the Nuclear Energy Research Advisory Committee (NERAC), "Technological Opportunities to Increase the Proliferation Resistance of Global Civilian Nuclear Power Systems," (2000) 
Yacout 2008

Youinou 2009
A. Yacout, T. Taiwo, "Isotopic Vector Estimation Methods for System Dynamics Fuel Cycle Models," ANL-AFCI-240, (2008)

G. Youinou, S. Bays, "Homogeneous Recycling of Pu or Pu+MA in PWRs Loaded with MOX-UE Fuel (MOX with U-235 enriched U support)," INL/EXT09-16091, AFCI-SYSA-TRAN-SS-RT-2009-000055, (2009) 